Antonio Sérgio Bento Moreira

\title{
NIVELAMENTO TRIGONOMÉTRICO E NIVELAMENTO GEOMÉTRICO CLASSE IIN DA NBR 13.133: LIMITES E CONDIÇÕES DE COMPATIBILIDADE
}

Dissertação apresentada à Escola de Engenharia de São Carlos da Universidade de São Paulo, como parte dos requisitos para a obtenção do Título de Mestre em Engenharia Civil: Transportes.

Orientador: Prof. Associado Paulo César Lima Segantine 
Ficha catalográfica preparada pela Seção de Tratamento da Informação do Serviço de Biblioteca - EESC/USP

Moreira, Antonio Sérgio Bento

Nivelamento trigonométrico e nivelamento geométrico classe IIN da NBR 13.133 : limites e condições de compatibilidade / Antonio Sérgio Bento Moreira. -- São Carlos, 2003.

Dissertação (Mestrado) -- Escola de Engenharia de São Carlos-Universidade de São Paulo, 2003.

Área: Transportes.

Orientador: Prof. Assoc. Paulo César Lima Segantine.

1. Nivelamento trigonométrico. 2. Nivelamento.

3. Estação total. 4. Erro em nivelamento. I. Título. 
Candidato: Engenheiro ANTONIO SÉRGIO BENTO MOREIRA

Dissertação defendida e julgada em 31-07-2003 perante a Comissão Julgadora:
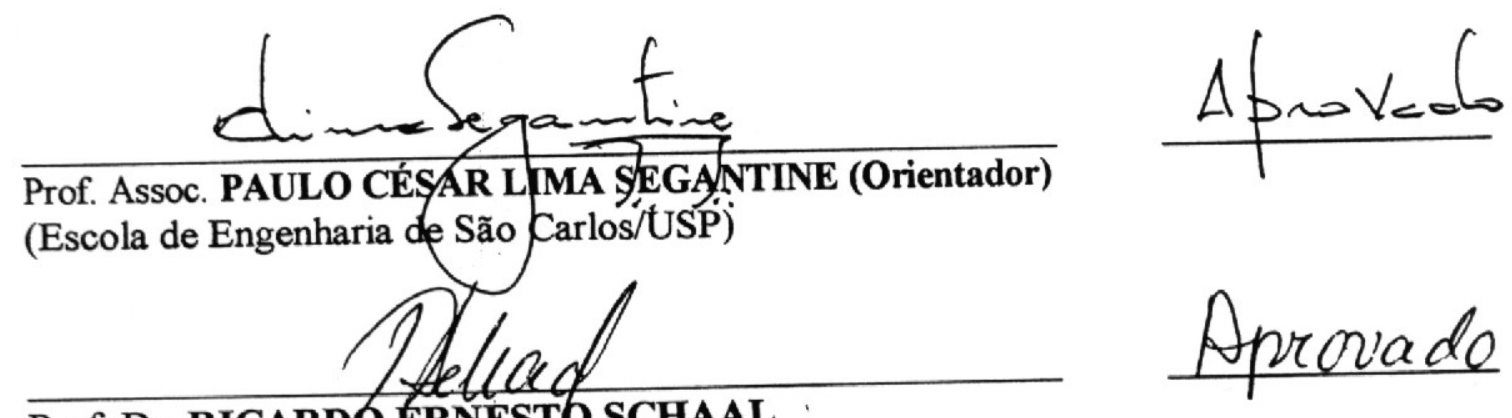

Prof. Dr. RICARDO ERNESTO SCHAAL

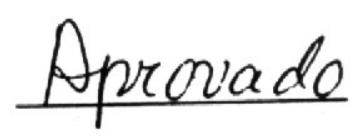

(Escola de Engenharia de São Carlos/USP)
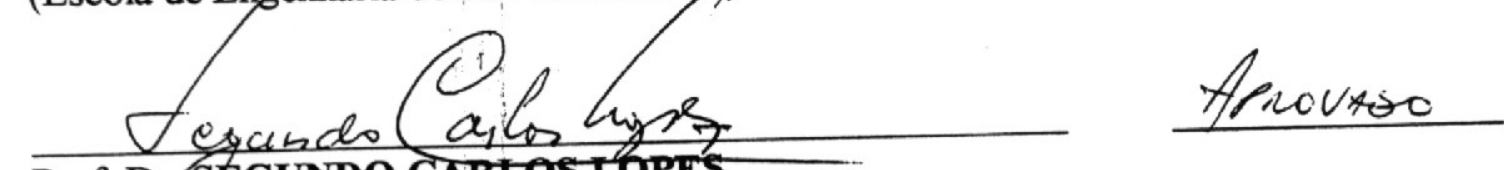

Prof. Dr/SEGUNDO CARTOS LOPES

(Universidade Federal de São Carlos/UFSCar)

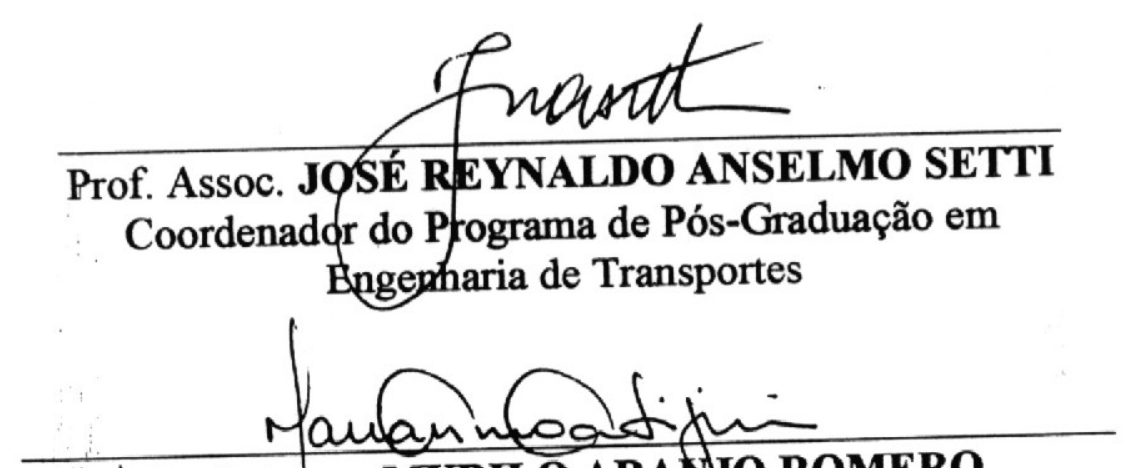

p) Prof. Assoc. MURILO ARA UJO ROMERO

Vice-Presidente da Comissão de Pós-Graduação da

EESC, em exercício 


\section{Dedicatória}

Aos meus pais José (in memorian) e Haydê pelo amor e dedicação

Às minhas irmãs Neta, Cínthia, Celma, Tina e Lú

À minha querida esposa Sandra 


\section{Agradecimentos}

À Deus por tudo...

Ao Prof. Dr. Paulo Cesar Lima Segantine pela oportunidade, orientação e sugestões durante a realização deste trabalho;

À minha esposa Sandra pela compreensão e incentivo nos momentos difíceis e por seu exemplo de ética, profissionalismo e humildade;

Ao Prof. Dr. Segundo Carlos Lopes pelo empréstimo do nível NI07;

Ao Prof. Dr. Irineu da Silva pelo empréstimo da estação total TC307;

À Autovias S.A. por permitir realizar os trabalhos de campo às margens da rodovia SP-318, sob sua concessão;

Aos funcionários do Departamento de Transportes da Escola de Engenharia de São Carlos pela presteza e convivência;

Aos Professores Fausto Soares de Andrade Júnior e Artur Caldas Brandão, da Escola Politécnica da Universidade Federal da Bahia, pelo incentivo e encorajamento ao iniciar esta jornada;

Aos amigos do forninho Maurício, Uchoa, Tule, Genival e do fornão Geraldo, Artur, Anderson, Flávia e Shirley pela preciosa colaboração nos trabalhos de campo e especialmente a Uchôa e Tule pela leitura e sugestões deste trabalho;

Aos colegas e novos amigos conquistados neste período pela convivência alegre e harmoniosa;

Aos amigos Pami e Lili pelo apoio e carinho numa etapa precedente e indispensável a esta; 
À minha família e amigos da Bahia, por estarem sempre torcendo pelo meu êxito;

Aos amigos Rogério, Kioko, Camila, Edgard, Pierre, Patrícia e Elce pela convivência e por proporcionarem momentos que ajudaram a amenizar as saudades;

Aos amigos e colegas da Caesb pelo aprendizado, companheirismo e excelente convivência;

À Coordenadoria de Aperfeiçoamento de Pessoal de Nível Superior - CAPES pela bolsa de estudo concedida. 


\section{Resumo}

MOREIRA, A.S.B. (2003). NIVELAMENTO TRIGONOMÉTRICO E NIVELAMENTO GEOMÉTRICO CLASSE IIN DA NBR 13.133: LIMITES E CONDIÇÕES DE COMPATIBILIDADE. Dissertação (Mestrado) - Escola de Engenharia de São Carlos, Universidade de São Paulo, São Carlos, 2003.

O nivelamento trigonométrico com estação total é uma écnica que tem sua aplicação revigorada em situações que até pouco tempo atrás, por razões de precisão, somente podiam ser atendidas com uso de nivelamento geométrico. A NBR 13.133 inclui este tipo de nivelamento em uma única classe e estabelece tolerâncias muito altas, e por essa razão limita a sua especificação por empresas contratantes. Neste trabalho, avaliou-se a precisão do nivelamento trigonométrico usando estações totais de baixa e média precisão, comparando as diferenças de níveis obtidos por nivelamento geométrico. Na avaliação foram consideradas as influências de alguns fatores na propagação dos erros: a obtenção da altura do instrumento, os efeitos atmosférico, o posicionamento e altura dos alvos, a precisão dos equipamentos e as distâncias de visadas. Os resultados possibilitaram definir as distâncias máximas de visada nas condições avaliadas, em que alcança a tolerância do nivelamento geométrico IIN.

Palavras-chave: nivelamento trigonométrico, nivelamento, estação total, erro em nivelamento. 


\section{Abstract}

MOREIRA, A.S.B. (2003). TRIGONOMETRICAL LEVELING AND LEVELING CLASS IIN OF NBR 13.133: COMPATIBILITY LIMITS AND CONDITIONS. Dissertation (Master's degree) - School of Engineering of São Carlos, University of São Paulo, São Carlos, 2003.

The trigonometrical leveling with total station is a technique that has been increased in situations in that even some time, for reasons of precision, the use of the leveling was demanded. The NBR 13.133 includes this trigonometrical leveling in a single class and it establishes very high tolerances, and for that reason it limits its specification for contracting companies. The precision of the trigonometrical leveling was evaluated using total stations of low and intermediate precision, comparing the differences of levels obtained by leveling. In the evaluation the influences of some factors were considered in the propagation of the errors: the instrument height determination, the atmospheric effects, the positioning and staff height determination, the precision of the equipments and the distances of staff. The results made possible to define the sight maximum distances in the evaluated conditions, in that it reaches the IIN tolerance leveling.

Keywords: trigono metrical leveling, leveling, total station, error in leveling. 


\section{Lista de Figuras}

Figura 2.1 - Superfícies utilizadas na Geodésia e Topografia........................................6

Figura 2.2 - Superfícies de nível e vertical do lugar. ..................................................

Figura 2.3 - Superfícies eqüipotenciais não paralelas. ............................................... 8

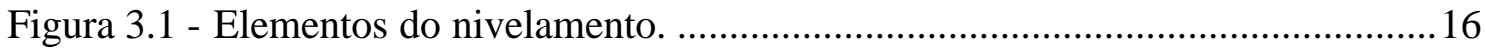

Figura 3.2 - Ilustração do nivelamento geométrico................................................... 17

Figura 4.1 - Ilustração do nivelamento trigono métrico com visada unilateral................27

Figura 4.2 - Ilustração de um lance de nivelamento trigonométrico "Leap-frog”...........30

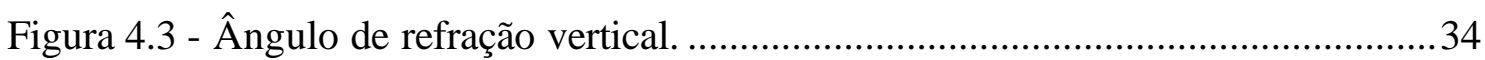

Figura 5.1 - Relação entre a altura geométrica e a altitude ortométrica.........................49

Figura 7.1 - Ilustração esquemática da seção de estudo...............................................58

Figura 7.2 - Vista da seção com o nível entre os pontos P7 e P8 e a mira em P7 ...........58

Figura 7.3 - Detalhe da materialização dos pontos. ........................................................59

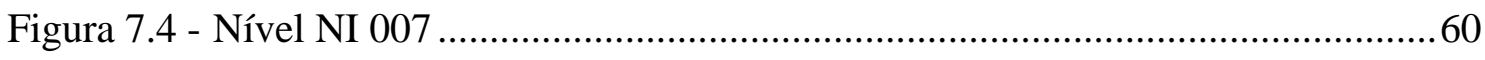

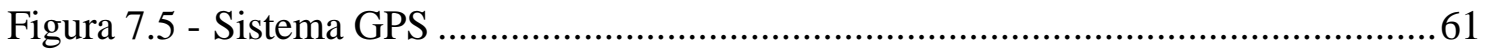

Figura 7.6 - Estações totais usada no nivelamento trigonométrico................................63

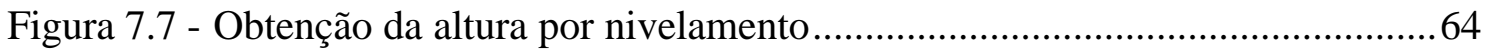

Figura 7.8 - Prisma em bastão apoiado com bipé. .......................................................65

Figura 7.9 - Ilustração da estratégia para o nivelamento trigonométrico.........................66

Figura 8.1 - Detalhe do posicionamento do "zero de referência" da trena no ponto. ......72

Figura 8.2 - Altura da linha de visada da estação P9 ao ponto PS2 .............................73

Figura 9.1 - Modelo de planilha usada nos cálculos das cotas.....................................98 


\section{Lista de Gráficos}

Gráfico 8.1 - Diferença dos desníveis do nivelamento e contranivelamento...................70

Gráfico 8.2 - Diferença de altura do instrumento medida por trena e nivelada ...............72

Gráfico 8.3 - Média dos erros padrões do nivelamento com TC400 e TC307 ...............75

Gráfico 8.4 - Diferença média x distância x combinação - TC400 .................................76

Gráfico 8.5 - Diferença média x distância x conbinação - TC307 ..................................77

Gráfico 8.6 - Erro do nivelamento trigonométrico e tolerância do nivelamento

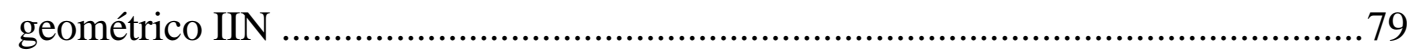

Gráfico 8.7 - Erro padrão do nivelamento trigonométrico na condição C15 - TC307 ...80

Gráfico 8.8 - Erro padrão do nivelamento trigonométrico na condição C15 - TC400 ...80

Gráfico 8.9 - Erro padrão do nivelamento trigonométrico na condição C4 - TC400 .....81

Gráfico 8.10 - Erro padrão do nivelamento trigonométrico na condição C4 - TC400 ...81

Gráfico 9.1 - Diferenças do nivelamento trigonométrico na condição C15....................91

Gráfico 9.2 - Diferenças do nivelamento trigonométrico na condição C4......................94 


\section{Lista de Tabelas}

Tabela 3.1 - Erro de leitura devido a verticalidade da mira. 20

Tabela 3.2 - Erro máximo por visada em função da tolerância 26

Tabela 4.1 - Coeficiente de refração 36

Tabela 4.2 - Variação da correção da distância (ppm) com a temperatura e umidade....37

Tabela 4.3 - Variação da correção da distância (ppm) com a temperatura e pressão .....38

Tabela 4.4 - Variação da correção da distância (ppm) com a temperatura e pressão .....38

Tabela 4.5 - Valor do desnível em função da distância, correção e ângulo vertical.......39

Tabela 4.6 - Valores de correção da curvatura e refração ..............................................40

Tabela 4.7 - Diferença da correção para valores de k .................................................40

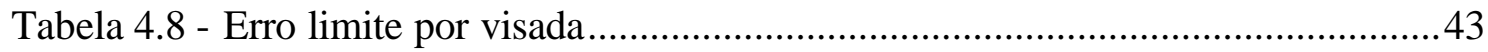

Tabela 4.9 - Erros em visadas unilaterais - Estação total de média precisão ...................44

Tabela 4.10 - Erros em visadas unilaterais - Estação total de baixa precisão ..................44

Tabela 4.11 - Erros em Leap-frog - Estação total de baixa precisão ...............................45

Tabela 4.12 - Erros em Leap-frog - Estação total de média precisão ...............................45

Tabela 4.13 - Erro limite por visada para o nivelamento Leap-frog.............................47

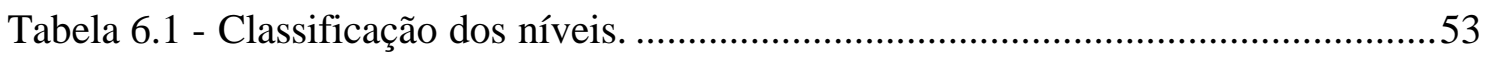

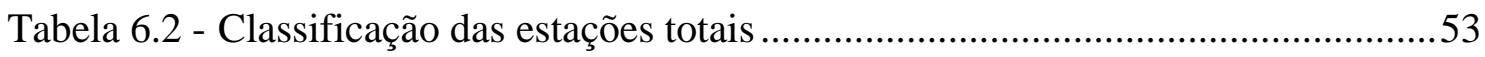

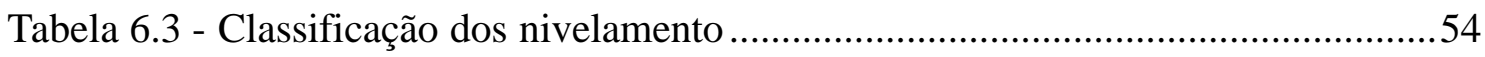

Tabela 6.4 - Especificações para nivelamento geométrico geodésico ............................55

Tabela 7.1 - Número de pontos nivelados x distância de visada.....................................66 
Tabela 7.2 - Combinação das diferentes condições para o cálculo do nivelamento trigonométrico .67

Tabela 7.3 - Pontos de estação e alvo nos cálculos do Leap-frog. .68

Tabela 8.1 - Resultados do nivelamento geométrico .70

Tabela 8.2 - Coordenadas geodésicas .70

Tabela 8.3 - Altura geométrica e altitude ortométrica 71

Tabela 8.4 - Diferença entre altura do instrumento medida à trena e por nivelamento ..72

Tabela 8.5 - Altura da linha de visada em relação ao solo. 73

Tabela 8.6 - Erro padrão x distância x condição avaliada - TC400 74

Tabela 8.7 - Erro padrão x distância x condição avaliada - TC307 75

Tabela 8.8 - Distâncias de visadas obtidas dos Gráficos 8.7, 8.8, 8.9 e 8.10. 78

Tabela 8.9 - Nivelamento de uma seção com Leap-frog. 82

Tabela 8.10 - Erros observado no nivelamento Leap-frog. 83

Tabela 9.1 - Condição do tempo durante o levantamento de campo - TC400. 97

Tabela 9.2 - Condição do tempo durante o levantamento de campo - TC307. 97

Tabela 9.3 - Umidade relativa do ar. 98 


\section{Lista de Siglas}

ABNT Associação Brasileira de Normas Técnic as;

DNER Departamento Nacional de Estradas e Rodagem;

DNIT Departamento Nacional de Infra-Estrutura de Transportes;

EESC Escola de Engenharia de São Carlos;

EMBRAPA Empresa Brasileira de Pesquisa Agropecuária;

EPUSP Escola Politécnica da USP;

GPS Global Positioning System;

IBGE Fundação Instituto Brasileiro de Geografia e Estatística;

IS Instrução de Serviço;

IUGG International Union of Geodesy and Geophysics;

MBG-92 Mapa Geoidal do Brasil - 1992;

MED Medidor Eletrônico de Distâncias

NBR Norma Brasileira Registrada;

RN Referencia de Nível;

RRNN Plural de Referência de Nível;

SAD-69 South Americam Datum - 1969;

SBG Sistema Geodésico Brasileiro;

UFSCar Universidade Federal de São Carlos;

USP Universidade de São Paulo;

WGS-84 World Geodetic System - 1984; 


\section{Sumário}

RESUMO

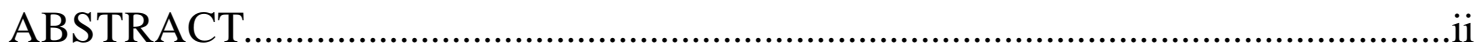

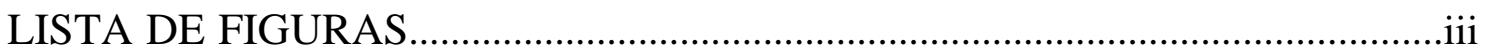

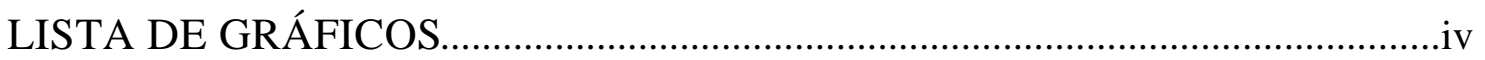

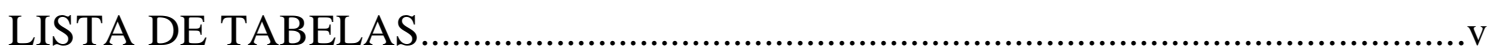

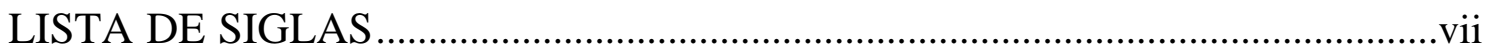

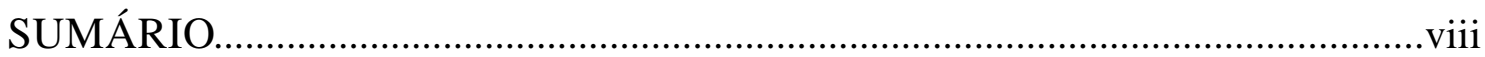

1 INTRODUÇÃ

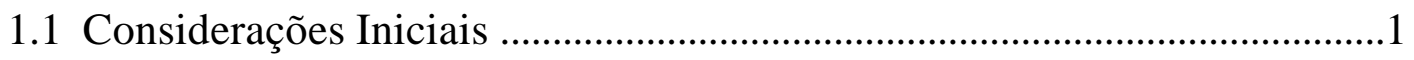

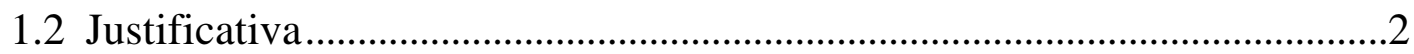

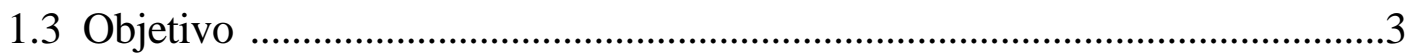

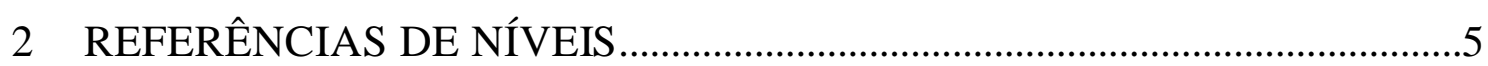

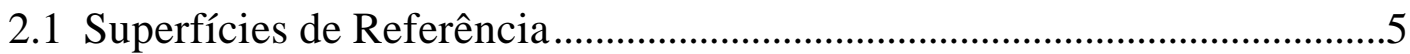

2.2 O Campo de Gravidade e Superfície Eqüipotencial ..................................6

2.3 Geóide e o Nível Médio dos Mares ..............................................................8

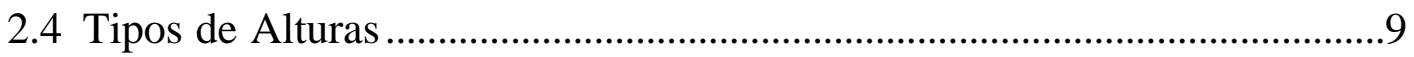

2.4.1 Alturas do tipo geométrico. ..................................................................... 10

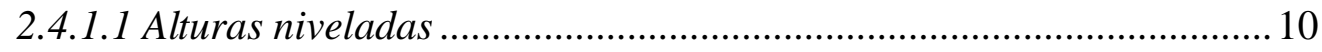

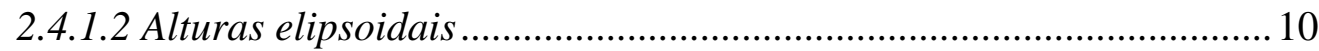

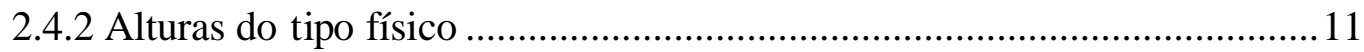

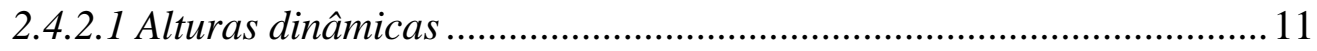

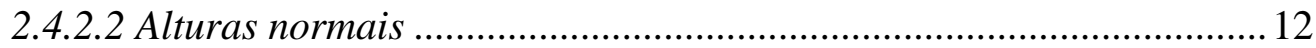

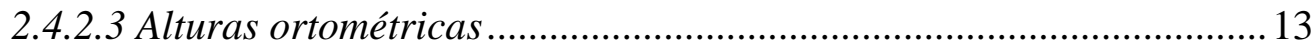

2.5 Referência de Nível no Brasil ............................................................... 14 


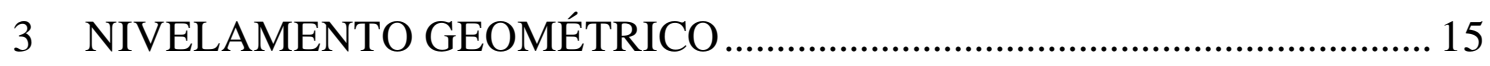

3.1 Fontes de Erro no Nivelamento Geométrico................................................ 18

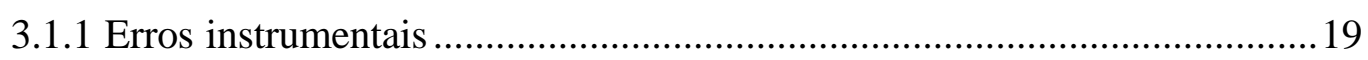

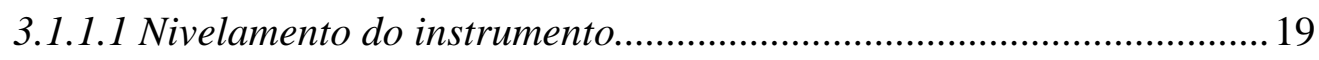

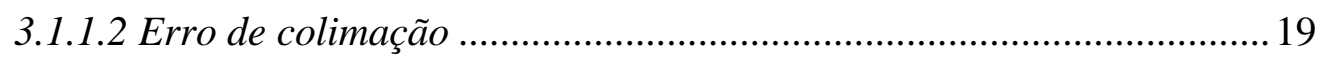

3.1.1.3 Erro de verticalidade da mira .........................................................20

3.1.1.4 Erro de graduação da mira ..............................................................20

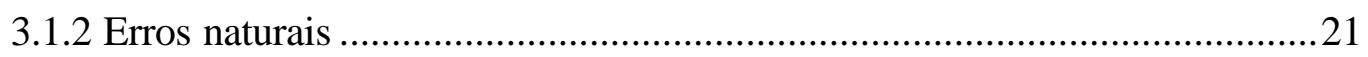

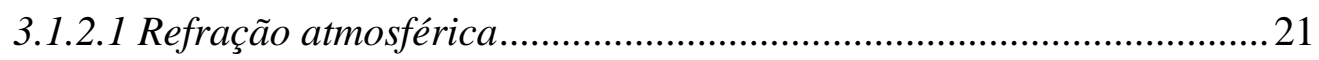

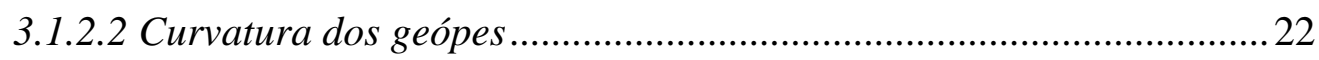

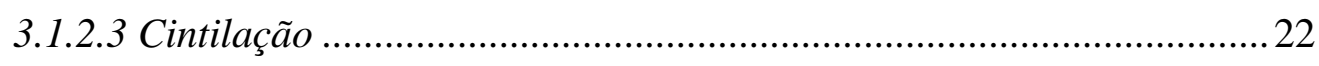

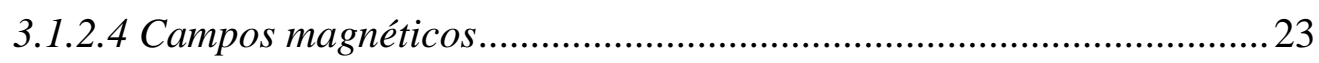

3.1.2.5 Efeitos da variação de temperatura no instrumento............................23

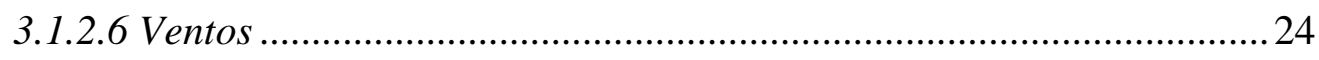

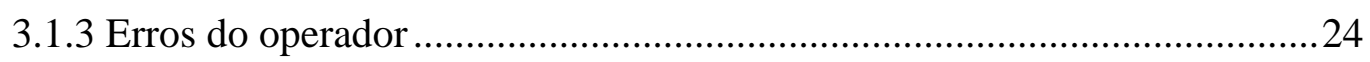

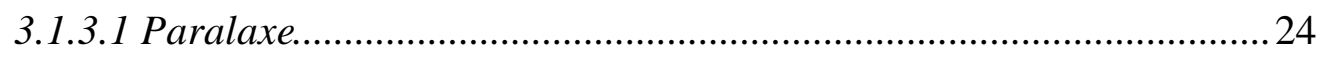

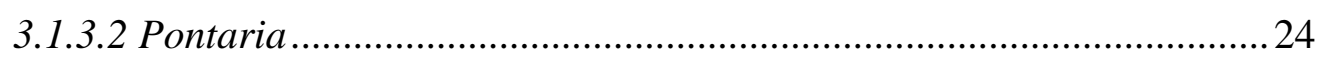

3.2 Propagação dos Erros Aleatórios em Nivelamento Geométrico .............. 24

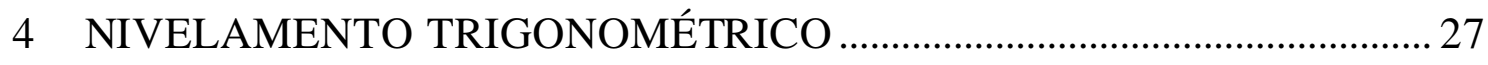

4.1 Visadas Unilaterais ................................................................................. 27

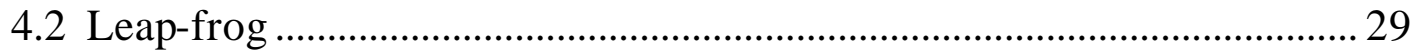

4.3 Fontes de Erro no Nivelamento Trigonométrico........................................... 31

4.3.1 Refração atmosférica …………………………………..........................

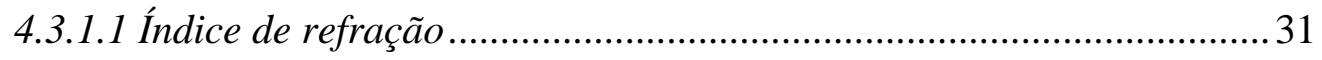

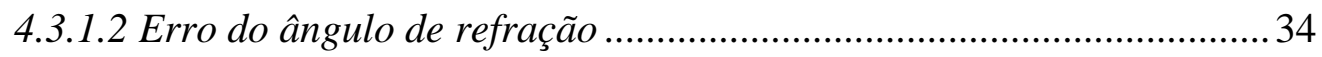

4.3.1.3 Avaliação dos efeitos da refração nas medições de distância ............37

4.3.1.4 Avaliação dos efeitos da refração na medição do ângulo zenital.......39

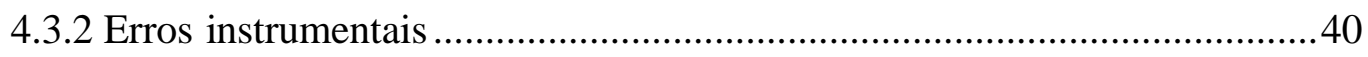

4.4 Propagação dos Erros em Visadas Unilaterais.............................................. 41

4.5 Propagação de Erro Leap-frog .......................................................................... 45

5 NIVELAMENTO VETORIAL COM GPS.................................................... 48

6 TOLERÂNCIA NOS NIVELAMENTOS …………………………………..... 51

6.1 Os Equipamentos ................................................................................... 51

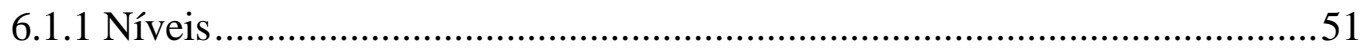




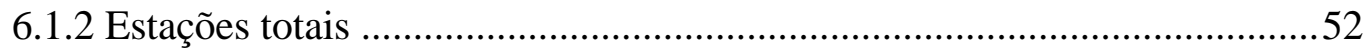

6.2 Recomendações da ABNT - NBR 13.133 …........................................... 52

6.3 Recomendações do IBGE - Resolução PR N ${ }^{\circ} 22$................................... 54

6.4 Recomendações do DNIT - IS 204 e IS 205 .......................................... 55

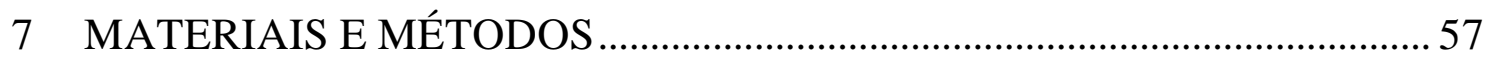

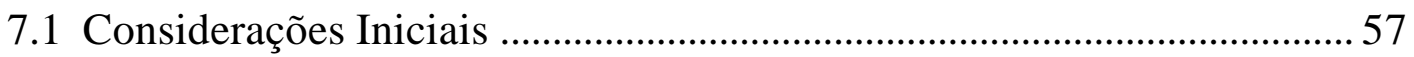

7.2 Definição da Seção de Estudo ................................................................... 57

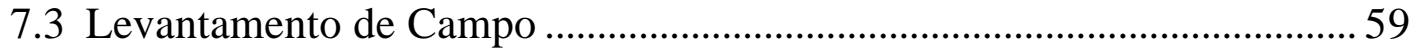

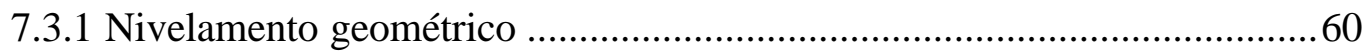

7.3.1.1 Equipamentos utilizados ..................................................................6 60

7.3.1.2 Estratégia de ocupação dos pontos e cálculo.....................................60

7.3.2 Nivelame nto com GPS ..........................................................................61

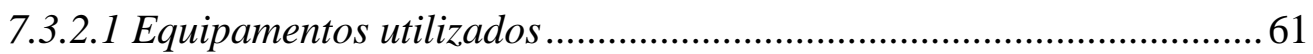

7.3.2.2 Estratégia de ocupação dos pontos e processamento .........................62

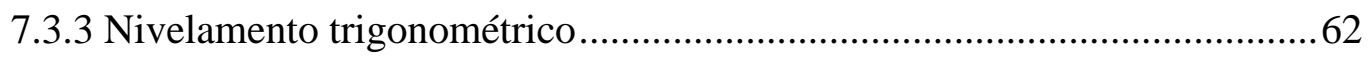

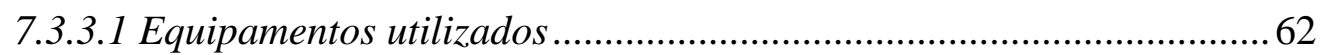

7.3.3.2 Coleta de dados atmosféricos .............................................................63

7.3.3.3 Medição da altura do instrumento ..................................................63

7.3.3.4 Posicionamento do alvo......................................................................6 65

7.3.3.5 Estratégia de ocupação dos pontos ....................................................65

7.3.3.6 Estratégia de processamento e avaliação dos dados ..........................67

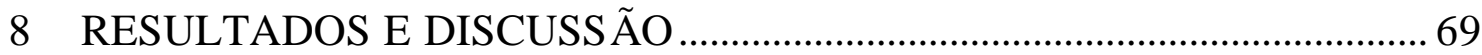

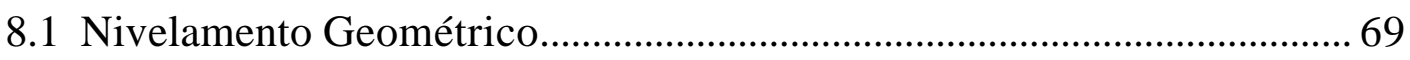

8.2 Nivelamento Com GPS....................................................................... 70

8.3 Nivelamento trigonométrico .................................................................... 71

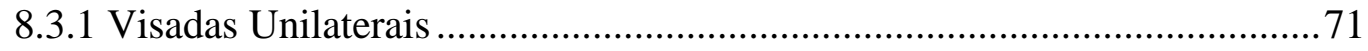

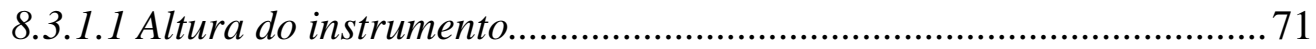

8.3.1.2 Linha de visada próxima do solo...................................................... 73

8.3.1.3 Avaliação das condições................................................................. 74

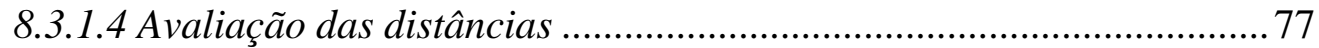

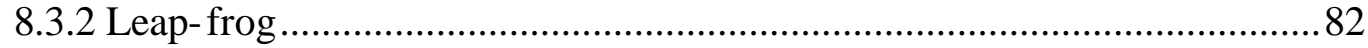

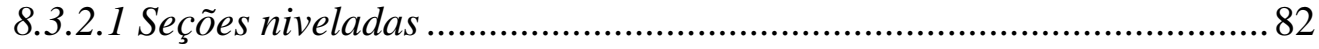

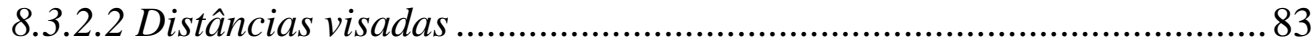

9 CONSIDERAÇÕES FINAIS E CONCLUSÕES ......................................... 84 


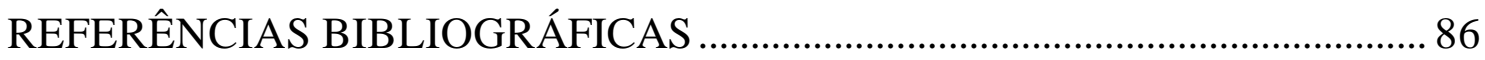

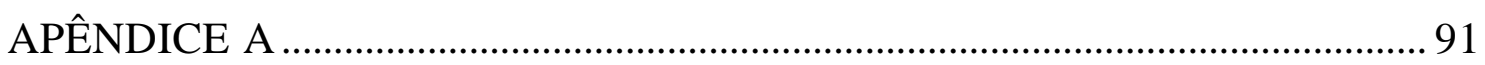

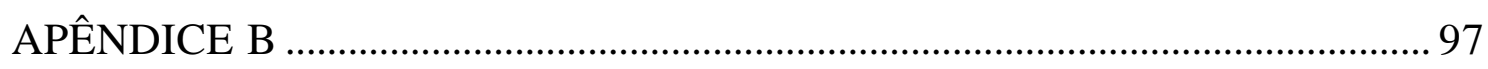

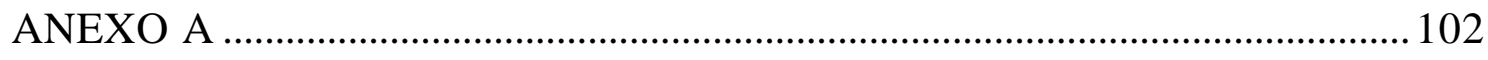




\section{Introdução}

\subsection{Considerações Iniciais}

Determinar e a altitude de pontos ou a diferença de altitude entre diversos pontos na superfície física da terra é uma necessidade, por diversas razões, durante o desenvolvimento das atividades dos profissionais de diferentes ramos da Engenharia de Agrimensura, Civil, Minas, Ambiental, Elétrica, Cartográfica, bem como da Geografia, Geologia e de outras áreas. O conhecimento da altitude é imprescindível para projetar, implantar e executar obras de engenharia.

A obtenção das altitudes é objeto da Geodésia ou da Topografia, dependendo da amplitude da área em estudo, que para isso utiliza-se de métodos de medições convenientes à extensão da área e a precisão desejada.

Os métodos mais difundidos para determinação de altitudes são as operações de campo designadas por nivelamentos. Estes podem ser classificados como: Barométrico, Trigonométrico, Geométrico, Fotogramétrico e Vetorial com sistema GPS ${ }^{1}$. A Fotogrametria apesar de não ser uma técnica exclusivamente de nivelamento, tal como o sistema GPS, também possibilita a determinação de altitude. A escolha do método leva em consideração o objetivo da operação, a característica do que se quer nivelar, a precisão requerida, o tempo gasto, os custos envolvidos e os equipamentos disponíveis.

Destes métodos, o nivelamento geométrico e trigonométrico são os de uso mais freqüientes nas atividades de engenharia e mais recentemente cresce a cada dia a uso do método com GPS. Para que possa ser explorada a potencialidade do GPS na altimetria,

\footnotetext{
${ }^{1}$ Global Positioning System: Sistema de Posicionamento Global.
} 
faz-se necessário o conhecimento de um modelo geoidal que propicie a obtenção da altura geoidal com precisão compatível com a precisão do nivelamento. Isto tem sido objeto de estudos de muitos pesquisadores. O nivelamento barométrico e o fotogramétrico são pouco usuais devido a sua precisão métrica .

Nos últimos anos as atividades de Topografia fazem uso cada vez mais freqüente das estações totais, que são equipamentos ópticos-mecânicos-eletronicos, em substituição aos equipamentos ditos apenas ópticos-mecânicos. Uma das conseqüências dessa substituição é a maior freqüência na utilização do método de nivelamento trigonométrico em situações onde antes, devido à precisão requerida, utilizava-se o método de nivelamento geométrico. Essas mudanças são conseqüências dos avanços tecnológicos que possibilitaram maior precisão nas medições de distâncias obtidas com Medidores Eletrônicos de Distâncias - MED, medição eletrônica de ângulos, armazenamento de dados e processamento automatizado no próprio equipamento, o que possibilitou o ganho sensível de produtividade e qualidade em todas as etapas dos trabalhos de Geodésia e Topografia.

\subsection{Justificativa}

Até o surgimento e popularização das estações totais, os nivelamentos necessários em muitas atividades de engenharia eram realizados aplicando-se o método do nivelamento geométrico. Dentre as atividades pode-se citar: nivelamento de perfil para obras rodoviárias, saneamento, mineração e locação altimétrica de fundações e superestrutura em edificações e obras industriais entre outras, que necessitam de acurácia e precisão na definição dos pontos de interesse.

A crescente popularização associada aos avanços tecnológicos aumentou significativamente o uso do nivelamento trigonométrico com estação total, uma vez que esta possibilita prescindir de cadernetas de campo, armazenam grande quantidade de dados e eliminam erros de anotação, medem ângulos e distâncias com grande precisão, importam e exportam os dados coletados no campo e possuem programas internos capazes de processar cálculos de alturas e desníveis com segurança e economia de tempo. 
A $\mathrm{ABNT}^{2}$ classifica o nivelamento trigonométrico realizado com distâncias obtidas com medidor eletrônico de distância (MED) numa única classe, classe IIIN, e estabelece tolerância de fechamento de $15(\mathrm{~cm}) \sqrt{L(\mathrm{~km})}$ para linhas e seções principais e $20(\mathrm{~cm}) \sqrt{L(\mathrm{~km})}$ para linhas ou seções secundária. No entanto estas tolerâncias são extremamente elevadas para muitas aplicações, motivo pelo qual limita a sua especificação em muitas atividades.

Isto motivou-nos a estudar as influências na precisão do nivelamento trigonométrico a fim de fundamentar a sua utilização, com visadas unilaterais, como nivelamento de precisão compatível com as tolerâncias estabelecidas pela ABNT para o nivelamento geométrico, e adicionalmente fornecer subsídio para melhor definição destes limites na referida norma.

Para tanto, foram utilizadas estações totais classificadas pela NBR 13.133 como de baixa e média precisão, classe 1 e 2 respectivamente, por serem as de uso mais comum na atualidade, para avaliar seu comportamento no nivelamento, já que atendem as necessidades das demais atividades usuais em engenharia.

\subsection{Objetivo}

A precisão do nivelamento trigonométrico é influenciada, em maior ou menor grau, pelos seguintes fatores:

$\checkmark$ Refração da atmosfera;

$\checkmark$ Determinação da altura da estação e do alvo;

$\checkmark$ Estabilidade posicional do alvo;

$\checkmark$ Precisão dos instrumentos usados.

Sendo assim, o objetivo deste trabalho é estabelecer a distância máxima de visada, considerando os fatores acima descritos, em que o nivelamento trigonométrico

\footnotetext{
2 Associação Brasileira de Normas Técnicas, através da Norma Brasileira NBR 13.133 - Execução de Levantamento Topográfico - Procedimento.
} 
com estação total de baixa e média precisão atinja precisão compatível com o nivelamento geométrico classe IIN.

Durante o desenvolvimento do trabalho fez-se:

$\checkmark$ Análise teórica da influência dos fatores descritos acima;

$\checkmark$ Análise dos resultados de um nivelamento trigonométrico numa seção experimental;

$\checkmark$ Análise da melhor maneira de obter a altura do instrumento e do alvo.

Para atingir os objetivos propostos, definiu-se uma reta com $680 \mathrm{~m}$ de extensão, com pontos materializados e espaçados de 40m no km 256 da Rodovia Thales de Lorena Peixoto (SP-318), a 22km da cidade de São Carlos (SP). Determinou-se as alturas relativas dos pontos por nivelamento geométrico, conforme as especificações do IBGE $^{3}$ para o nivelamento geodésico de precisão e em seguida realizou-se o nivelamento trigonométrico destes pontos com estação total de cada uma das classes citadas. As alturas relativas obtidas pelo nivelamento geométrico foram usadas como referência para avaliar o nivelamento trigonométrico.

3 Fundação Instituto Brasileiro de Geografia e Estatística: Especificações e normas gerais para levantamentos geodésicos. 


\section{Referências de Níveis}

A elevação de um ponto qualquer sobre a superfície da Terra é definida pela distância entre este ponto e uma superfície de referência, medida ao longo da linha normal a esta. As alturas utilizadas em Geodésia classificam-se segundo sua determinação, sua aplicação e o modelo matemático ou físico considerado. Quando a elevação é relacionada a uma superfície matemática ou elipsoidal é definida como altura geométrica, e quando relacionada a uma superfície geoidal, de altitude ortométrica.

\subsection{Superfícies de Referência}

A materialização de pontos e a realização das observações topográficas e geodésicas são realizadas na superfície física da Terra. Esta superfície é irregular e de definição matemática complexa aplicável a pequenas regiões (MDT - Modelo Digital do Terreno), por esta razão em levantamentos topográficos ou geodésicos torna-se necessário adotar uma superfície de referência (SCHOFIELD, 1993).

As superfícies de referências são usadas como base para os cálculos das orientações e distâncias entre pontos, áreas das figuras e referência de nível para alturas (DEAKIN, 1996). Em Topografia convencional os ângulos e distâncias são utilizados em verdadeira grandeza, entretanto em muitas aplicações as medições lineares e angulares realizadas na superfície física são reduzidas para distâncias e ângulos equivalentes na superfície de referência. As diferentes superfícies que são consideradas na Topografia e Geodésia estão representadas esquematicamente na Figura 2.1. 
$\mathrm{Na}$ Geodésia as extensões dos levantamentos normalmente são de dimensões tal que a terra não pode ser considerada plana ou esférica, e como superfície de referência adota-se um elipsóide de revolução, aproximadamente do tamanho e forma da terra.

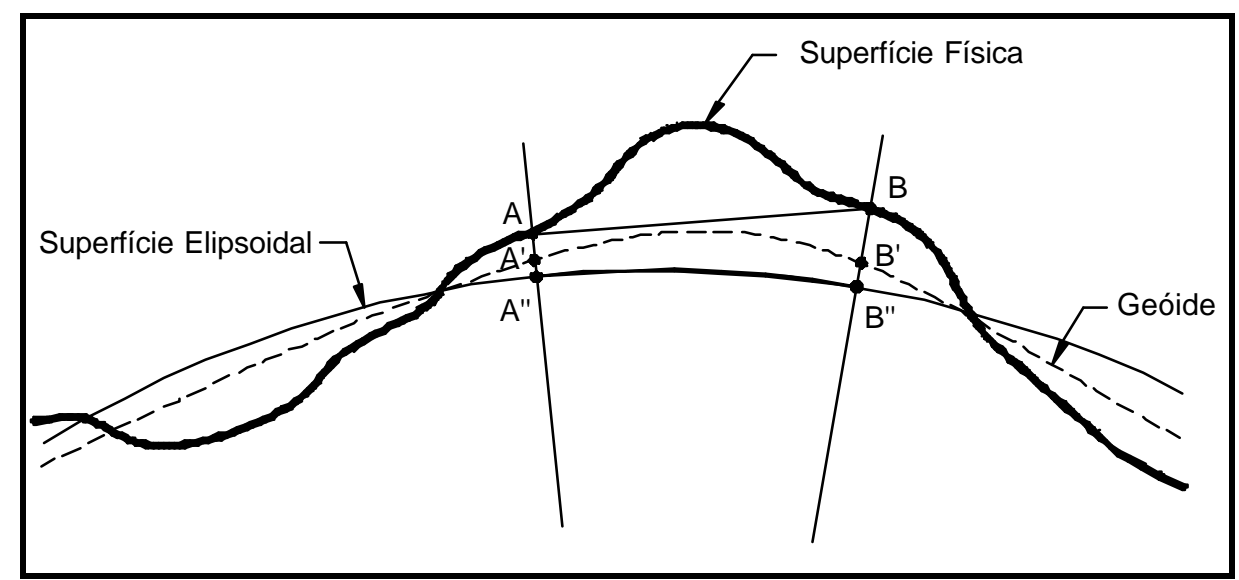

Figura 2.1 - Superfícies utilizadas na Geodésia e Topografia

A extensão dos levantamentos topográficos é geralmente pequena em comparação com a Terra e a superfície de referência é normalmente o plano horizontal local. Segundo a ABNT (1994), este plano de projeção para o plano topográfico local tem sua dimensão máxima limitada a $80 \mathrm{~km}$ da origem para que o erro relativo, devido a não consideração da curvatura, não ultrapasse 1/35.000 nesta dimensão e 1/15.000 nas imediações da extremidade desta dimensão.

Nos levantamentos altimétricos a altitude de cada ponto está relacionada a uma referência de nível que neste sentido são superfícies de referências para a componente vertical. A referência de nível pode ser arbitrária, onde as alturas de pontos são referenciadas a um ponto fixo com altitude também arbitrária, ou em relação ao nível médio do mar que é a superfície que mais se aproxima do geóide (seção 2.3). De acordo com TORGE (1991), nas aplicações geodésicas e topográficas as altitudes são definidas no campo da gravidade, e tomam o geóide como referência zero.

\subsection{O Campo de Gravidade e Superfície Eqüipotencial}

O campo gravitacional da Terra é um campo vetorial, entretanto, em Geodésia é muito mais conveniente trabalhar-se com um campo escalar, onde uma função de um único valor é atribuída a cada ponto. Este campo escalar é conhecido como potencial 
gravitacional $(W)$, resultante da soma do potencial devido à atração de massas $\left(W_{g}\right)$ e potencial centrífugo $\left(W_{c}\right)$, (DEAKIN, 1996).

$$
W=W_{g}+W_{c}
$$

As superfícies eqüipotenciais da terra têm potencial gravitacional constante, e são freqüentemente chamadas de superfície de nível ou geópe:

$$
W(x, y, z)=C(\text { constante })
$$

Infinitas destas superfícies podem ser encontradas assumindo diferentes valores para o potencial. As linhas de força do campo de gravidade da Terra são chamadas de linhas de prumo ou vertical do lugar, conforme ilustra a Figura 2.2.

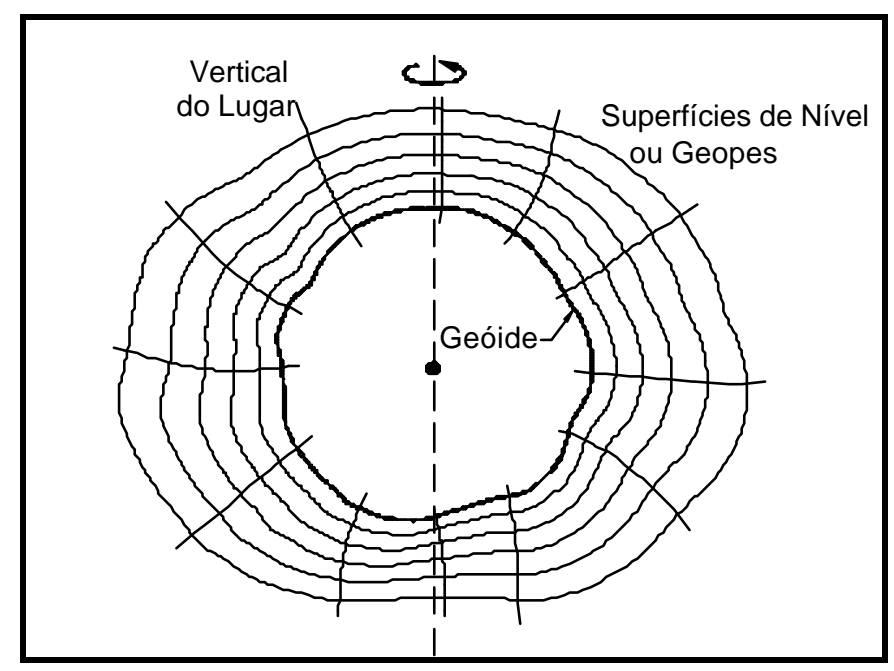

Figura 2.2 - Superfícies de nível e vertical do lugar.

As superfícies eqüipotenciais não são paralelas e, portanto, o transporte da altitude de um ponto a outro depende do caminho percorrido. A Figura 2.3 ilustra de maneira exagerada este fato. 


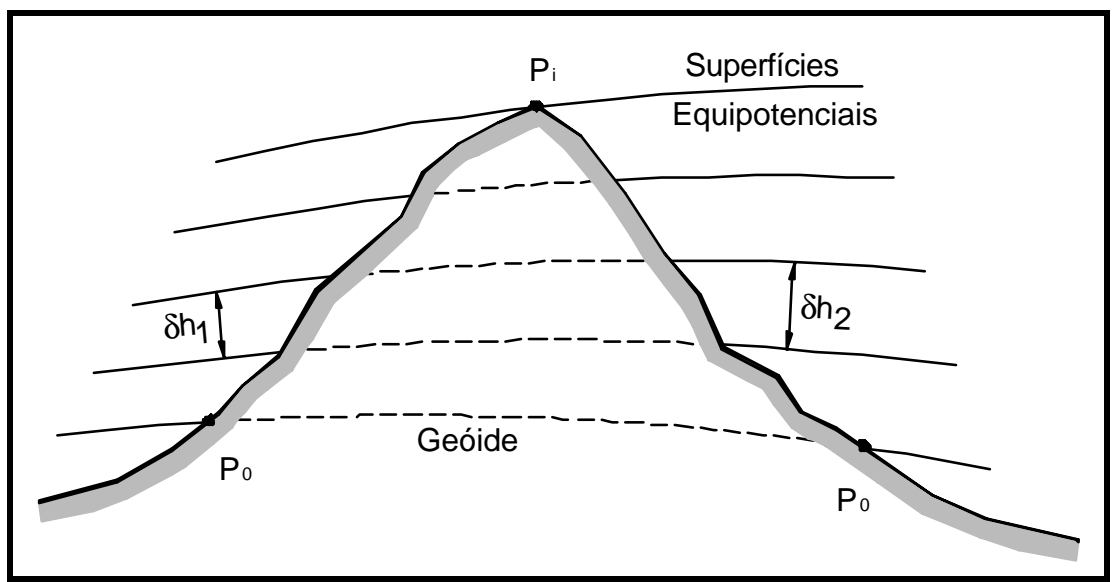

Figura 2.3 - Superfícies eqüipotenciais não paralelas. Adaptado de (VANICEK, 1986).

A altura do ponto $P_{i}$ em relação ao ponto $P_{0}$, que está no mesmo referencial geoidal na outra extremidade da figura, é obtida pela soma dos $\delta h$ que corresponde à distância existente entre as superfícies eqüipotencia is do campo de gravidade. Como as superfícies não são paralelas o desnível do ponto $P_{i}$ obtido pelo lado esquerdo da figura será diferente do obtido pelo lado direito.

\subsection{Geóide e o Nível Médio dos Mares}

Quem primeiro propôs utilizar uma superfície eqüipotencial correspondendo ao nível médio dos oceanos como superfície matemática da terra foi o matemático alemão Carl Friederich Gauss (1777-1855) (DEAKIN, 1996).

Vários autores definem o geóide como a superfície eqüipotencial do campo de gravidade da terra que melhor se ajusta ao nível médio dos mares, (VANICEK, 1986), (TORGE, 1991), (SCHOFIELD, 1993), (DEAKIN, 1996), (ANDERSON, 1998) e (GEMAEL, 1999). Por causa da variação de densidade na crosta terrestre estas superfícies são suavemente onduladas e não podem ser descritas matematicamente como uma superfície analítica e por isso não serve como superfície para determinação de posição (TORGE, 1991).

Segundo BITENCOURT ${ }^{4}$ (1994) citado por PEREIRA (1999) a determinação do geóide implica em encontrar as distâncias que separam pontos correspondentes nas

\footnotetext{
${ }^{4}$ BITTENCOURT, J. (1994). Topografia e Geodésia. Revista Fator GIS, Curitiba
} 
superfícies geoidal e elipsoidal. Esta determinação pode ser realizada por vários métodos:

$\checkmark$ Métodos gravimétricos: através da determinação dos valores da gravidade sobre a terra;

$\checkmark$ Método astro-geodésico: através da comparação entre as coordenadas geodésicas e as astronômicas possibilitando determinar a inclinação do geóide em relação ao elipsóide;

$\checkmark$ Método astro-gravimétrico: pela combinação dos dois anteriores;

$\checkmark$ Observação da perturbação da órbita de satélites artificiais: através da comparação de alturas geométricas, referenciadas ao elipsóide, obtidas por satélites artificiais como o GPS, e das altitudes ortométricas, referenciadas ao geóide, obtidas por nivelamento geométrico.

O posicionamento do datum vertical em relação a um marco de referência é feito com a determinação do nível médio dos mares (NMM). Esta determinação é empírica e baseada em medições instantâneas num marégrafo. No entanto vários fenômenos físicos podem estar alterando continuamente a posição do NMM, são eles: variação da pressão atmosférica, efeito dinâmico das correntes marinhas, variação dos ventos, mudança da temperatura, flutuações de descargas de rios, mudança de configurações batimétricas, derretimento glacial e maré de longo período (VANICEK, 1986).

A determinação do NMM para o datum vertical brasileiro foi realizada a partir do marégrafo localizado no porto Henrique Lajes, na cidade de Imbituba-SC.

\subsection{Tipos de Alturas}

Segundo DREWES (1998), as alturas utilizadas em Geodésia classificam-se segundo sua determinação, sua aplicação e o modelo matemático ou físico considerado. Nesta ótica distinguem-se as alturas do tipo geométrico e as do tipo físico descritas a seguir. 


\subsubsection{Alturas do tipo geométrico.}

\subsubsection{Alturas niveladas}

São as obtidas pelo processo de nivelamento geométrico com métodos óticos de medição. As diferenças de alturas $(d h)$ correspondem à distância entre as superfícies eqüipotenciais do campo de gravidade terrestre e sua soma possibilita conhecer a diferença de alturas entre dois pontos de interesse. Como as superfícies eqüipotenciais não são paralelas os desníveis dependem do caminho percorrido na medição, como descrito na seção 2.2 .

\subsubsection{Alturas elipsoidais}

Correspondem a distância $(h)$ de separação entre a superfície física e o elipsóide ao longo da linha perpendicular ao elipsóide. É obtida a partir das coordenadas cartesianas $(\mathrm{X}, \mathrm{Y}, \mathrm{Z})$ definidas sobre um elipsóide de referência conforme a equação (2.3).

$$
\begin{gathered}
h=\frac{\sqrt{X^{2}+Y^{2}}}{\cos \phi}-N \\
N=\frac{a^{2}}{\sqrt{\left(a^{2} \cdot \cos ^{2} \phi\right)+\left(b^{2} \operatorname{sen}^{2} \phi\right)}}
\end{gathered}
$$

onde

$h: \quad$ Altura elipsoidal;

$X$ e Y: Abscissa e ordenada no sistema cartesiano;

$N$ : Raio de curvatura da primeira vertical;

$\phi: \quad$ Latitude do ponto;

a: $\quad$ semi-eixo maior do elipsóide de referência;

$b$ : $\quad$ semi-eixo menor do elipsóide de referência. 


\subsubsection{Alturas do tipo físico}

O potencial gravitacional em um ponto é único e a diferença de potencial obtida entre dois pontos quaisquer são iguais e independentes do caminho percorrido. A diferença entre o potencial do geópe $\left(W_{P}\right)$ que contém um ponto $P$ qualquer da superfície física da terra e do geóide $\left(W_{0}\right)$ é conhecida como número geopotencial:

$$
C_{P}=W_{0}-W_{P}=\int_{0}^{P} g d n
$$

onde:

$C_{P}: \quad$ Número geopotencial $\left(\mathrm{m}^{2} / \mathrm{s}^{2}\right)$;

$W_{0}$ : Geopotencial sobre o geóide $\left(\mathrm{m}^{2} / \mathrm{s}^{2}\right)$;

$W_{P}$ : Geopotencial sobre o geópe que passa pelo ponto $\mathrm{P}\left(\mathrm{m}^{2} / \mathrm{s}^{2}\right)$;

g: $\quad$ Gravidade em P $\left(\mathrm{m} / \mathrm{s}^{2}\right)$;

$d n: \quad$ Diferença de altura $(\mathrm{m})$.

Os números gopotenciais podem ser expressos em unidades de comprimento bastando dividi-los por um valor convencional de gravidade:

$$
H=\frac{C_{P}}{G}
$$

onde:

H: $\quad$ Altura (m);

$C_{P}$ : Número geopotencial em $\mathrm{P}\left(\mathrm{m}^{2} / \mathrm{s}^{2}\right)$;

$G$ : $\quad$ Valor da gravidade $\left(\mathrm{m} / \mathrm{s}^{2}\right)$.

Dependendo do tipo de gravidade utilizado, tem-se uma classe de altura física.

\subsubsection{Alturas dinâmicas}

São obtidas dividindo o número geopotencial por um valor constante de gravidade para uma latitude padrão arbitrária. Este valor é definido para um modelo elipsoidal utilizado como aproximação da Terra real. Segundo RODRIGUES (1988) 
usa-se normalmente a gravidade para uma latitude de $45^{\circ}$, mas pode-se usar uma latitude média para a região considerada.

$$
H_{(\text {din })}=\frac{C}{\gamma_{c t e}}
$$

onde:

$H_{(\operatorname{din})}$ : Altura dinâmica $(\mathrm{m})$;

C: $\quad$ Número geopotencial $\left(\mathrm{m}^{2} / \mathrm{s}^{2}\right)$;

$?_{c t e}: \quad$ Valor constante da gravidade $\left(\mathrm{m} / \mathrm{s}^{2}\right)$.

Para DREWES (1998) a vantagem da altura dinâmica consiste em que alturas iguais representam uma superfície eqüipotencial do campo da gravidade e a principal desvantagem é que devido à convergência das superfícies eqüipotenciais a altura geométrica entre elas varia sensivelmente chegando a $50 \mathrm{~cm}$ entre o equador e os pólos, sem alterar sua altura dinâmica.

\subsubsection{Alturas normais}

Nas alturas normais os números geopotenciais são divididos pelo valor médio da gravidade normal entre a superfície de referência, neste caso o quase-geóide ou teluróide, e o ponto considerado (DREWES, 1998).

$$
H_{(n o r)}=\frac{C}{\gamma^{\prime}}
$$

onde:

$H_{(n o r)}:$ Altura normal (m);

C: $\quad$ Número geopotencial $\left(\mathrm{m}^{2} / \mathrm{s}^{2}\right)$;

?': Valor médio da gravidade normal $\left(\mathrm{m} / \mathrm{s}^{2}\right)$.

O valor médio da gravidade normal é obtido a partir da fórmula da gravidade normal terrestre que é função apenas da latitude geográfica do ponto no elipsóide de referência utilizado. As correções normais aplicadas às alturas niveladas são menores que as das alturas dinâmicas, já que ?’ considera a convergência das superfícies eqüipotenciais (DREWES, 1998). 
As alturas normais podem ser obtidas a partir das alturas elipsoidais, e os valores de $\zeta$ obtém-se a partir dos cálculos geoidais realizados por métodos gravimétricos ou por satélites.

$$
H_{(\text {norm })}=h-\zeta
$$

onde:

?: $\quad$ Ondulação do quase-geóide ou teluróide;

$h$ : $\quad$ Altura elipsoidal.

\subsubsection{Alturas ortométricas}

Para as alturas ortométricas o número geopotencial é dividido pelo valor médio da gravidade entre o geóide e o ponto avaliado. Este tipo de altura é tratado na engenharia como altitude ortométrica ou simplesmente altitude.

$$
H_{(o r t)}=\frac{C}{g^{\prime}}
$$

onde:

$H_{(o r t)}:$ Altitude ortométrica (m);

C: $\quad$ Número geopotencial $\left(\mathrm{m}^{2} / \mathrm{s}^{2}\right)$;

$g^{\prime}$ : Valor médio da gravidade normal $\left(\mathrm{m} / \mathrm{s}^{2}\right)$.

Não é possível determinar com rigor o valor da gravidade no interior da crosta, visto que não se conhece a verdadeira distribuição de densidade ao longo da vertical. Desta forma o valor da altura ortométrica calculada depende das hipóteses a respeito da distribuição de densidade de massa terrestres (RODRIGUES, 1988). Os métodos mais comuns na determinação das altitudes ortométricas correspondem com as hipóteses de Helmert, Vignal, Baranov e Faye (DREWES, 1998).

As altitudes ortométricas podem ser obtidas a partir das alturas elipsoidais subtraindo o valor das ondulações geoidais N:

$$
H_{(o r t)}=h-N
$$

onde:

$N$ : Ondulação geoidal; 
$h$ : Altura elipsoidal.

DREWES (1998) recomenda que o Sistema Vertical de Referência para a América do Sul seja fundamentado nos tipos de alturas elipsoidais e alturas normais. E justifica sua recomendação com os seguintes argumentos:

$\checkmark$ As alturas normais têm aplicação prática semelhante às altitudes ortométricas, mas sua determinação não requer formulação de hipóteses ou modelos geofísicos da densidade das massas internas terrestres;

$\checkmark$ As alturas normais utilizam o quase-geóide como plataforma de referência, o qual é calculado por métodos gravimétricos e observações de satélites enquanto que o geóide requer formulação de modelos geofísicos para sua determinação, implicando em variação de alturas sempre que mudar a hipótese de estimativa;

$\checkmark$ As alturas normais são obtidas mais facilmente a partir das medições GPS que as altitudes ortométricas. Isto ocorre pois, para as alturas normais, as alturas elipsoidais são diminuídas por valores calculados matematicamente (alturas anômalas do quase geóide- $\zeta$ ) e a segunda valores derivados de hipóteses geofísicas (ondulação geoidal -N);

\subsection{Referência de Nível no Brasil}

No Brasil os trabalhos de nivelamentos geométricos de alta precisão com objetivo de estabelecer Rede Altimétrica do Sistema Geodésico Brasileiro (SGB) para servir de suporte às grandes obras de engenharia teve início em outubro de 1945. Em 1946 foi conectada ao marégrafo de Torres, Rio Grande do Sul, construído em 1919, (LIBAULT, 1975). Em 1958, após mais de 30.000km estarem nivelados, o datum foi transferido para o marégrafo de Imbituba, em Santa Catarina, que à época contava com nove anos de funcionamento ininterrupto.

A rede altimétrica atinge os estados mais distantes como Acre e Roraima e em 1988 a Fundação Instituto Brasileiro de Geografia e Estatística (IBGE) iniciou o projeto de ajustamento da rede altimétrica, com o objetivo de homogeneizar as altitudes da rede altimétrica do SGB (IBGE, 2003). 


\section{Nivelamento Geométrico}

O nivelamento geométrico consiste em uma técnica, vista superficialmente como simples, onde a determinação da diferença de altura entre pontos é feita por visadas horizontais em miras verticais. Essa simplicidade lhe garante uma ampla aplicação em diversas atividades da engenharia, entretanto vale ressaltar que para sua utilização na implantação dos sistemas de altitudes faz-se necessário entender os processos físicos relacionados ao campo gravitacional da terra.

Para melhor entendimento e clareza dos procedimentos envolvendo as atividades de nivelamento apresentam-se algumas definições relacionadas com a Figura 3.1, conforme descrito por ELFICK et al. ${ }^{5}$ (1994) citado por MAIA (1999):

$\checkmark$ Linha de vertical: Linha que segue a direção da gravidade, linha de prumo;

$\checkmark$ Superfície de nível: Superfície curva em que todos os pontos são perpendiculares à linha de prumo local. São aproximadamente elípticas, mas tratadas como plana para pequenas áreas;

$\checkmark$ Linha de nível: Linha na superfície de nível, (linha curva);

$\checkmark$ Plano horizontal: Plano perpendicular ao vetor gravidade;

$\checkmark$ Linha horizontal: Linha no plano horizontal;

$\checkmark$ Datum vertical: Superfície de nível de referência (nível médio dos mares);

$\checkmark$ Nível médio dos mares (NMM): Altura média da superfície do mar para todos os estágios de maré para um período de 19 anos;

\footnotetext{
${ }^{5}$ ELFICK, M. et al. (1994). Elementary surveying. 8th ed. London: Harper Colins Publishers Ltd.
} 
$\checkmark$ Convergência das superfícies de nível: Fenômeno devido ao achatamento da terra na direção polar de modo que as superfícies em elevações diferentes não são paralelas; Esta condição requer uma correção ortométrica;

$\checkmark$ Elevação: Distância vertical do datum ao ponto.

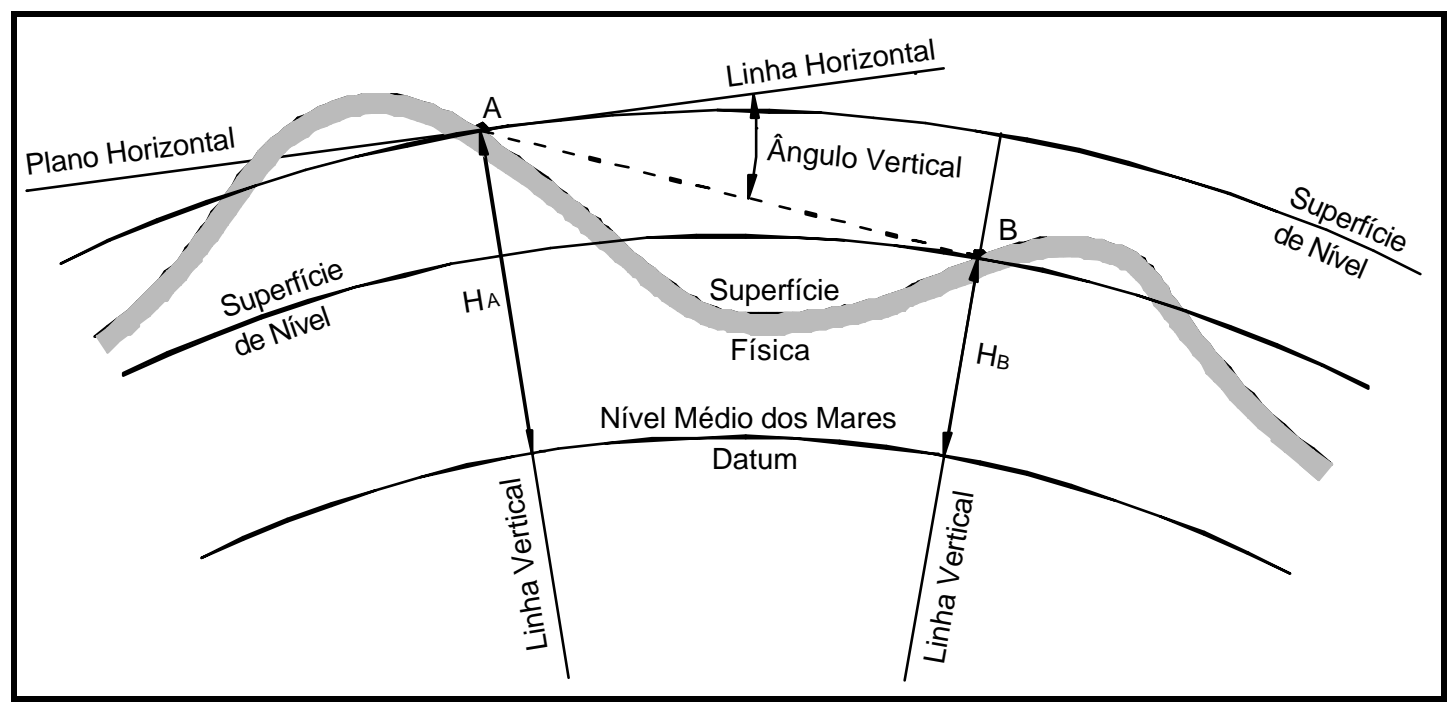

Figura 3.1 - Elementos do nivelamento.

Algumas definições que serão usadas neste trabalho são apresentadas segundo BRASIL (1975) ${ }^{6}$ citado por MEDEIROS (1999) que esclarece e facilita o entendimento.

$\checkmark$ Estação do Instrumento: Posição do instrumento na tomada das leituras sobre as miras;

$\checkmark$ Visada: Leitura da mira realizada numa estação do instrumento, podendo ser visada à ré e visada à vante;

$\checkmark$ Lance: É a distância correspondente à soma da distância da estação a visada de ré e vante;

$\checkmark$ Seções: São trechos nivelados da ordem de 2 a $3 \mathrm{~km}$ em cujas extremidades possuem RN;

$\checkmark$ Linhas: São composições de seções.

${ }^{6}$ BRASIL (1975). Manual Técnico: Nivelamento geométrico.2.ed. Ministério do Exército. Diretoria do Serviço Geográfico. Rio de Janeiro: 1975 
Conforme ilustra a Figura 3.2 a diferença de nível entre os pontos A e B pode ser estimada por:

$$
d n_{A-B}=\sum h_{i}=\sum R_{i}-\sum V_{i}
$$

e

$$
h_{i}=R_{i}-V_{i}
$$

onde:

$h_{i}$ : $\quad$ Diferença de nível entre visadas;

$R_{i}$ : $\quad$ Leitura na mira a ré;

$V_{i}: \quad$ Leitura na mira a vante.

Devido à pequena distância $(<100 \mathrm{~m})$ e a eqüidistância entre o nível e as miras, pode-se negligenciar a convergência das superfícies eqüipotenciais, a variação na curvatura da superfície de nível que passa através do eixo ótico do nível, bem como a influência sistemática da refração.

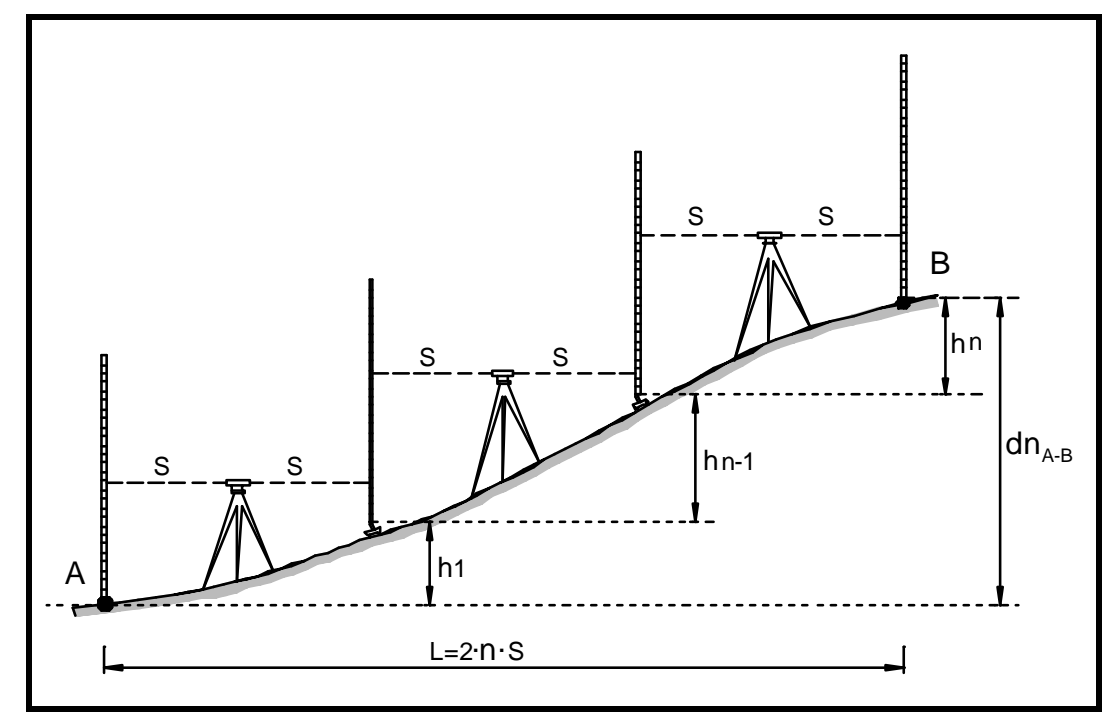

Figura 3.2 - Ilustração do nivelamento geométrico.

O nivelamento geométrico clássico proporciona exatidão e precisão da ordem de décimo de milímetros e por isso é o método utilizado em trabalhos mais rigorosos como na implantação de redes altimétricas de $1^{\mathrm{a}}$ ordem, controles de obras, locação de máquinas entre outros. 


\subsection{Fontes de Erro no Nivelamento Geométrico}

Toda observação por mais cuidadosa que tenha sido sua realização, caracterizase pela presença de erros de medição proveniente de imperfeições dos equipamentos, influência das condições do ambiente e de falhas humanas (GEMAEL, 1994). A qualidade dos resultados do nivelamento geométrico é função da natureza e magnitude dos erros associados às medições individuais.

Os erros são classificados em grosseiros, sistemáticos e acidentais. Os erros grosseiros são cometidos devido à falta de atenção ou falta de prática do operador. Os erros sistemáticos são decorrentes de causas constantes e se caracterizam por ocorrer com o mesmo valor de sinal. Os erros acidentais também chamados de erros aleatórios ou estatísticos são devidos a causas fortuitas.

De acordo com VUOLO (1992) os erros sistemáticos podem ter causas diversas: sistemáticos instrumentais - resultante da descalibração do instrumento de medida; sistemáticos teóricos - resultantes de uso de fórmulas teóricas aproximadas ou valores aproximados de constantes físicas; sistemáticos ambientais - devido aos efeitos ambientais sobre as observações; sistemáticos observacionais - decorrentes de falhas ou limitações do próprio observador, como o efeito de paralaxe na leitura de escalas de instrumentos.

Segundo D'ALGE, (1986) nas operações de nivelamento geométrico os erros grosseiros, decorrentes de falhas dos operadores, são eliminados através de operações de nivelamento e contra-nivelamento, utilização de miras com escala dupla e comparações entre nivelamentos recentes e antigos. Os erros grosseiros mais comuns são o deslocamento de estações de miras, erro de leitura superior a $5 \mathrm{~mm}$ e inversão entre as visadas a ré e a vante.

Os erros acidentais decorrem de variações instrumentais imprevisíveis, mudanças aleatórias no meio ambiente e no processo de nivela mento. Não podem ser eliminados e são tratados estatisticamente.

Apresenta-se a seguir uma descrição mais detalhada dos tipos de erros acima citados. 


\subsubsection{Erros instrumentais}

A função essencial de um nível é definir um plano horizontal que contém a linha de visada. Para isso é necessário que a linha de visada e o eixo vertical do instrumento sejam, respectivamente, paralela e perpendicular ao eixo da bolha de nível. Os níveis automáticos possuem dispositivo compensador que agem sob efeito da gravidade e corrigem automaticamente pequenos desvios da linha horizontal de visada (LOPES, 1996).

\subsubsection{Nivelamento do instrumento - sistemático e aleatório}

Os erros resultantes do desajuste na centragem de bolha, ou impedimento na oscilação livre do compensador, nos níveis automáticos, causam afastamento da linha de visada do horizonte; estes erros são compensados quando o instrumento é instalado a mesma distância da ré e da vante. Os erros aleatórios que dependem do instrumento (incerteza no ajustamento da bolha ou compensador) são menores que 0,01 a $0,03 \mathrm{~mm}$ por estação (TORGE, 1991).

\subsubsection{Erro de colimação - sistemático}

A linha de visada deve ser perpendicular à direção do vetor gravidade no ponto em que o nível está instalado, o que implica em uma linha de visada horizontal. O erro de colimação ocorre quando a linha de visada está inclinada para cima ou para baixo, formando um ângulo com a linha do horizonte e é proporcional a diferença das distâncias. Para lances com mesma distância de visada ré e vante esse erro é cancelado. Como nem sempre é possível obter lances com distâncias de visadas iguais torna-se necessário realizar a correção da colimação.

A correção de colimação $(C)$ é o valor da inclinação em unidade de altura por unidade de comprimento e para determiná-la, instala-se o nível a igual distância $\left(L_{m}\right)$ dos pontos $A$ e $B$ e mede-se a diferença de nível entre os pontos $\left(d h_{1}\right)$. Em seguida desloca-se o equipamento para um ponto $P$, distante $L_{A}$ do ponto $A$ e $L_{B}$ do ponto $B$ e mede-se novamente a diferença de nível entre os pontos $\left(d h_{2}\right)$. Se $d h_{l}$ for igual $d h_{2} \mathrm{o}$ aparelho está ajustado, caso contrário, o nível precisa ser ajustado e $d h_{2}$ é uma diferença de elevação falsa e a correção de colimação é dado por: 


$$
C=\frac{\delta h_{1}-\delta h_{2}}{L_{B}-L_{A}}
$$

Para se obter melhores resultados é necessário testar e se necessário ajustar os equipamentos periodicamente, ou antes de iniciar uma atividade.

\subsubsection{Erro de verticalidade da mira - sistemático}

A mira deve coincidir com o vetor gravidade em cada estação de mira. Quando não há verticalidade, um erro é introduzido em cada observação. Este erro acumula-se sistematicamente com a variação da altitude, especialmente em terrenos com inclinações acentuadas, pois as leituras são efetuadas alternadamente nos extremos superior e inferior da mira. Em miras com nível de bolha esse erro é mantido pequeno. A Tabela 3.1 mostra os erros, em milímetro, que são introduzidos em cada observação quando a leitura é realizada em determinada posição de uma mira de $4 \mathrm{~m}$ e sua extremidade superior encontra-se deslocada da vertical do ponto nivelado.

Tabela 3.1 - Erro de leitura devido a verticalidade da mira.

\begin{tabular}{cccccc}
\hline Altura da & \multicolumn{5}{c}{ Deslocamento da Vertical (cm) } \\
\cline { 2 - 6 } Mira (m) & 2 & 5 & 10 & 15 & 20 \\
\hline 0,5 & 0,0 & 0,0 & 0,2 & 0,4 & 0,6 \\
1,0 & 0,0 & 0,1 & 0,3 & 0,7 & 1,2 \\
1,5 & 0,0 & 0,1 & 0,5 & 1,1 & 1,9 \\
2,0 & 0,0 & 0,2 & 0,6 & 1,4 & 2,5 \\
2,5 & 0,0 & 0,2 & 0,8 & 1,8 & 3,1 \\
3,0 & 0,0 & 0,2 & 0,9 & 2,1 & 3,7 \\
3,5 & 0,0 & 0,3 & 1,1 & 2,5 & 4,4 \\
4,0 & 0,0 & 0,3 & 1,2 & 2,8 & 5,0 \\
\hline
\end{tabular}

\subsubsection{Erro de graduação da mira - sistemático}

Segundo MEDEIROS (1999) os erros de graduação ocorrem no próprio processo de gravação ou pela ação ambiental que provoca rachaduras na pintura da fita afastando dois traços próximos e aproximando um terceiro, acarretando erros da ordem de décimo de milímetros.

A incerteza quanto a posição ocupada pelo "zero" da escala da mira acarreta no erro de índice. Este erro pode ser eliminado realizando um número par de lances para 
cada seção, pois dessa forma as RN são ocupadas pela mesma mira, minimizando a importância do erro de índice nas aplicações práticas (D’ALGE, 1986) ou utilizando uma única mira.

Estes erros são minimizados com os procedimentos de controle instrumental através de certificados de aferição por laboratórios especializados. No Brasil a aferição de mira pode ser realizada m Laboratório de Aferição e Instrumentação Geodésica LAIG, da Universidade Federal do Paraná.

\subsubsection{Erros ambientais}

\subsubsection{Refração atmosférica - sistemático e aleatório}

A atmosfera terrestre é composta por uma mistura de vários gases, sendo que apresenta uma concentração de nitrogênio, oxigênio, argônio e dióxido de carbono de cerca de 99,98\%. Vapor d'água, outro importante componente, é encontrado, principalmente, nas camadas inferiores da atmosfera e é extremamente variável temporal e espacialmente devido ao ciclo hidrológico (SILVA, 1998).

Segundo SCHAAL (1995) a ação conjunta da aceleração da gravidade, radiação solar, ventos e outros tornam essa mistura de gases heterogêneas e anisotrópicas, fazendo com que uma onda eletromagnética ao atravessar esse ambiente altere sua velocidade e direção de propagação.

As linhas de visadas são curvadas na direção em que aumenta a densidade da atmosfera, que por sua vez, varia basicamente em função da temperatura. O efeito da refração é minimizado, e pode ser negligenciado, realizando-se visadas eqüidistantes do nível. Esta suposição não é freqüentemente válida, particularmente em terreno inclinado, onde a linha de visada atravessa camadas atmosféricas com temperaturas e densidades diferente, (BRUNNER, 1984).

Muito próximo do solo a linha de visada sofre o efeito da mudança de densidade do ar que faz com que a refração seja imprevisível. Por isso torna-se necessário que a 
separação entre a linha de visada e o solo seja maior que 50cm (KUKKAMAKI, 19797) citado por (D’ALGE, 1986).

Mudanças grandes e súbitas na refração atmosférica são importantes em trabalho de precisão. Os erros devido à refração tendem a ser acidental em um período longo de tempo mas podem ser sistemáticos no decorrer de um dia (BRINKER e TAYLOR, 1961).

\subsubsection{Curvatura dos geópes - sistemático}

A linhas de visadas supostamente horizontais não acompanham a curvatura dos geópes que passam pelo centro ótico do nível. Isso acarreta um erro de curvatura que pode ser eliminado se consideráramos o comportamento do geópe simétrico e tomarmos distâncias iguais para as visadas à ré e a vante. A não uniformidade dos geópes implica em acumulo sistemáticos da diferença de curvatura das visadas à ré e a vante, principalmente em regiões de relevo variável e com linhas de nivelamento na direção norte sul (D’ALGE, 1988). As correções podem ser obtidas para um modelo esférico da terra e devem ser aplicadas sempre que ocorrer visadas desequilibradas em linhas de nivelamento extensas.

\subsubsection{Cintilação - aleatório}

As cintilações ou vibrações aparente da graduação da mira são ocasionadas pela movimentação ascendente do ar quente, próximo ao solo, em decorrência do gradiente vertical da temperatura ser negativo. A amplitude e a frequiência da vibração depende do gradiente vertical de temperatura.

Durante a noite as camadas de ar mais frias e densas ficam abaixo das menos densas não ocorrendo turbulência. A cintilação não introduz erros sistemáticos, apenas dificulta leitura e torna maiores erros acidentais (D’ALGE, 1986)

7 KUKKAMAKI, T.J. (1979). Levelling refraction research: its present state and future possibilites. In.TENGSTRON, E. \& TELEKI, G. Refractional influences in astrometry and geodesy.Dordrecht, D. Reidel, p.293-95 


\subsubsection{Campos magnéticos - sistemático e aleatório}

Nos níveis automáticos o compensador funciona como um pêndulo rígido que toma a direção da vertical do lugar mediante ação da gravidade e a linha de visada, que é perpendicular ao pêndulo, assume a posição horizontal. A presença de um campo magnético causa pequena deflexão no sistema compensador e conseqüentemente na linha de visada. Segundo PELZER ${ }^{8}$ (1983) citado por D'ALGE (1986) as deflexões depende das propriedades magnéticas do material e da forma e disposição do compensador no nível.

A eliminação do efeito deste tipo de erro depende do processo de construção dos sistemas de compensação. Para nivelamentos de alta precisão alguns cuidados devem ser tomados: evitar túneis com linhas de transmissão de energia e regiões com linhas de transmissão no subsolo, manter uma distância mínima de 500 metros de cabos de alta tensão e linhas de metrô e utilizar níveis não automáticos nos locais em que são esperados efeitos magnéticos significativos (D’ALGE, 1986).

\subsubsection{Efeitos da variação de temperatura no instrumento - sistemático}

Em uma bolha de nível tubular o calor faz o líquido se expand ir encurtando a bolha sem produzir erro, a menos que uma extremidade do tubo seja mais aquecida e a bolha divague para uma delas. Outras partes dos instrumentos podem deformar por causa de aquecimento desigual, e esta distorção afetar os ajustes e, conseqüentemente, provocar pequeno deslocamento na linha de visada do instrumento (BRINKER e TAYLOR, 1969).

Em visadas eqüidistantes este erro é anulado, mas algumas precauções devem ser adotadas: não começar a operar um nível tão logo seja retirado do estojo de transportes, até que se ajuste as condições térmicas locais, manter o nível coberto ao transportá-lo, e protegê-lo por um guarda-sol quando estiver instalado, (DÁLGE, 1986).

\footnotetext{
${ }^{8}$ PELZER, H. (1983). Systematic instrumental errors. In. Workshop on precise levelling, 1983, Hanover. Proceedings.Bonn: Dümmer-Verlag. P.9-15.
} 


\subsubsection{Ventos - aleatório}

Ventos fortes causam vibração no instrumento e torna difícil manter a bolha centrada, nos casos de níveis de bolha; nos níveis automáticos movimentam o compensador pendular do nível provocando movimentos na linha de visada. Esses erros podem ser reduzidos com visadas mais curtas e fixando bem o tripé no chão com as pernas o mais afastado possível. Entretanto nivelamentos precisos não devem ser realizados em dias ventosos.

\subsubsection{Erros do operador}

\subsubsection{Paralaxe - sistemático e aleatório}

Erro causado pela focalização incorreta da lente objetiva e/ou da lente ocular em relação ao retículo, acarretando erro de leitura da mira.

\subsubsection{Pontaria-sistemático e aleatório}

São os erros resultantes das imperfeições do olho humano que não consegue repetir com precisão uma pontaria e pode ser agravado com o efeito da cintilação ou alterações instrumentais imprevisíveis.

Pode-se reduzir este erro com o uso de níveis precisos dotados de micrômetros e placas plano paralelas e com a redução da distância de visada (D'ALGE,1986).

\subsection{Propagação dos Erros Aleatórios em Nivelamento Geométrico}

Embora a precisão alcançada seja influenciada pelo instrumento usado, em grande parte depende do grau de refinamento com que o trabalho é executado. Assumindo que os procedimentos do nivelamento são adequados e os cuidados são tomados em detalhes, os erros sistemáticos podem ser quase totalmente eliminados e os erros remanescentes são aleatórios e atribuídos à incerteza no ajustamento da bolha de nível ou compensador pendular do equipamento, as leituras na mira e a variação do índice de refração do ar. Como a diferença de nível entre dois pontos é composta de 
numerosas observações individuais $h_{i}$, deve-se dispensar atenção especial à propagação de erro.

A precisão no nivelamento geométrico é obtida aplicando a lei de propagação de erro na equação (3.2). Assumindo iguais as distâncias de visadas à ré e a vante e o erro médio de leitura na mira, tem-se conforme VERONEZ (1998) que:

$$
\begin{gathered}
d n_{A-B}=\left(R_{1}-V_{1}\right)+\left(R_{2}-V_{2}\right)+\cdots \cdots+\left(R_{N-1}-V_{N-1}\right)+\left(R_{N}-V_{N}\right) \\
\sigma_{R_{1}}^{2}=\sigma_{V_{1}}^{2}=\cdots \cdots=\sigma_{R_{N}}^{2}=\sigma_{V_{N}}^{2}=\sigma^{2} \\
\sigma_{d n A-B}^{2}=2 \cdot n \cdot \sigma^{2} \quad \text { e } \quad 2 \cdot n=\frac{L}{S} \\
\sigma_{d n A-B}= \pm \sigma \cdot \sqrt{\frac{L}{S}}
\end{gathered}
$$

onde:

$\sigma_{d n A-B}:$ Erro do desnível do ponto A ao ponto B (mm);

$\sigma: \quad$ Erro aleatório de leitura na mira $(\mathrm{mm})$

L: $\quad$ Comprimento total da linha ou seção nivelada $(\mathrm{km})$;

$S: \quad$ Distância de visada $(\mathrm{km})$.

Fazendo uma análise da propagação de erro com os valores estabelecidos por ABNT (1994) para o nivelamento IIN, determinam-se os valores máximos permitidos para o erro por visada, à ré e a vante, em função da distância.

Para uma seção de comprimento $L$ e distância de visadas $S$, o erro de nivelamento é dado por:

$$
E= \pm \sigma \cdot \sqrt{\frac{L}{S}}
$$

onde

$E: \quad$ Erro de desnível para uma seção de comprimento $L$

Segundo ABNT (1994) a tolerância para os nivelamentos é dada pela expressão:

$$
T=\alpha \cdot \sqrt{L}
$$


onde:

T: $\quad$ Tolerância $(\mathrm{mm})$;

a: $\quad$ Valor constante $(\mathrm{mm})$;

L: $\quad$ Comprimento da seção ou linha nivelada $(\mathrm{km})$.

Logo o módulo do erro deverá ser menor ou igual a tolerância,

$$
\begin{gathered}
|E| \leq T \\
\sigma \cdot \sqrt{\frac{L}{S}} \leq \alpha \cdot \sqrt{L} \\
\sigma \leq \alpha \cdot \sqrt{S}
\end{gathered}
$$

Tabela 3.2 - Erro máximo por visada em função da tolerância

\begin{tabular}{cc}
\hline \multicolumn{2}{c}{ Nivelamento Geométrico - IN } \\
\hline \multirow{2}{*}{$\mathrm{S}(\mathrm{m})$} & $\mathrm{a}=12 \mathrm{~mm}$ \\
\cline { 2 - 2 } & $\sigma(\mathrm{mm})$ \\
\hline 20 & 1,7 \\
40 & 2,4 \\
60 & 2,9 \\
80 & 3,4 \\
100 & 3,8 \\
120 & 4,2 \\
\hline
\end{tabular}

\begin{tabular}{cc}
\hline \multicolumn{2}{c}{ Nivelamento Geométrico - IIN } \\
\hline \multirow{2}{*}{$S(\mathrm{~m})$} & $\mathrm{a}=20 \mathrm{~mm}$ \\
\hline 20 & $\sigma(\mathrm{mm})$ \\
40 & 2,8 \\
60 & 4,0 \\
80 & 4,9 \\
100 & 5,7 \\
120 & 6,3 \\
\hline
\end{tabular}

A equação (3.12) possibilita avaliar o erro máximo por visada em função da distância e do valor da constante " $\alpha$ ” definida pela ABNT (1994). A Tabela 3.2 mostra a distância de visada e o erro máximo que pode ser cometido na leitura da mira, em um nivelamento geométrico, para que resulte abaixo das tolerâncias para os nivelamentos geométricos classe IN e IIN. 


\section{Nivelamento Trigonométrico}

No nivelamento trigonométrico, a diferença de altura entre pontos é obtida através da resolução de triângulos, fundamentada na relação trigonométrica entre ângulos e distâncias medidos. O procedimento envolve a observação do ângulo zenital ou vertical de altura e a distância inclinada ou horizontal entre os pontos, e pode ser executado por visadas unilaterais ou visadas recíprocas.

\subsection{Visadas Unilaterais}

A Figura 4.1 ilustra o nivelamento com visadas unilaterais em que o ponto A é conhecido e a diferença de altura para o ponto Bé dada por:

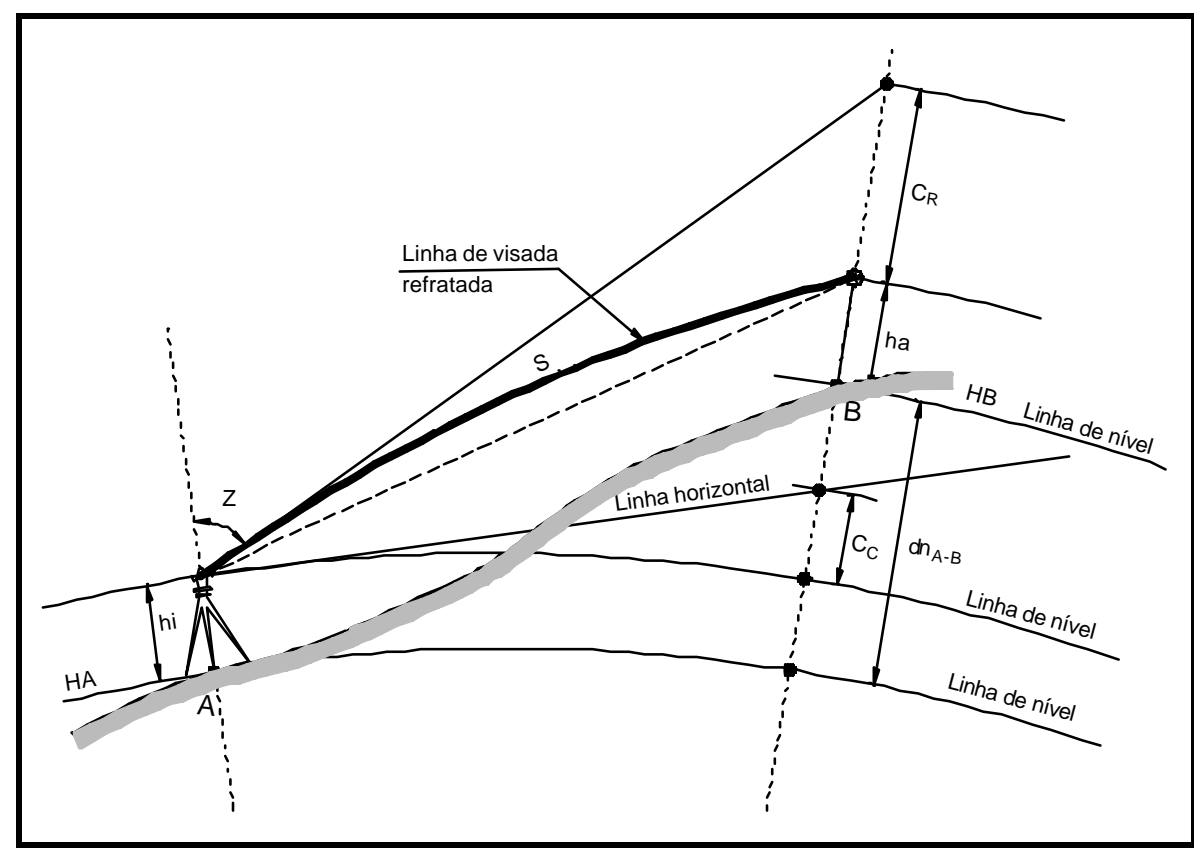

Figura 4.1 - Ilustração do nivelamento trigonométrico com visada unilateral. 


$$
\begin{gathered}
d n_{A-B}=S \cdot \cos Z+h i-h a+C_{C}-C_{R} \\
H_{B}=H_{A}+S \cdot \cos Z+h i-h a+C_{C}-C_{R}
\end{gathered}
$$

onde:

$S$ : $\quad$ Distância inclinada $(\mathrm{m})$;

$Z$ : $\quad$ Ângulo zenital;

$h i$ : $\quad$ Altura do instrumento (m);

ha: $\quad$ Altura do alvo (m);

$C_{C}: \quad$ Correção da curvatura terrestre $(\mathrm{m}) ;$

$C_{R}: \quad$ Correção da refração atmosférica $(\mathrm{m})$;

$H_{A}$ e $H_{B}:$ Altitude dos pontos A e B, respectivamente (m).

É um método rápido para obtenção de diferença de nível entre pontos em terrenos com grandes inclinações e áreas montanhosas. É mais indicado para curtas distâncias. Para longas distâncias o método com visadas zenitais recíprocas e simultâneas deve ser o preferido.

De acordo com a Figura 4.1 a correção da curvatura e da refração atmosférica é dada por:

$$
\begin{gathered}
C_{C}=\frac{S^{2}}{2 \cdot R} \\
C_{R}=-\frac{S^{2}}{2 \cdot R} \cdot k
\end{gathered}
$$

onde:

$R: \quad$ Raio da terra $(\mathrm{m})$

$k$ : Coeficiente de refração

O valor médio do coeficiente de refração para atmosfera padrão ou no estado neutro é $k=0,13$ (BRASIL, 1975). Para a região de São Carlos (SP), $R=6.356 .778 \mathrm{~m}$. Nestas condições o efeito conjunto da curvatura da terra e refração é: 


$$
\begin{aligned}
C_{R C} & =\left(\frac{1-k}{2}\right) \cdot \frac{S^{2}}{R} \\
C_{R C} & =6,83 \cdot 10^{-8} \cdot S^{2}
\end{aligned}
$$

Como mostra as equações $(4.1$ e 4.2$)$ a precisão no resultado do nivelamento trigonométrico depende da precisão do equipamento utilizado nas medições de ângulo e distância, da precisão com que são realizadas as medições da altura do instrumento e altura do alvo, da estimativa do raio médio de curvatura da terra no local e de quão próximo o modelo de correção atmosférica está das condições ambientais do instante da medição.

\subsection{Leap-frog}

Com o método de observações recíprocas observando ângulos verticais com dois teodolitos operando simultaneamente, consegue-se anular o efeito da curvatura e atenuar os efeitos da refração. Este método é mais exato, no entanto sua aplicação fica limitada a situações em que é possível instalar o instrumento no ponto observado.

O "Leap-frog" é uma forma de conduzir o nivelamento com visadas unilaterais sem no entanto ter de medir a altura do instrumento nem fazer as correções da curvatura e da refração, e conseqüentemente sem acrescer os erros advindos dessas operações. $\mathrm{O}$ equipamento é estacionado entre os pontos a serem nivelados de modo semelhante ao nivelamento geométrico, sempre "saltando", daí o nome, os pontos nivelados.

De acordo com CHRZANOWSKI (1989) a University of New Brunswick no Canadá testou uma variação deste método com bastões especialmente projetados com altura de até $5 \mathrm{~m}$ e 3 ou 4 alvos dispostos em altura diferente, e conseguiu acurácia da

ordem de $2 m m \sqrt{L(\mathrm{~km})}$ com distância de visadas de 300 metros. Esta variação é denominada Método UNB.

De acordo com a Figura 4.2, a diferença de nível entre os pontos A e B é determinada como segue:

$$
\begin{aligned}
& d n_{O A^{\prime}}=S_{A} \cdot \cos Z_{A}+C_{C A}-C_{R A} \\
& d n_{O B^{\prime}}=S_{B} \cdot \cos Z_{B}+C_{C B}-C_{R B}
\end{aligned}
$$




$$
\begin{gathered}
H_{O}=H_{A}+h a_{A}-d n_{O A^{\prime}} \\
H_{B}=H_{O}-h a_{B}+d n_{O B^{\prime}}
\end{gathered}
$$

onde:

$S_{A} e S_{B}$ : Distância inclinada para o ponto A e B;

$d n_{O-A^{\prime}}: \quad$ Diferença de nível do eixo ótico do aparelho até o alvo em A;

$d n_{O-B^{\prime}}$ : $\quad$ Diferença de nível do eixo ótico do aparelho até o alvo em B;

$Z_{A}$ e $Z_{B}$ : $\quad$ Ângulos zenitais para o ponto A e B, respectivamente;

$C_{C A e} C_{C B}$ : Correção atmosférica nas direções de $\mathrm{A}$ e B, respectivamente;

$C_{R A} C_{R B}$ : Correção de curvatura nas direções de $\mathrm{A}$ e B, respectivamente;

$h a_{A}$ e $h a_{B}: \quad$ Altura dos alvos em A e B, respectivamente;

$H_{A}, H_{B}$ e $H_{O}$ : Altura em relação a um sistema de referencia dos pontos A, B e centro ótico do instrumento.

Admitindo alvos com mesma altura $h a_{A}$ e $h a_{B}$ e considerando as correções de curvatura e refração para distâncias aproximadamente iguais:

$$
S_{A} \approx S_{B} \Rightarrow C_{C A} \approx C_{C B} \text { e } C_{R A} \approx C_{R B}
$$

tem-se então:

$$
H_{B}=H_{A}-S_{A} \cdot \cos Z_{A}+S_{B} \cdot \cos Z_{B}
$$

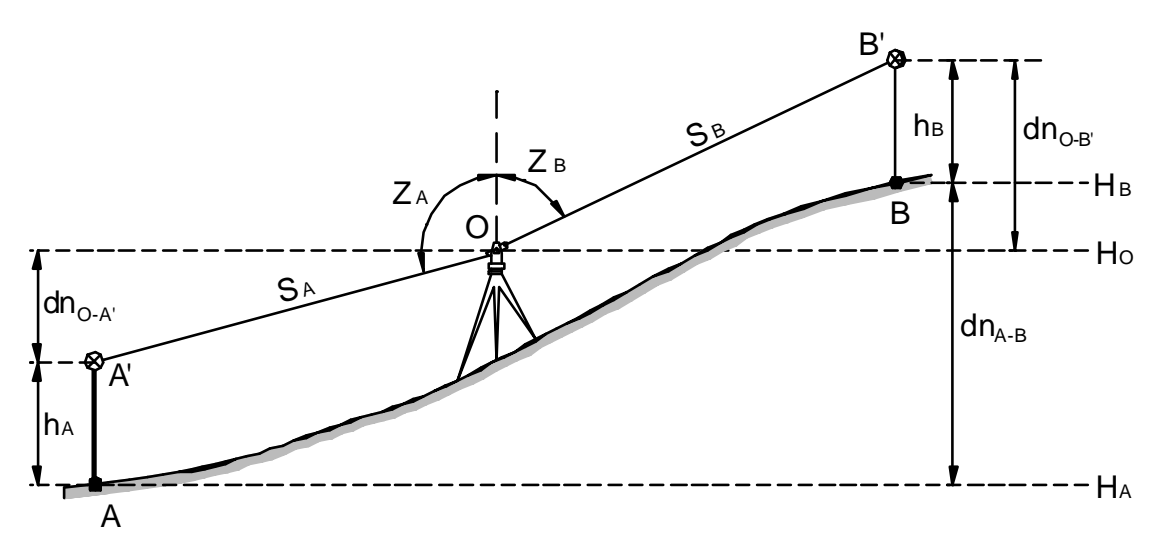

Figura 4.2 - Ilustração de um lance de nivelamento trigonométrico "Leap-frog" 


\subsection{Fontes de Erro no Nivelamento Trigonométrico}

\subsubsection{Refração atmosférica}

A principal fonte de erro em nivelamento trigonométrico é o efeito da refração atmosférica. BRUNNER (1984) afirma que a flutuação do efeito da refração representa o limite fundamental na precisão de medições geodésicas. Em medição eletrônica de distâncias, a velocidade da onda eletromagnética depende do valor médio do índice de refração ao longo do caminho e em nivelamento trigonométrico a linha real de visada para o alvo se torna curva pela variação do índice de refração, (WILLIAMS e KAHMEN, 1984).

Várias soluções são sugeridas por diferentes pesquisadores, e o método mais popular que tem sido aplicado em nivelamento geodésico é baseado no gradiente de temperatura, que pode ser obtido por medição direta da temperatura do ar em diferentes alturas ou por modelagem atmosférica usando as teorias da física atmosférica, (KHARAGHANI, 1987).

\subsubsection{1 Índice de refração}

O índice de refração médio é definido como a razão entre a velocidade da luz no vácuo, $c_{o}$, e a velocidade $c$ da luz no meio:

$$
n=\frac{c_{0}}{c}
$$

A velocidade da luz no vácuo é $c_{0}=299794458 \pm 1,2 \mathrm{~m} / \mathrm{s}$ estabelecido no $\mathrm{XVI}^{\text {th }}$ General Assembly of the IUGG. ${ }^{9}$ em 1975 (SCHOFIELD, 1993) e (TORGE, 1991).

A variação do índice de refração do ar depende da variação da temperatura, pressão e umidade. Em razão do valor do índice ser próximo da unidade, adota-se o conceito de refratividade $(\mathrm{N})$, dado por:

$$
N=(n-1) \cdot 10^{6}
$$

A fórmula adotada pelo Internacional Association of Geodesy (IAG) em 1960:

\footnotetext{
${ }^{9}$ International Union of Geodesy and Geophysics.
} 


$$
N=\frac{\left(n_{g}-1\right)}{1+\alpha t} \cdot \frac{p}{1013,25}-\frac{4,125 \cdot e}{1+\alpha t} \cdot 10^{-8}
$$

onde:

$n_{g}: \quad$ Índice de refração de grupo;

$\alpha$ : $\quad$ Coeficiente de expansão térmica do ar (1/273);

$t: \quad$ Temperatura $\left({ }^{\circ} \mathrm{C}\right)$

$p: \quad$ Pressão atmosférica (mbar);

$e: \quad$ Pressão parcial do vapor d'água (mbar).

A refratividade de grupo $N_{g}$ é a refratividade de um feixe de luz modulado, no ar padrão com $0^{\circ} \mathrm{C}$ de temperatura, 1013,25 mbar de pressão e ar seco com $0,03 \%$ de $\mathrm{CO}_{2}$, e é dada por Barel e Sears (SCHOFIELD, 1993) e (SCHAAL, 1995):

$$
N_{g}=\left(n_{g}-1\right) \cdot 10^{6}=287,604+3 \cdot \frac{1,6288}{\lambda^{2}}+5 \cdot \frac{0,0136}{\lambda^{4}}
$$

onde:

\section{$\lambda: \quad$ Comprimento de onda $\quad(\mu \mathrm{m})$.}

Os MED’s são calibrados numa determinada condição padrão de temperatura e pressão e umidade relativa do ar, e são utilizados em condições diferentes, por esta razão torna-se necessário corrigir as medidas realizadas.

Para o comprimento de onda $\lambda=0,91 \mu m$ tem-se $N_{g}=293,6$. A equação (4.14) também pode ser escrita em função da refratividade:

$$
N=\frac{0,2696 \cdot N_{g} \cdot p}{273,15+t}-\frac{11,27 \cdot e}{273,15+t}
$$

SCHAAL (1995) aplicou a lei de propagação de erro na eq.(4.16) e verificou que numa condição típica de $p=1007$ mbar, $t=15^{\circ} \mathrm{C}, e=13$ mbar e $N_{g}=304,5$ o desvio de $1^{\circ} \mathrm{C}$ na medida de temperatura, 1 mbar na pressão e 1 mbar na pressão parcial de vapor d'água, implica em erro de $1 \mathrm{ppm}, 0,3 \mathrm{ppm}$ e 0,04ppm, respectivamente. 
Segundo BOMFORD ${ }^{10}$ (1971) citado por KHARAGHANI (1987) o gradiente vertical do índice de refração pode ser expresso pela diferenciação da equação (4.14) em relação a altura $(z)$ :

$$
\frac{d n}{d z}=\frac{78,9}{T}\left[\left(\frac{d p}{d z}-0,14 \frac{d e}{d z}\right)-\left(\frac{p-0,14 e}{T}\right) \cdot \frac{d t}{d z}\right] \cdot 10^{-6}
$$

onde:

$T: \quad$ Temperatura absoluta $(\mathrm{K})$

p: $\quad$ Pressão (mbar);

Informa ainda que em condições normais $0,14 \cdot(d e / d z)$ é menor que $2 \%$ de $(d p / d z)$ e $0,14 \cdot e$ podem ser desprezados. O gradiente vertical de pressão é aproximado por:

$$
\begin{gathered}
\frac{d p}{d z}=-\frac{g}{M} \cdot \frac{p}{T} \\
\frac{g}{M}=0,0342\left({ }^{\circ} \mathrm{K} / \mathrm{m}\right)
\end{gathered}
$$

onde:

g: $\quad$ Aceleração gravitacional;

M: $\quad$ Constante específica do gás para o ar seco.

Este valor é conhecido como taxa de variação térmica e representa a diminuição da temperatura com a altitude. Substituindo a equação (4.19) em (4.17) e fazendo as simplificações o gradiente do índice de refração é dado por:

$$
\frac{d n}{d z}=\frac{-78,9 \cdot p}{T^{2}}\left(0,0342+\frac{d t}{d z}\right) \cdot 10^{-6}
$$

Em uma atmosfera homogênea, a densidade é independente da altura. A equação (4.20) mostra que sob tais condições a taxa de variação térmica de $-0,0342^{\circ} \mathrm{K} / \mathrm{m}$ é necessária para compensar o decréscimo na pressão atmosférica com a altura, (KHARAGHANI, 1987).

\footnotetext{
${ }^{10}$ BOMFORD, G. (1971). Geodesy.3rd ed. Oxford, England: Clarendon Press.
} 


\subsubsection{2 Ângulo de refração vertical}

Como mostra a Figura 4.3, o ângulo de refração $\beta$ é o angulo entre a tangente à trajetória ótica em uma das extremidades e a corda. Se $d n / d z$ é conhecido em todos os pontos ao longo de $\mathrm{AB}$, o ângulo de refração vertical pode ser calculado pela equação (BRUNNER e ANGUS-LEPAN 1976) ${ }^{11}$ citado por (KHARAGHANI, 1987):

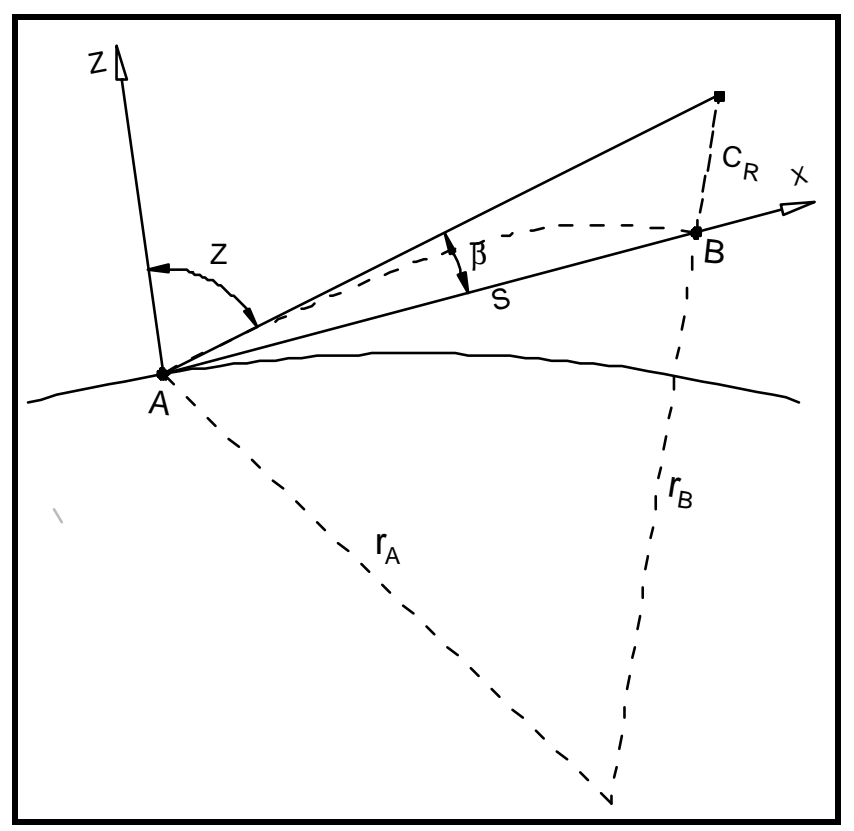

Figura 4.3 - Ângulo de refração vertical.

$$
\beta=\frac{\sin Z}{S} \int_{0}^{S} d n / d z(S-x) d x
$$

onde:

$S$ : $\quad$ Comprimento da corda $\mathrm{AB}$;

$Z$ : $\quad$ Ângulo zenital;

$x$ : Distância ao longo da corda.

Substituindo a equação (4.17) em (4.20) e assumindo $\sin Z=1$, tem-se:

${ }^{11}$ BRUNNER, F.K. e ANGUS-LEPPAN, P.V. (1976). On the significance of meteorological parameters for terrestrial refraction. In: UNISURV G25. Sydney, Austrália, p.95-108. 


$$
\beta=\frac{10^{-6}}{S} \int_{0}^{S}\left[\frac{-78,9 \cdot p}{T^{2}}\left(0,0342+\frac{d t}{d z}\right)\right](S-x) d x
$$

Da Figura 4.3, a correção da refração é dada por:

$$
C_{R}=-\beta \cdot S
$$

A correção também pode ser calculada em termos da curvatura da trajetória de um raio de luz $(r)$ e o coeficiente de refração:

$$
\frac{1}{r}=-\frac{d n}{d z} \cdot \sin Z
$$

O coeficiente de refração é definido como a razão entre o raio da terra $R$ e o raio de curvatura da trajetória da luz:

$$
k=\frac{R}{r}
$$

Substituindo as equações (4.20) e (4.24) em (4.25) e adotando $R=6.356 .778 \mathrm{~m}$ tem-se:

$$
k=\frac{502,7 \cdot p}{T^{2}} \cdot\left(0,0342+\frac{d t}{d z}\right)
$$

Então a equação (4.23) pode ser escrita como

$$
C_{R}=-\beta \cdot S=-\frac{1}{R} \int_{0}^{S} k \cdot(S-x) d x
$$

Em um caso simples o coeficiente de refração é constante ao longo da linha de visada $A B$, o ângulo de refração é dado por:

$$
\beta=\frac{S}{2 \cdot r}
$$

Substituindo $r$ da equação (4.25) em (4.28), tem-se:

$$
\beta=\frac{S \cdot k}{2 \cdot R}
$$


Então, a correção da refração para uma trajetória circular da refração, com k constante ao longo da linha visada.

$$
C_{R}=-\frac{S^{2}}{2 \cdot R} \cdot k
$$

O que significa que o erro da refração é função do quadrado da distância visada. A equação (4.22) mostra que para calcular o ângulo de refração, é necessário conhecer o gradiente de temperatura, $d t / d z$, ao longo da linha de visada. O gradiente de temperatura pode ser obtido por observação da temperatura do ar em diferentes alturas do solo e posterior ajustamento destes valores observados para uma função temperatura, ou modelando em termos da sensibilidade do fluxo de calor e alguns outros parâmetros meteorológico.

BRASIL, (1975) recomenda realizar as observações de ângulos zenitais por volta do meio dia, pois entre 11 e 13 horas o coeficiente de refração é menor e mais estável e o valor médio geralmente adotado nos cálculos é $k=0,13$. A Tabela 4.1 mostra alguns valores do coeficiente de refração obtidos em função de observações recíprocas.

Tabela 4.1 - Coeficiente de refração. Fonte (BRASIL, 1975)

\begin{tabular}{lc}
\hline \multicolumn{1}{c}{ Região } & $\boldsymbol{k}$ \\
\hline Rio de Janeiro & 0,14 \\
Juiz de Fora & 0,15 \\
Litoral do Nordeste & 0,11 \\
Ponta Grossa & 0,07 \\
Resende & 0,13 \\
\hline
\end{tabular}

Ressalta-se que apesar deste modelo ser de simples aplicação sua validade limita-se as situações de atmosfera padrão sem turbulência ou no estado neutro que ocorre normalmente em longos períodos encoberto por nuvens (SCHAAL, 1995). Maiores informações a respeitos de outros modelos e considerações para correção atmosférica são encontradas em BRUNNER (1984) e SCHAAL (1995). 


\subsubsection{Avaliação dos efeitos da refração nas medições de distância}

Para as distâncias, as Tabelas 4.2, 4.3 e 4.4 mostram o comportamento da correção dos efeitos da refração, em ppm, com a variação da umidade, pressão e temperatura de acordo com a fórmula empírica de Barrel e Sears.

A correção média é $0,3 \pm 0,2$ ppm para variação de $10 \%$ na umidade do ar, 2,8 \pm $0,1 \mathrm{ppm}$ para variação de $7,8 \mathrm{mmHg}$ na pressão atmosférica ou $100 \mathrm{~m}$ na altura e $4,6 \pm$ 0,3 ppm para cada $5^{\circ} \mathrm{C}$ de temperatura. A temperatura é a componente cuja variação, apresenta maiores valores na correção e cuja estimativa está sujeita a maior variação ao longo da linha de visada.

Isto resulta que o erro de $50 \%$ na estimativa da umidade relativa, $16 \mathrm{mmHg}$ na estimativa da pressão ou $200 \mathrm{~m}$ na altitude e $10^{\circ} \mathrm{C}$ na temperatura implica em erro de $16,3 \pm 1,8 \mathrm{ppm}$. E conforme a Tabela 4.5 para uma distância de $300 \mathrm{~m}$ com ângulo vertical de $15^{\circ}$ o erro é de apenas $1,2 \mathrm{~mm}$. Pode-se concluir que para curta distância, até 300m, a correção atmosférica da distância com determinação aproximada da temperatura, pressão e umidade implica em erros desprezíveis, menores que 1,5mm, na determinação da altitude.

Tabela 4.2 - Variação da correção da distância (ppm) com a te mperatura e umidade

\begin{tabular}{|c|c|c|c|c|c|c|c|c|c|c|c|}
\hline \multirow{2}{*}{$\begin{array}{c}\mathbf{P} \\
(\mathbf{m m H g})\end{array}$} & \multirow{2}{*}{700} & \multicolumn{9}{|c|}{$\mathrm{T}\left({ }^{\circ} \mathrm{C}\right)$} & \multirow{8}{*}{ 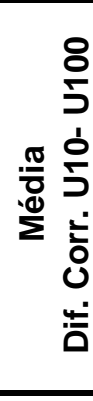 } \\
\hline & & 5 & 10 & 15 & 20 & 25 & 30 & 35 & 40 & 45 & \\
\hline \multirow{6}{*}{$\frac{\widehat{\varrho}}{\supset}$} & 10 & 15,4 & 20,1 & 24,7 & 29,1 & 33,4 & 37,5 & 41,5 & 45,4 & 49,2 & \\
\hline & 20 & 15,5 & 20,2 & 24,8 & 29,2 & 33,5 & 37,7 & 41,7 & 45,7 & 49,5 & \\
\hline & 40 & 15,5 & 20,3 & 24,9 & 29,4 & 33,7 & 38,0 & 42,1 & 46,2 & 50,2 & \\
\hline & 60 & 15,6 & 20,4 & 25,0 & 29,6 & 34,0 & 38,3 & 42,5 & 46,7 & 50,9 & \\
\hline & 80 & 15,7 & 20,5 & 25,2 & 29,7 & 34,2 & 38,6 & 42,9 & 47,3 & 51,6 & \\
\hline & 100 & 15,8 & 20,6 & 25,3 & 29,9 & 34,4 & 38,9 & 43,4 & 47,8 & 52,2 & \\
\hline \multicolumn{2}{|c|}{ Dif. Corr. $U_{10}-U_{100}$} & 0,3 & 0,4 & 0,6 & 0,8 & 1,1 & 1,4 & 1,8 & 2,4 & 3,1 & 1,3 \\
\hline
\end{tabular}


Tabela 4.3 - Variação da correção da distância (ppm) com a temperatura e pressão

\begin{tabular}{|c|c|c|c|c|c|c|c|c|c|c|c|}
\hline \multirow{2}{*}{ U (\%) } & \multirow{2}{*}{60} & \multicolumn{9}{|c|}{$\mathrm{T}\left({ }^{\circ} \mathrm{C}\right)$} & \multirow{12}{*}{ م. } \\
\hline & & 5 & 10 & 15 & 20 & 25 & 30 & 35 & 40 & 45 & \\
\hline \multirow{10}{*}{$\begin{array}{l}\text { 옴 } \\
\frac{1}{\varepsilon} \\
\underline{\xi} \\
a\end{array}$} & 760,0 & $-7,2$ & $-2,0$ & 3,0 & 7,9 & 12,7 & 17,4 & 21,9 & 26,5 & 30,9 & \\
\hline & 752,2 & $-4,2$ & 0,9 & 5,9 & 10,7 & 15,5 & 20,1 & 24,6 & 29,1 & 33,5 & \\
\hline & 744,4 & $-1,3$ & 3,8 & 8,7 & 13,5 & 18,2 & 22,8 & 27,3 & 31,7 & 36,1 & \\
\hline & 736,6 & 1,7 & 6,7 & 11,6 & 16,3 & 21,0 & 25,5 & 30,0 & 34,4 & 38,7 & \\
\hline & 728,8 & 4,7 & 9,6 & 14,5 & 19,2 & 23,7 & 28,2 & 32,6 & 37,0 & 41,3 & \\
\hline & 721,0 & 7,6 & 12,5 & 17,3 & 22,0 & 26,5 & 31,0 & 35,3 & 39,6 & 43,9 & \\
\hline & 713,2 & 10,6 & 15,5 & 20,2 & 24,8 & 29,3 & 33,7 & 38,0 & 42,3 & 46,5 & \\
\hline & 705,4 & 13,6 & 18,4 & 23,1 & 27,6 & 32,0 & 36,4 & 40,7 & 44,9 & 49,1 & \\
\hline & 697,6 & 16,5 & 21,3 & 25,9 & 30,4 & 34,8 & 39,1 & 43,4 & 47,5 & 51,7 & \\
\hline & 690,0 & 19,4 & 24,1 & 28,7 & 33,2 & 37,5 & 41,8 & 46,0 & 50,1 & 54,2 & \\
\hline \multicolumn{2}{|c|}{ Dif. Corr. $\mathbf{P}_{760}-\mathbf{P}_{690}$} & 26,6 & 26,1 & 25,7 & 25,2 & 24,8 & 24,4 & 24,0 & 23,6 & 23,3 & 24,9 \\
\hline
\end{tabular}

Tabela 4.4 - Variação da cor reção da distância (ppm) com a temperatura e pressão

\begin{tabular}{|c|c|c|c|c|c|c|c|c|c|c|c|}
\hline \multirow{2}{*}{ U (\%) } & \multirow{2}{*}{60} & \multicolumn{9}{|c|}{$\begin{array}{ll} & (\mathrm{mmHg}) \\
\end{array}$} & \multirow{10}{*}{ 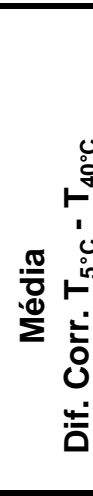 } \\
\hline & & 760 & 750 & 740 & 730 & 720 & 710 & 700 & 690 & 680 & \\
\hline \multirow{8}{*}{$\begin{array}{l}\text { O্ } \\
\text { II } \\
\qquad\end{array}$} & 5 & $-7,2$ & $-3,4$ & 0,4 & 4,2 & 8,0 & 11,8 & 15,6 & 19,4 & 23,2 & \\
\hline & 10 & $-2,0$ & 1,7 & 5,5 & 9,2 & 12,9 & 16,7 & 20,4 & 24,1 & 27,9 & \\
\hline & 15 & 3,0 & 6,7 & 10,4 & 14,0 & 17,7 & 21,4 & 25,0 & 28,7 & 32,4 & \\
\hline & 20 & 7,9 & 11,5 & 15,1 & 18,7 & 22,3 & 25,9 & 29,6 & 33,2 & 36,8 & \\
\hline & 25 & 12,7 & 16,2 & 19,8 & 23,3 & 26,9 & 30,4 & 34,0 & 37,5 & 41,1 & \\
\hline & 30 & 17,4 & 20,8 & 24,3 & 27,8 & 31,3 & 34,8 & 38,3 & 41,8 & 45,3 & \\
\hline & 35 & 21,9 & 25,4 & 28,8 & 32,2 & 35,7 & 39,1 & 42,5 & 46,0 & 49,4 & \\
\hline & 40 & 26,5 & 29,8 & 33,2 & 36,6 & 40,0 & 43,3 & 46,7 & 50,1 & 53,5 & \\
\hline \multicolumn{2}{|c|}{ Dif. Corr. $\mathrm{T}_{5^{\circ} \mathrm{C}}-\mathrm{T}_{40}$} & 33,7 & 33,2 & 32,8 & 32,4 & 32,0 & 31,5 & 31,1 & 30,7 & 30,3 & 32,0 \\
\hline
\end{tabular}


Tabela 4.5 - Valor do desnível em função da distância, correção e ângulo vertical

\begin{tabular}{|c|c|c|c|c|c|c|}
\hline \multirow{2}{*}{ Distância } & \multicolumn{2}{|c|}{ Correção } & \multicolumn{4}{|c|}{ Ângulo Vertical } \\
\hline & (ppm) & $\mathrm{mm}$ & $5^{\circ}$ & $10^{\circ}$ & $15^{\circ}$ & $20^{\circ}$ \\
\hline \multirow{6}{*}{ 음 } & 5 & 0,5 & 0,0 & 0,1 & 0,1 & 0,2 \\
\hline & 10 & 1,0 & 0,1 & 0,2 & 0,3 & 0,3 \\
\hline & 15 & 1,5 & 0,1 & 0,3 & 0,4 & 0,5 \\
\hline & 20 & 2,0 & 0,2 & 0,3 & 0,5 & 0,7 \\
\hline & 25 & 2,5 & 0,2 & 0,4 & 0,6 & 0,9 \\
\hline & 30 & 3,0 & 0,3 & 0,5 & 0,8 & 1,0 \\
\hline \multirow{6}{*}{ 유 } & 5 & 1,0 & 0,1 & 0,2 & 0,3 & 0,3 \\
\hline & 10 & 2,0 & 0,2 & 0,3 & 0,5 & 0,7 \\
\hline & 15 & 3,0 & 0,3 & 0,5 & 0,8 & 1,0 \\
\hline & 20 & 4,0 & 0,3 & 0,7 & 1,0 & 1,4 \\
\hline & 25 & 5,0 & 0,4 & 0,9 & 1,3 & 1,7 \\
\hline & 30 & 6,0 & 0,5 & 1,0 & 1,6 & 2,1 \\
\hline \multirow{6}{*}{ ৪্ల } & 5 & 1,5 & 0,1 & 0,3 & 0,4 & 0,5 \\
\hline & 10 & 3,0 & 0,3 & 0,5 & 0,8 & 1,0 \\
\hline & 15 & 4,5 & 0,4 & 0,8 & 1,2 & 1,5 \\
\hline & 20 & 6,0 & 0,5 & 1,0 & 1,6 & 2,1 \\
\hline & 25 & 7,5 & 0,7 & 1,3 & 1,9 & 2,6 \\
\hline & 30 & 9,0 & 0,8 & 1,6 & 2,3 & 3,1 \\
\hline \multirow{6}{*}{ 움 } & 5 & 2,0 & 0,2 & 0,3 & 0,5 & 0,7 \\
\hline & 10 & 4,0 & 0,3 & 0,7 & 1,0 & 1,4 \\
\hline & 15 & 6,0 & 0,5 & 1,0 & 1,6 & 2,1 \\
\hline & 20 & 8,0 & 0,7 & 1,4 & 2,1 & 2,7 \\
\hline & 25 & 10,0 & 0,9 & 1,7 & 2,6 & 3,4 \\
\hline & 30 & 12,0 & 1,0 & 2,1 & 3,1 & 4,1 \\
\hline \multirow{6}{*}{ రి } & 5 & 2,5 & 0,2 & 0,4 & 0,6 & 0,9 \\
\hline & 10 & 5,0 & 0,4 & 0,9 & 1,3 & 1,7 \\
\hline & 15 & 7,5 & 0,7 & 1,3 & 1,9 & 2,6 \\
\hline & 20 & 10,0 & 0,9 & 1,7 & 2,6 & 3,4 \\
\hline & 25 & 12,5 & 1,1 & 2,2 & 3,2 & 4,3 \\
\hline & 30 & 15,0 & 1,3 & 2,6 & 3,9 & 5,1 \\
\hline
\end{tabular}

\subsubsection{Avaliação dos efeitos da refração na medição do ângulo zenital}

No caso dos ângulos, considerando a atmosfera no estado neutro, os valores da correção da refração para distância de visadas até 300 metros é inferior a 2mm, considerando uma variação de índice de refração de $k=0,01$ até $k=0,25$ como mostra a Tabela 4.6.

Entretanto, fazendo as correções da refração considerando o valor médio de e $k=0,13$ admitindo que as condições reais de campo apresente variação do índice de refração de até $100 \%$ da média adotada $(k=0,01$ a $k=0,25)$, a diferença máxima para as condições reais é de apenas $\pm 0,8 \mathrm{~mm}$ como mostra a Tabela 4.7. 
Isso mostra que para distâncias curtas, até 300 metros, e em condições de atmosfera no estado neutro, a adoção do valor médio do coeficiente de refração é suficiente, sem necessidades de modelos mais refinados.

Tabela 4.6 - Valores de correção da curvatura e refração

\begin{tabular}{ccccccc}
\hline \multirow{2}{*}{$\begin{array}{c}\text { Distância } \\
(\mathbf{m})\end{array}$} & $\begin{array}{c}\text { Correção } \\
\text { Curvatura } \\
(\mathbf{m m})\end{array}$ & \multicolumn{5}{c}{ Correção da Refração - (mm) } \\
\cline { 3 - 8 } & $\mathbf{k}=$ & $\mathbf{0 , 1 3}$ & $\mathbf{0 , 0 1}$ & $\mathbf{0 , 0 7}$ & $\mathbf{0 , 1 9}$ & $\mathbf{0 , 2 5}$ \\
\hline 50 & 0 & 0,0 & 0,0 & 0,0 & 0,0 & 0,0 \\
100 & 1 & 0,1 & 0,0 & 0,1 & 0,1 & 0,2 \\
150 & 2 & 0,2 & 0,0 & 0,1 & 0,3 & 0,4 \\
200 & 3 & 0,4 & 0,0 & 0,2 & 0,6 & 0,8 \\
250 & 5 & 0,6 & 0,0 & 0,3 & 0,9 & 1,2 \\
300 & 7 & 0,9 & 0,1 & 0,5 & 1,3 & 1,8 \\
400 & 13 & 1,6 & 0,1 & 0,9 & 2,4 & 3,1 \\
500 & 20 & 2,6 & 0,2 & 1,4 & 3,7 & 4,9 \\
750 & 44 & 5,7 & 0,4 & 3,1 & 8,4 & 11,1 \\
\hline
\end{tabular}

Tabela 4.7 - Diferença da correção da refração(mm) para valores de $k$

\begin{tabular}{ccccc}
\hline \multirow{2}{*}{ Distância } & \multicolumn{4}{c}{ Diferença para $\mathrm{k}=0,13$} \\
\cline { 2 - 5 } & 0,01 & 0,07 & 0,19 & 0,25 \\
\hline 50 & 0,0 & 0,0 & 0,0 & 0,0 \\
100 & $-0,1$ & 0,0 & 0,0 & 0,1 \\
150 & $-0,2$ & $-0,1$ & 0,1 & 0,2 \\
200 & $-0,4$ & $-0,2$ & 0,2 & 0,4 \\
250 & $-0,6$ & $-0,3$ & 0,3 & 0,6 \\
300 & $-0,8$ & $-0,4$ & 0,4 & 0,8 \\
400 & $-1,5$ & $-0,8$ & 0,8 & 1,5 \\
500 & $-2,4$ & $-1,2$ & 1,2 & 2,4 \\
750 & $-5,3$ & $-2,7$ & 2,7 & 5,3 \\
\hline
\end{tabular}

\subsubsection{Erros instrumentais}

Erros devido a imperfeições instrumentais ou não ajustamento dos equipamentos são todos sistemáticos. E podem ser eliminados ou reduzidos a uma quantia desprezível pelos próprios métodos do procedimento.

Devido às observações deste trabalho estarem limitadas aos ângulos verticais, será dada atenção aos erros que envolvem ângulo vertical. Mais detalhes a respeito dos 
demais erros podem ser obtidos em SCHOFIELD (1993), MOREIRA (1998), ANDERSON (1998) e MAIA (1999).

O erro de colimação do círculo vertical ocorre quando o $0^{\circ} 00^{\prime} 00^{\prime}$ do círculo vertical não coincide exatamente com o zênite. O efeito do erro de colimação pode ser facilmente eliminado fazendo leituras dos ângulos zenitais nas duas posições da luneta e tomando a média das observações.

Segundo MAIA (1999) os equipamentos eletrônicos modernos são equipados com alguma forma de compensador mecânico-eletrônico, que permitem a correção automática dos erros instrumentais. O usuário visa um ponto bem definido nas duas posições da luneta e os erros calculados pelos compensadores são armazenados no instrumento e os ângulos lidos são compensados durante as observações.

\subsection{Propagação dos Erros em Visadas Unilatera is}

A maior fonte de erros na determinação da diferença de alturas através deste método é a incerteza na correção da refração causada pelas variações das condições atmosféricas.

No nivelamento trigonométrico as distâncias de visadas normalmente são maiores que no nivelamento geométrico. A precisão para uma visada m nivelamento trigonométrico unilateral é obtida aplicando a lei de propagação de erro na equação (4.1), e tem-se conforme SCHOFIELD (1993) que:

$$
\sigma_{d n A B}^{2}=\left(\cos Z \sigma_{S}\right)^{2}+\left(S \sin Z \sigma_{Z}\right)^{2}+\sigma_{i}^{2}+\sigma_{a}^{2}+\left(S^{2} \sigma_{K} / 2 R\right)^{2}+\left(S^{2}(1+k) \sigma_{R} / 2 R^{2}\right)^{2}
$$

onde:

$\sigma_{d n A-B}:$ Erro do desnível do ponto entre os pontos A e B;

$\sigma_{S}: \quad$ Erro da distância;

$\sigma_{Z}: \quad$ Erro do ângulo zenital;

$\sigma_{i}: \quad$ Erro na determinação da altura do instrumento;

$\sigma_{a}: \quad$ Erro na determinação da altura do alvo; 
$\sigma_{k}: \quad$ Erro do coeficiente de refração;

$\sigma_{R}: \quad$ Erro na estimativa do raio da terra;

De modo análogo ao nivelamento geométrico, para uma seção de comprimento L com distância de visada S, consideradas iguais e com erro por visadas s calculado pela equação (4.31), tem-se:

$$
\begin{gathered}
d h_{P-Q}=d h_{1}+d h_{2}+\cdots \cdots+d h_{n-1}+d h_{n} \\
\sigma_{d h_{1}}^{2}=\sigma_{d h_{2}}^{2}=\cdots \cdots=\sigma_{d h_{n-1}}^{2}=\sigma_{d h_{n}}^{2}=\sigma^{2} \\
\sigma_{d h P-Q}^{2}=n \cdot \sigma^{2} \\
n=\frac{L}{S} \\
\sigma_{d h P-Q}= \pm \sigma \cdot \sqrt{\frac{L}{S}}
\end{gathered}
$$

$\sigma_{d h P-Q}:$ Erro da diferença de nível numa seção $\mathrm{P}-\mathrm{Q}(\mathrm{mm})$

$\sigma: \quad$ Erro da diferença de nível de uma visada (mm);

n: $\quad$ Número de estações $(\mathrm{km})$;

L: $\quad$ Comprimento total da seção nivelada $(\mathrm{km})$;

S: $\quad$ Distância de visada $(\mathrm{km})$.

Comparando o erro de uma seção com a tolerância estabelecida para o nivelamento geométrico IIN, obtém-se os valores máximos dor erros permitidos para uma visada em função da distância.

$$
E=\sigma_{d h P-Q}= \pm \sigma \cdot \sqrt{\frac{L}{S}}
$$

E: $\quad$ Erro de desnível para uma seção de comprimento $L$.

Conforme já visto na seção 3.3 a equação (3.9) relaciona a tolerância para os nivelamentos com o comprimento da seção.

$$
T=\alpha \cdot \sqrt{L}
$$


onde:

T: $\quad$ Tolerância $(\mathrm{mm})$;

a: $\quad$ Valor constante $(\mathrm{mm})$;

L: $\quad$ Comprimento da seção ou linha nivelada.

De modo semelhante a seção 3.3 o módulo do erro deverá ser menor ou igual a tolerância:

$$
\begin{gathered}
|E| \leq T \\
\sigma \cdot \sqrt{\frac{L}{S}} \leq \alpha \cdot \sqrt{L} \\
\sigma \leq \alpha \cdot \sqrt{S}
\end{gathered}
$$

O erro máximo por visada é determinado pela equação (4.39). Tabela 4.8 a o erro máximo por distância de visada para não ultrapassar as tolerâncias estabelecidas

\begin{tabular}{|c|c|c|c|}
\hline \multicolumn{2}{|c|}{ Geométrico - IIN } & \multicolumn{2}{|c|}{ Trigonométrico - IIIN } \\
\hline \multirow{2}{*}{$S(m)$} & $\alpha=20 \mathrm{~mm}$ & $\alpha=150 \mathrm{~mm}$ & $\alpha=200 \mathrm{~mm}$ \\
\hline & $\sigma(\mathrm{mm})$ & $\sigma(\mathrm{mm})$ & $\sigma(\mathrm{mm})$ \\
\hline 40 & 4,0 & 30,0 & 40,0 \\
\hline 80 & 5,7 & 42,4 & 56,6 \\
\hline 120 & 6,9 & 52,0 & 69,3 \\
\hline 160 & 8,0 & 60,0 & 80,0 \\
\hline 200 & 8,9 & 67,1 & 89,4 \\
\hline 240 & 9,8 & 73,5 & 98,0 \\
\hline 280 & 10,6 & 79,4 & 105,8 \\
\hline 320 & 11,3 & 84,9 & 113,1 \\
\hline 360 & 12,0 & 90,0 & 120,0 \\
\hline 400 & 12,6 & 94,9 & 126,5 \\
\hline 440 & 13,3 & 99,5 & 132,7 \\
\hline 480 & 13,9 & 103,9 & 138,6 \\
\hline 520 & 14,4 & 108,2 & 144,2 \\
\hline
\end{tabular}
para os nivelamento classe IIN e IIIN.

Tabela 4.8 - Erro limite por visada

Estes valores serão comparados com os erros obtidos para o nivelamento trigonométrico realizado para as diversas distâncias em todas as combinações previstas na metodologia. A maior distância que apresentarem erros menores que os previstos 
para o nivelamento geométrico IIN será o limite de visada que atende a especificações da ABNT (1994).

Tabela 4.9 - Erros em visadas unilaterais - Estação total de média precisão

\begin{tabular}{|c|c|c|c|c|c|c|c|c|c|c|c|c|c|c|c|}
\hline \multicolumn{3}{|c|}{ Precisões } & \multirow{2}{*}{\multicolumn{13}{|c|}{ Propagação de erro no Nivelamento Tigonométrico (mm) }} \\
\hline \multicolumn{2}{|c|}{$\begin{array}{l}\text { Distância } \\
\text { Ângulo }\end{array}$} & \multirow{3}{*}{$\begin{array}{c}5 \mathrm{~mm}+5 \mathrm{ppm} \\
07 " \\
1 \mathrm{~mm} \\
2 \mathrm{~mm} \\
100 \% \\
10 \mathrm{~km}\end{array}$} & & & & & & & & & & & & & \\
\hline $\begin{array}{l}\text { Altur } \\
\text { Altur }\end{array}$ & $\begin{array}{l}\text { Alvo } \\
\text { Instrumento }\end{array}$ & & \multicolumn{13}{|c|}{ Distâncias (m) } \\
\hline \multicolumn{2}{|c|}{$\begin{array}{l}\text { Coef. de Refração } \\
\text { Raio daTerra }\end{array}$} & & 40 & 80 & 120 & 160 & 200 & 240 & 280 & 320 & 360 & 400 & 440 & 480 & 520 \\
\hline \multirow{9}{*}{$\frac{\text { o }}{\text { 음 }}$} & $90^{\circ} 00^{\prime} 00,0^{\prime \prime}$ & $0^{\circ}$ & 2,6 & 3,5 & 4,6 & 5,9 & 7,2 & 8,5 & 9,8 & 11,1 & 12,5 & 13,9 & 15,2 & 16,6 & 18,0 \\
\hline & $91^{\circ} 00^{\prime} 00,0^{\prime \prime}$ & $1^{\circ}$ & 2,6 & 3,5 & 4,6 & 5,9 & 7,2 & 8,5 & 9,8 & 11,1 & 12,5 & 13,9 & 15,2 & 16,6 & 18,0 \\
\hline & $93^{\circ} 00^{\prime} 00,0^{\prime \prime}$ & $3^{\circ}$ & 2,6 & 3,5 & 4,7 & 5,9 & 7,2 & 8,5 & 9,8 & 11,1 & 12,5 & 13,8 & 15,2 & 16,6 & 18,0 \\
\hline & $95^{\circ} 00^{\prime} 00,0^{\prime \prime}$ & $5^{\circ}$ & 2,7 & 3,5 & 4,7 & 5,9 & 7,2 & 8,5 & 9,8 & 11,1 & 12,5 & 13,8 & 15,2 & 16,6 & 17,9 \\
\hline & $100^{\circ} 00^{\prime} 00,0^{\prime \prime}$ & $10^{\circ}$ & 2,8 & 3,6 & 4,7 & 5,9 & 7,1 & 8,4 & 9,7 & 11,0 & 12,4 & 13,7 & 15,1 & 16,4 & 17,8 \\
\hline & $115^{\circ} 00^{\prime} 00,0^{\prime \prime}$ & $25^{\circ}$ & 3,4 & 4,0 & 4,9 & 5,9 & 7,0 & 8,2 & 9,3 & 10,5 & 11,7 & 13,0 & 14,2 & 15,4 & 16,7 \\
\hline & $120^{\circ} 00^{\prime} 00,0^{\prime \prime}$ & $30^{\circ}$ & 3,6 & 4,2 & 5,0 & 6,0 & 7,0 & 8,0 & 9,1 & 10,3 & 11,4 & 12,6 & 13,8 & 14,9 & 16,1 \\
\hline & $125^{\circ} 00^{\prime} 00,0^{\prime \prime}$ & $35^{\circ}$ & 3,9 & 4,4 & 5,1 & 6,0 & 6,9 & 7,9 & 8,9 & 10,0 & 11,1 & 12,1 & 13,3 & 14,4 & 15,5 \\
\hline & $130^{\circ} 00^{\prime} 00,0^{\prime \prime}$ & $40^{\circ}$ & 4,2 & 4,6 & 5,3 & 6,0 & 6,9 & 7,8 & 8,7 & 9,7 & 10,7 & 11,7 & 12,7 & 13,7 & 14,8 \\
\hline
\end{tabular}

Tabela 4.10 - Erros em visadas unilaterais - Es tação total de baixa precisão

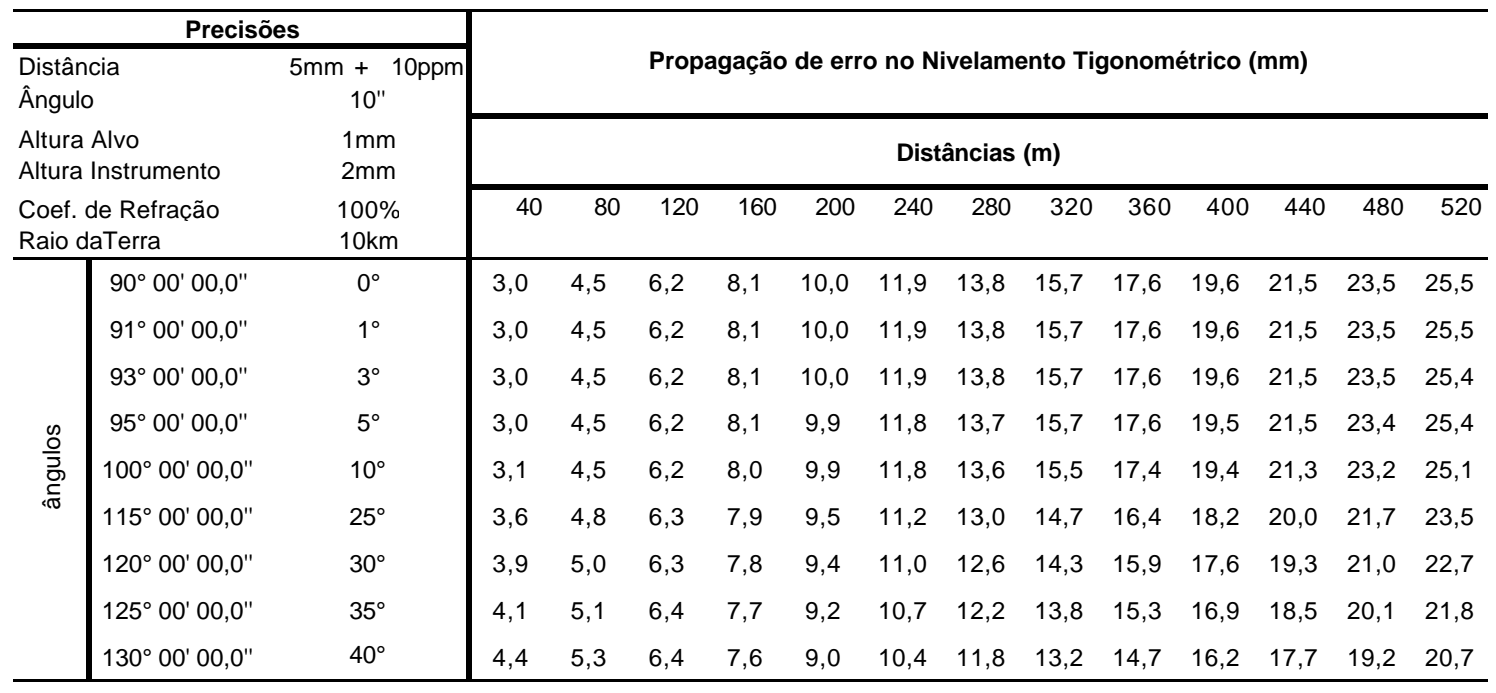

Comparando os valores das Tabelas 4.9 e 4.10 com a Tabela 4.8, verifica-se que o nivelamento trigonométrico unilateral com a estação de baixa precisão, com erro angular de 10" alcança a precisão do nivelamento IIN para distâncias de visadas um menores que 160 metros; Com a estação de média precisão, com erro angular de 7" fica dentro da tolerância no nivelamento IIN para distâncias de até 320 metros. 


\subsection{Propagação de Erro Leap-frog}

Conforme descrito na seção 4.2 e equação (4.11), as distâncias $S_{A}$ e $S_{B}$ são aproximadamente iguais e admite-se o mesmo erro para a distância.

$$
\begin{gathered}
d n_{A-B}=S_{B} \cdot \cos Z_{B}-S_{A} \cdot \cos Z_{A} \\
\sigma_{S_{B}}=\sigma_{S_{A}}=\sigma_{S} \\
\sigma_{Z_{B}}=\sigma_{Z_{A}}=\sigma_{Z}
\end{gathered}
$$

Aplicando a lei de propagação de erro na equação (4.11) tem-se que:

$$
\sigma_{d n_{A-B}}=\sigma_{S}^{2} \cdot\left(\cos ^{2} Z_{A}+\cos Z_{B}^{2}\right)+\sigma_{Z}^{2} \cdot\left(S_{A}^{2} \cdot \sin ^{2} Z_{A}+S_{B}^{2} \cdot \sin ^{2} Z_{B}\right)
$$

A Tabela 4.11 e 4.12 mostra o erro esperado com as precisões lineares e

\begin{tabular}{|c|c|c|c|c|c|c|c|c|c|c|c|c|c|c|}
\hline \multicolumn{2}{|c|}{ Precisões } & \multirow{2}{*}{\multicolumn{13}{|c|}{$\begin{array}{l}\text { Erro no nivelamento trigonométrico leap-frog } \\
\qquad(\mathrm{mm})\end{array}$}} \\
\hline Angular $=$ & $10^{\prime \prime}$ & & & & & & & & & & & & & \\
\hline Distancia $=$ & $5+10 \mathrm{ppm}$ & 40 & 80 & 120 & 160 & 200 & 240 & 280 & 320 & 360 & 400 & 440 & 480 & 520 \\
\hline \multirow{9}{*}{$\frac{\infty}{\frac{0}{5}}$} & $90^{\circ} 00^{\prime} 00,0^{\prime \prime}$ & 2,7 & 5,5 & 8,2 & 11,0 & 13,7 & 16,5 & 19,2 & 21,9 & 24,7 & 27,4 & 30,2 & 32,9 & 35,7 \\
\hline & $89^{\circ} 00^{\prime} 00,0^{\prime \prime}$ & 2,7 & 5,5 & 8,2 & 11,0 & 13,7 & 16,5 & 19,2 & 21,9 & 24,7 & 27,4 & 30,2 & 32,9 & 35,6 \\
\hline & $88^{\circ} 00^{\prime} 00,0^{\prime \prime}$ & 2,8 & 5,5 & 8,2 & 11,0 & 13,7 & 16,4 & 19,2 & 21,9 & 24,7 & 27,4 & 30,2 & 32,9 & 35,6 \\
\hline & $85^{\circ} 00^{\prime} 00,0^{\prime \prime}$ & 2,8 & 5,5 & 8,2 & 11,0 & 13,7 & 16,4 & 19,1 & 21,9 & 24,6 & 27,3 & 30,1 & 32,8 & 35,5 \\
\hline & $80^{\circ} 00^{\prime} 00,0^{\prime \prime}$ & 3,0 & 5,6 & 8,2 & 10,9 & 13,6 & 16,3 & 19,0 & 21,7 & 24,4 & 27,1 & 29,8 & 32,5 & 35,2 \\
\hline & $75^{\circ} 00^{\prime} 00,0^{\prime \prime}$ & 3,3 & 5,7 & 8,3 & 10,9 & 13,5 & 16,1 & 18,8 & 21,4 & 24,0 & 26,7 & 29,3 & 32,0 & 34,6 \\
\hline & $70^{\circ} 00^{\prime} 00,0^{\prime \prime}$ & 3,7 & 5,9 & 8,3 & 10,8 & 13,3 & 15,9 & 18,4 & 21,0 & 23,6 & 26,1 & 28,7 & 31,3 & 33,9 \\
\hline & $65^{\circ} 00^{\prime} 00,0^{\prime \prime}$ & 4,1 & 6,1 & 8,3 & 10,7 & 13,1 & 15,6 & 18,0 & 20,5 & 23,0 & 25,4 & 27,9 & 30,4 & 32,9 \\
\hline & $60^{\circ} 00^{\prime} 00,0^{\prime \prime}$ & 4,5 & 6,3 & 8,4 & 10,6 & 12,9 & 15,2 & 17,5 & 19,9 & 22,2 & 24,6 & 27,0 & 29,3 & 31,7 \\
\hline
\end{tabular}
angulares dos equipamentos de baixa e média precisão usados nesta pesquisa, para diferentes situações de ângulos e distâncias.

\begin{tabular}{|c|c|c|c|c|c|c|c|c|c|c|c|c|c|c|}
\hline \multicolumn{2}{|c|}{ Precisões } & \multirow{2}{*}{\multicolumn{13}{|c|}{$\begin{array}{l}\text { Erro no nivelamento trigonométrico leap-frog } \\
\qquad(\mathrm{mm})\end{array}$}} \\
\hline Angular & 07" & & & & & & & & & & & & & \\
\hline Distancia = & $5+5 \mathrm{ppm}$ & 40 & 80 & 120 & 160 & 200 & 240 & 280 & 320 & 360 & 400 & 440 & 480 & 520 \\
\hline \multirow{9}{*}{ 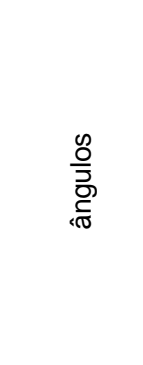 } & $90^{\circ} 00^{\prime} 00,0^{\prime \prime}$ & 1,9 & 3,8 & 5,8 & 7,7 & 9,6 & 11,5 & 13,4 & 15,4 & 17,3 & 19,2 & 21,1 & 23,0 & 25,0 \\
\hline & $89^{\circ} 00^{\prime} 00,0^{\prime \prime}$ & 1,9 & 3,8 & 5,8 & 7,7 & 9,6 & 11,5 & 13,4 & 15,4 & 17,3 & 19,2 & 21,1 & 23,0 & 25,0 \\
\hline & $88^{\circ} 00^{\prime} 00,0^{\prime \prime}$ & 1,9 & 3,8 & 5,8 & 7,7 & 9,6 & 11,5 & 13,4 & 15,4 & 17,3 & 19,2 & 21,1 & 23,0 & 24,9 \\
\hline & $85^{\circ} 00^{\prime} 00,0^{\prime \prime}$ & 2,0 & 3,9 & 5,8 & 7,7 & 9,6 & 11,5 & 13,4 & 15,3 & 17,2 & 19,1 & 21,1 & 23,0 & 24,9 \\
\hline & $80^{\circ} 00^{\prime} 00,0^{\prime \prime}$ & 2,3 & 4,0 & 5,8 & 7,7 & 9,6 & 11,4 & 13,3 & 15,2 & 17,1 & 19,0 & 20,9 & 22,8 & 24,6 \\
\hline & $75^{\circ} 00^{\prime} 00,0^{\prime \prime}$ & 2,7 & 4,2 & 5,9 & 7,7 & 9,5 & 11,4 & 13,2 & 15,0 & 16,9 & 18,7 & 20,6 & 22,4 & 24,3 \\
\hline & $70^{\circ} 00^{\prime} 00,0^{\prime \prime}$ & 3,1 & 4,5 & 6,1 & 7,7 & 9,5 & 11,2 & 13,0 & 14,8 & 16,6 & 18,4 & 20,1 & 21,9 & 23,7 \\
\hline & $65^{\circ} 00^{\prime} 00,0$ & 3,6 & 4,7 & 6,2 & 7,8 & 9,4 & 11,1 & 12,8 & 14,5 & 16,2 & 17,9 & 19,6 & 21,3 & 23,1 \\
\hline & $60^{\circ} 00^{\prime} 00,0^{\prime \prime}$ & 4,0 & 5,1 & 6,4 & 7,8 & 9,3 & 10,9 & 12,5 & 14,1 & 15,7 & 17,3 & 19,0 & 20,6 & 22,3 \\
\hline
\end{tabular}

Tabela 4.11 - Erros em Leap-frog - Estação total de baixa precisão

Tabela 4.12 - Erros em Leap-frog - Estação total de média precisão 
A propagação do erro para uma seção de comprimento $L$ com lance de comprimento $d$, distância de visada iguais de comprimento $S$ com erro por visada igual a s calculado pela equação (4.43), tem-se:

$$
\begin{gathered}
d h_{P-Q}=d h_{1}+d h_{2}+\cdots \cdots+d h_{n-1}+d h_{n} \\
\sigma_{d h_{1}}^{2}=\sigma_{d h_{2}}^{2}=\cdots \cdots=\sigma_{d h_{n-1}}^{2}=\sigma_{d h_{n}}^{2}=\sigma^{2} \\
\sigma_{d h P-Q}^{2}=n \cdot \sigma^{2} \\
n=\frac{L}{d} \quad d=2 \cdot S \\
E=\sigma_{d h P-Q}= \pm \sigma \cdot \sqrt{\frac{L}{2 \cdot S}}
\end{gathered}
$$

$\sigma_{d h P-Q}:$ Erro da diferença de nível em uma seção $\mathrm{P}-\mathrm{Q}(\mathrm{mm})$

$\sigma: \quad$ Erro da diferença de nível de um único lance $(\mathrm{mm})$

n: $\quad$ Número de estações $(\mathrm{km})$;

L: $\quad$ Comprimento total da seção nivelada $(\mathrm{km})$;

S: $\quad$ Distância de visada $(\mathrm{km})$;

$d: \quad$ Comprimento do lance $(\mathrm{km})$.

De modo semelhante ao que foi feito para o nivelamento geométrico na seção 3.3 e o nivelamento com visadas unilaterais na seção 4.5 tem-se.

$$
E=\sigma_{d h P-Q}= \pm \sigma \cdot \sqrt{\frac{L}{2 \cdot S}}
$$

E: $\quad$ Erro de desnível para uma seção de comprimento $L$

$$
T=\alpha \cdot \sqrt{L}
$$

onde:

T: $\quad$ Tolerância $(\mathrm{mm})$;

a: $\quad$ Valor constante $(\mathrm{mm})$;

L: $\quad$ Comprimento da seção ou linha nivelada. 
De modo semelhante a seção 3.3 e 4.5 o módulo do erro deverá ser menor ou igual a tolerância:

$$
\begin{gathered}
|E| \leq T \\
\sigma \cdot \sqrt{\frac{L}{2 \cdot S}} \leq \alpha \cdot \sqrt{L} \\
\sigma \leq \alpha \cdot \sqrt{2 \cdot S}
\end{gathered}
$$

O erro máximo por seção é determinado pela equação (4.51). A Tabela 4.13 apresenta o erro máximo por distância de visada para não ultrapassar as tolerâncias

\begin{tabular}{|c|c|c|}
\hline \multicolumn{2}{|c|}{ Geométrico - IN } & Geométrico - IIN \\
\hline \multirow{2}{*}{$\mathrm{S}(\mathrm{m}$} & $\alpha=12$ & $\alpha=20$ \\
\hline & $\sigma(\mathrm{mm})$ & $\sigma(\mathrm{mm})$ \\
\hline 40 & 3,4 & 5,7 \\
\hline 80 & 4,8 & 8,0 \\
\hline 120 & 5,9 & 9,8 \\
\hline 160 & 6,8 & 11,3 \\
\hline 200 & 7,6 & 12,6 \\
\hline 240 & 8,3 & 13,9 \\
\hline 280 & 9,0 & 15,0 \\
\hline 320 & 9,6 & 16,0 \\
\hline 360 & 10,2 & 17,0 \\
\hline 400 & 10,7 & 17,9 \\
\hline 440 & 11,3 & 18,8 \\
\hline 480 & 11,8 & 19,6 \\
\hline 520 & 12,2 & 20,4 \\
\hline
\end{tabular}
estabelecidas para os nivelamentos classe IN e IIN.

Tabela 4.13 - Erro limite por visada para o nivelamento Leap-frog

Comparando os valores das Tabelas 4.11 e 4.12 com a Tabela 4.13 , verifica-se que o nivelamento Leap-frog com a estação de baixa precisão, com erro angular de 10" alcança a precisão do nivelamento IIN para distâncias de visadas de até 160 metros. Com a estação de média precisão, com erro angular de 7" fica abaixo da tolerância do nivelamento IN para distâncias de até 80 metros e limitado a ângulos verticais de $\pm 25^{\circ}$ e para o IIN com distâncias de até 320 metros. 


\section{Nivelamento Vetorial com GPS}

Para MONICO et al. (1996) a determinação de altitudes ortométricas via GPS para substituir o nivelamento geométrico, é um objetivo de longa duração e ainda requer soluções locais, tendo em vista limitações dos modelos de geóides com precisão compatíveis àquelas obtidas com GPS.

O GPS fornece ao usuário altura geométrica (h), em relação ao elipsóide WGS84, que é uma grandeza puramente matemática. Para obter a altitude ortométrica $(\mathrm{H})$ é necessário conhecer a ondulação geoidal $(\mathrm{N})$ em relação a este referencial. $\mathrm{O}$ modelo geoidal oficialmente adotado no Brasil é o mapa geoidal MGB-92 (IBGE/EPUSP ${ }^{12}$ ), com precisão absoluta da ordem de 3 metros e precisão relativa de $1 \mathrm{~cm} / \mathrm{km}$, (BLITZKOW et al. ${ }^{13}, 1993$ ) citado por (MONICO et al.,1996).

A Figura 5.1 ilustra a relação entre a altura geométrica, a altitude ortométrica e a ondulação geoidal que de forma simplificada é dada por:

$$
H=h-N
$$

onde

$H$ : $\quad$ Altitude ortométrica;

$h: \quad$ Altura geométrica;

$N$ : Ondulação geoidal.

\footnotetext{
${ }^{12}$ Escola Politécnica da Universidade de São Paulo.

${ }^{13}$ BLITZKOW, D. et al. (1993). Mapa goidal do Brasil - 1992. Rio de Janeiro: IBGE, 1993.
} 


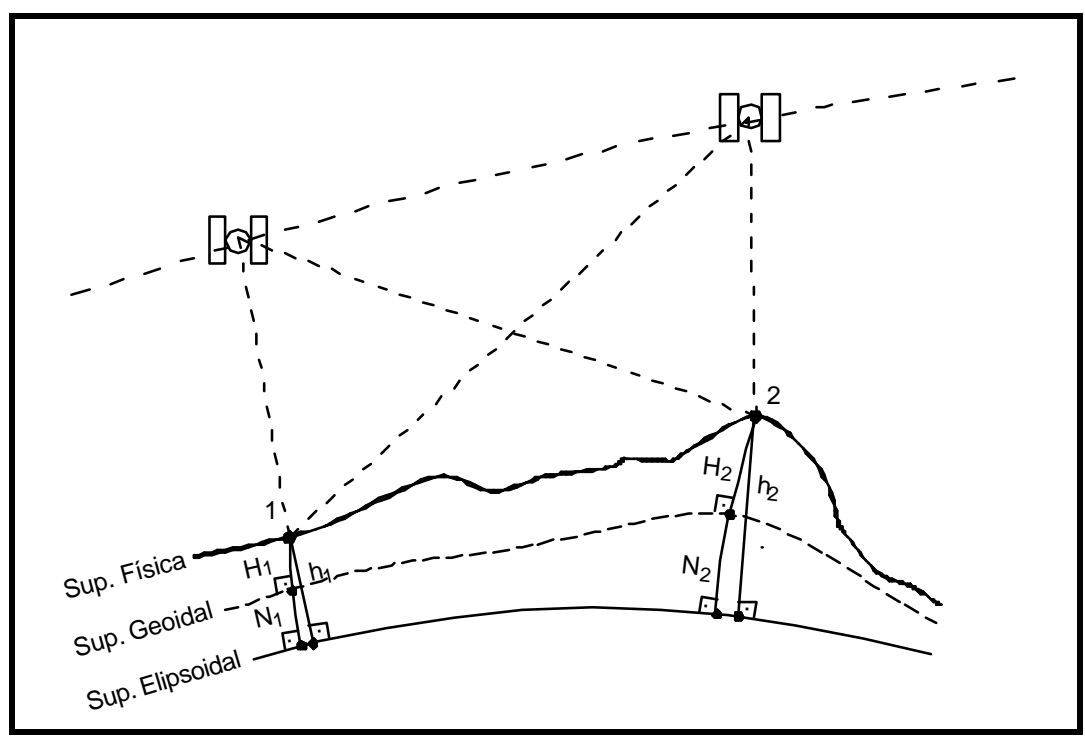

Figura 5.1 - Relação entre a altura geométrica e a altitude ortométrica.

Em trabalhos topográficos ou geodésicos a tecnologia GPS é quase sempre utilizada no método diferencial ou relativo, o que implica em dispor de, pelo menos, um ponto com coordenadas geodésicas conhecidas como base para o levantamento. Se a altitude ortométrica deste ponto for conhecida, os demais pontos levantados também poderão ter suas altitudes ortométricas determinadas, (SOARES, 1996), (PACILEO NETTO et al., 1996) e (VERONEZ, 1998).

Com o GPS não se tem medida de ângulo nem relação com o géoide, mas somente medida vetorial. Por isso torna-se necessário mais uma informação para o nivelamento, a ondulação geoidal. Considerando o ponto 1 de coordenadas $\left(\phi_{1}, \lambda_{l}, h_{l}\right) \mathrm{e}$ altitude ortométrica $\left(H_{1}\right)$ conhecidas e o ponto $2\left(\phi_{2}, \lambda_{2}, h_{2}\right)$ e $\left(H_{2}\right)$ a ser determinado.

$$
\begin{aligned}
& h_{1}=H_{1}-N_{1} \\
& h_{2}=H_{2}-N_{2}
\end{aligned}
$$

As ondulações $N_{1}$ e $N 2$ podem ser obtidas por mapas geoidais ou por superfície matemática resultante da interpolação geométrica a partir observações GPS em pontos com altitude ortométrica conhecida. Da combinação das equações (5.2) e (5.3) obtémse:

$$
H_{2}=H_{1}+\Delta h-\Delta N
$$


A vantagem na metodologia diferencial é que a incerteza na altura geométrica $h_{l}$ é eliminada e não é transferida para $h_{2}$ e de modo semelhante a outras técnicas de nivelamento o erro na determinação $H_{1}$ se propaga diretamente sobre $H_{2}$, (PACILEO NETTO et al., 1996).

PACILEO NETTO et al. (1996) mostra que para a região da grande São PauloSP o erro na determinação da altitude ortométrica por GPS, com altura geoidal de uma superfície matemática interpolada em $\mathrm{RNs}$ da rede de nivelamento de $1^{\mathrm{a}}$ ordem do IBGE, é da ordem de centímetros. VERONEZ et al.,(2001) em trabalho semelhante numa área de 87 hectares, obteve-se discrepância média de $10 \mathrm{~mm}$ nos pontos de controle. MONICO et al., (1996) numa área de $240 \mathrm{~km}^{2}$, obteve-se erro quadrático médio de $14 \mathrm{~mm}$ e $17 \mathrm{~mm}$, com ondulações obtidas por GPS nos pontos de RN e por interpolação do mapa geoidal do MGB-92 (IBGE/EPUSP) (Mapa Geoidal do Brasil 1992) usando o programa MAPGEO. Segundo TEDESCO et al. (2000) o nivelamento utilizando o método estático rápido possibilita bons resultados para bases curtas, desde que se realize um planejamento e rastreio de no mínimo seis satélites.

Para PESSOA (1998) a limitação desta técnica é exatamente a resolução dos modelos geopotenciais relacionados a um datum global, em geral incapaz de substituir o tradicional nivelamento geométrico e o desafio do geodesista para os próximos anos é possibilitar o usuário do GPS obter altitudes ortométricas com grande acurácia.

Estes resultados mostraram que o nivelamento com GPS possibilita resultados dentro das tolerâncias exigidas para muitas atividades da engenharia. 


\section{Tolerância nos Nivelamentos}

\subsection{Os Equipamentos}

A indústria de equipamentos topográficos tem desenvolvido equipamentos cada vez mais precisos. Entretanto, ressalta-se que muitas empresas e profissionais ainda utilizam equipamentos com precisão angular próximo do limite para os equipamentos de baixa precisão definidos por ABNT (1994).

\subsubsection{Níveis}

Os níveis óticos disponíveis no mercado para as atividades de topografia são encontrados com precisões de $3 \mathrm{~mm}$ a $1 \mathrm{~mm}$ por quilômetro em nivelamento duplo. Para atividades que exigem grande precisão dispõe se de equipamentos com micrômetro que possibilita precisões de $0,25 \mathrm{~mm}$ por quilômetro de duplo nivelamento.

Os níveis digitais surgiram no mercado no início da década de noventa e preencheram uma necessidade de nível completamente automatizado. O princípio de medição destes equipamentos baseia-se no tratamento da imagem unidimensional do sinal de medida codificado.

O valor da leitura e obtida comparando sinal da imagem que aparece no visor ótico do nível, com um sinal de referência que corresponde ao código completo da mira. Esta comparação é feita automaticamente por um microprocessador no interior do instrumento (ARABATZI, 1993).

Os níveis digitais apresentam excelente rendimento aliado à boa precisão entretanto pequena obstrução no campo visual da luneta impede que a medição se 
realize (FAGGION, 1998). Os níveis digitais são encontrados com precisões de 0,3 a 0,9 milímetro por um quilômetro de duplo nivelamento.

\subsubsection{Estações totais}

Há uma variedade de modelos de estações totais disponíveis no mercado brasileiro, dos mais diversos fabricantes. Uma verificação nos catálogos eletrônicos de cinco fabricantes Leica, Nikon, Sokkia, Topcon, Trimble e Zeiss constatou-se que os equipamentos disponíveis atualmente tem precisão angular menor ou igual a dez segundos, de acordo com a norma DIN 18723 ou ISO 12857-2 1997, sendo que a maior variedade de equipamentos oferecidos estão entre 3 e 7 segundos e com precisão na medição de distância entre $2 \mathrm{~mm}+2 \mathrm{ppm}$ a $5 \mathrm{~mm}+5 \mathrm{ppm}$.

\subsection{Recomendações da ABNT - NBR 13.133}

No Brasil, a ABNT (1994) é quem estabelece os critérios para execução de levantamentos topográficos e classifica os tipos de nivelamentos em função da precisão desejada e dos equipamentos utilizados. De acordo com a finalidade do levantamento topográfico seleciona métodos, processos e equipamentos que assegurem propagação de erros acidentais inferior as tolerâncias admissíveis.

A classificação dos equipamentos ocorre segundo suas características. Os níveis são classificados conforme o desvio padrão apresentado em nivelamento e contra nivelamento de $1 \mathrm{~km}$ de nivelamento duplo. As estações totais são classificadas conforme o desvio padrão que as caracterizam, de acordo com as Tabelas 6.1 e 6.2. Serão consideradas equipamentos de baixa precisão aqueles com precisão menor que 10 segundos, em função do que a industria tem oferecido.

O nivelamento geométrico está presente em duas das quatro classes de nivelamento estabelecidas pela NBR 13.133. O nivelamento classe IN tem por finalidade a implantação de referência de nível (RN) e a classe IIN a determinação de altitudes em pontos de segurança e vértices de poligonais destinados a projetos básicos, projetos executivos, como executado e obras de engenharia. 
O nivelamento trigonométrico também ocupa duas classes, sendo que a classe IVN é específica para nivelamento taqueométrico onde se utiliza mira para determinação das distâncias. O nivelamento classe IIIN é definido para determinação de altitudes em poligonais de levantamento, nivelamento de perfis para estudos preliminares e ou de estudo viabilidade nos projetos. A Tabela 6.3 apresenta a classificação dos nivelamentos feita pela NBR 13.133.

Muitas empresas têm utilizado o nivelamento trigonométrico em atividades em que, para atender rigorosamente a NBR 13.133, deveria ser realizado por nivelamento geométrico. Apesar disso em muitas situações as empresas públicas e privadas que necessitam contratar serviços altimétricos não especificam o nivelamento trigonométrico, pois o seu limite de tolerância de fechamento é muito alto. Por isso torna-se necessário que haja um desdobramento da classificação deste método de nivelamento.

Tabela 6.1 - Classificação dos níveis. Fonte (ABNT, 1994).

\begin{tabular}{ll}
\hline Classes de níveis & Desvio - Padrão \\
\hline 1 - precisão baixa & $> \pm 10 \mathrm{~mm} / \mathrm{km}$ \\
2 - precisão média & $= \pm 10 \mathrm{~mm} / \mathrm{km}$ \\
3 - precisão alta & $= \pm 3 \mathrm{~mm} / \mathrm{km}$ \\
4 - precisão muito alta & $= \pm 1 \mathrm{~mm} / \mathrm{km}$ \\
\hline
\end{tabular}

Tabela 6.2 - Classificação das estações totais. Fonte (ABNT, 1994).

\begin{tabular}{ccc}
\hline Classes de estações totais & $\begin{array}{c}\text { Desvio - Padrão } \\
\text { Precisão angular }\end{array}$ & $\begin{array}{c}\text { Desvio - Padrão Precisão } \\
\text { linear }\end{array}$ \\
\hline 1 - precisão baixa & $= \pm 30 "$ & $\pm(5 \mathrm{~mm}+10 \mathrm{ppm} \times \mathrm{D})$ \\
2 - precisão média & $= \pm 07 "$ & $\pm(5 \mathrm{~mm}+5 \mathrm{ppm} \times \mathrm{D})$ \\
3 - precisão alta & $= \pm 02 "$ & $\pm(3 \mathrm{~mm}+3 \mathrm{ppm} \times \mathrm{D})$ \\
\hline
\end{tabular}


Tabela 6.3 - Classificação dos nivelamento. Fonte (ABNT, 1994)

\begin{tabular}{|c|c|c|c|c|c|c|c|}
\hline \multirow[b]{2}{*}{ Classe } & \multirow[b]{2}{*}{ Metodologia } & \multicolumn{5}{|c|}{ Desenvolvimento } & \multirow{2}{*}{$\begin{array}{l}\text { Tolerâncias de } \\
\text { fechamento }\end{array}$} \\
\hline & & $\begin{array}{l}\text { Linha } \\
\text { Seção }\end{array}$ & $\begin{array}{c}\text { Extenção } \\
\text { Máxima }\end{array}$ & $\begin{array}{c}\text { Lance } \\
\text { Máximo }\end{array}$ & $\begin{array}{l}\text { Lance } \\
\text { Mínimo }\end{array}$ & $\begin{array}{c}\text { № Max. } \\
\text { De } \\
\text { lances }\end{array}$ & \\
\hline $\begin{array}{c}\text { IN } \\
\text { Geom. }\end{array}$ & $\begin{array}{l}\text { Nivelamento geométrico a ser executado com nível } \\
\text { classe } 3 \text {, utilizando miras dobráveis, centímetricas, } \\
\text { devidamente aferidas, providas de prumo esférico, } \\
\text { leitura a ré e vante dos três fios, visadas } \\
\text { equidistantes com diferença máxima de } 10 \mathrm{~m} \text {, ida e } \\
\text { volta em horários distintos e com Ponto de } \\
\text { Segurança (PS) a cada km, no máximo. }\end{array}$ & & $10 \mathrm{~km}$ & $80 m$ & $15 \mathrm{~m}$ & & $12 \mathrm{mmv} K$ \\
\hline $\begin{array}{c}\text { IIN } \\
\text { Geom. }\end{array}$ & $\begin{array}{l}\text { Nivelamento geométrico a ser executado com nível } \\
\text { classe } 2 \text {, utilzando miras dobráveis, centímétricas, } \\
\text { devidamente aferidas, providas de prumo esférico, } \\
\text { leitura do fio médio, ida e volta ou circuito fechado, } \\
\text { com Pontos de Segurança (OS) a cada dois km, } \\
\text { no máximo. }\end{array}$ & & $10 \mathrm{~km}$ & $80 m$ & $15 \mathrm{~m}$ & & $20 \mathrm{mmv} K$ \\
\hline $\begin{array}{l}\text { IIIN } \\
\text { Trig. }\end{array}$ & $\begin{array}{l}\text { Nivelamento trigonométrico a ser realizado através } \\
\text { de medidas de distâncias executadas com medidor } \\
\text { eletrônoco de distância - MED - classe 1, leituras } \\
\text { reciprocras (vante e ré) em uma única série, ou } \\
\text { medidas de distâncias executadas à trena de aço } \\
\text { devidamente aferida, com controle estadimétrico de } \\
\text { erro grosseiro, leituras do ângulo vertical } \\
\text { conjugadas, direta e inversa, em uma série direta e } \\
\text { inversa, com teodolito classe } 2 \text { ou estação total } \\
\text { classe } 2 \text {. }\end{array}$ & $\begin{array}{l}\text { Princ. } \\
\text { Sec. }\end{array}$ & $\begin{array}{l}10 \mathrm{~km} \\
5 \mathrm{~km}\end{array}$ & $\begin{array}{l}500 \mathrm{~m} \\
300 \mathrm{~m}\end{array}$ & $\begin{array}{l}40 m \\
30 m\end{array}$ & $\begin{array}{l}40 \\
20\end{array}$ & $\begin{array}{l}0,15 \mathrm{mv} K \\
0,20 \mathrm{mv} K\end{array}$ \\
\hline $\begin{array}{c}\text { IVN } \\
\text { Taqueo. }\end{array}$ & $\begin{array}{l}\text { Nivelamento taqueométrico a ser realizado através } \\
\text { de leitura dos três fios sobre miras centímetricas, } \\
\text { devidamente aferidas, providas de prumo esférico, } \\
\text { leitura vante e ré, leitura do ângulo vertical simples, } \\
\text { com correção de PZ ou de índice obtido noinício e } \\
\text { no fim da jornada de trabalho, por leituras } \\
\text { conjugadas, direta e inversa, com teodolito classe } \\
1 .\end{array}$ & $\begin{array}{l}\text { Princ. } \\
\text { Sec. }\end{array}$ & $\begin{array}{l}5 \mathrm{~km} \\
2 \mathrm{~km}\end{array}$ & $\begin{array}{l}150 \mathrm{~m} \\
150 \mathrm{~m}\end{array}$ & $\begin{array}{l}30 \mathrm{~m} \\
30 \mathrm{~m}\end{array}$ & $\begin{array}{l}40 \\
20\end{array}$ & $\begin{array}{l}0,30 \mathrm{mv} K \\
0,40 \mathrm{mv} K\end{array}$ \\
\hline
\end{tabular}

\subsection{Recomendações do IBGE - Resolução PR $\mathbf{N}^{\circ} 22$}

O IBGE (1983) estabelece os critérios e configurações para os circuitos e linhas de nivelamentos geodésicos, especifica os procedimentos e os instrumentos para a medição de desníveis, define critérios para o controle de qualidade dos trabalhos e o erro padrão máximo para uma linha após o ajustamento e recomenda alguns cuidados que devem ser tomados que para minimizar a propagação de erros sistemáticos. A Tabela 6.4 mostra as diferenças máximas permitidas entre o nivelamento $\mathrm{e}$ contranivelamento.

Os cuidados que devem ser tomados durante a execução dos nivelamentos são: 
$\checkmark$ Comprimentos iguais de visada de ré e vante;

$\checkmark$ Comprimento máximo de 100m nas visadas, sendo 60m ideal;

$\checkmark$ Visar à mira acima de $20 \mathrm{~cm}$ do solo, para evitar os efeitos do fenômeno da reverberação;

$\checkmark$ Usar miras aos pares e alterná-las entre ré e vante;

$\checkmark$ Colocar as miras sempre sobre chapas, pinos ou sapatas.

Tabela 6.4 - Especificações para nivelamento geométrico geodésico. Adaptado de (IBGE, 1983)

\begin{tabular}{|c|c|c|c|c|}
\hline \multirow{3}{*}{ ITEM } & \multicolumn{4}{|c|}{ LEVANTAMENTOS GEODÉSICOS } \\
\hline & \multirow{2}{*}{$\frac{\text { De alta Precisão }}{\text { Fundamental }}$} & \multicolumn{2}{|c|}{ De Precisão } & \multirow{2}{*}{\begin{tabular}{|c} 
Para Fins Topográficos \\
Local
\end{tabular}} \\
\hline & & $\begin{array}{c}\text { Áreas Mais } \\
\text { Desenvolvidas }\end{array}$ & $\begin{array}{l}\text { Áreas Menos } \\
\text { Desenvolvidas }\end{array}$ & \\
\hline $\begin{array}{l}\text { Diferença entre nivelamento e } \\
\text { contranivelamento de uma seção. }\end{array}$ & $3 m m v K$ & $6 \mathrm{mmv} K$ & $8 \mathrm{mmv} K$ & $12 \mathrm{mmvK}$ \\
\hline $\begin{array}{l}\text { Diferença entre nivelamento e } \\
\text { contranivelamento de uma linha. }\end{array}$ & $4 \mathrm{mmvK}$ & $6 \mathrm{mmv} K$ & $8 \mathrm{mmv} K$ & $12 \mathrm{mmvK}$ \\
\hline $\begin{array}{l}\text { Razão entre a discrepância acumulada e o } \\
\text { perímetro do circuito. }\end{array}$ & $0,5 \mathrm{~mm} / \mathrm{km}$ & $5 \mathrm{~mm} / \mathrm{km}$ & $5 \mathrm{~mm} / \mathrm{km}$ & $10 \mathrm{~mm} / \mathrm{km}$ \\
\hline $\begin{array}{l}\text { Erro padrão máximo para uma linha após o } \\
\text { ajustamento. }\end{array}$ & $2 \mathrm{mmv} K$ & $3 \mathrm{mmv} K$ & $4 \mathrm{mmv} K$ & $6 \mathrm{mmv} K$ \\
\hline
\end{tabular}

\subsection{Recomendações do DNIT - IS 204 e IS 205}

O Departamento Nacional de Infra-Estrutura de Transportes (DNIT), antigo Departamento Nacional de Estradas e Rodagem (DNER), define e especifica os serviços topográficos a serem desenvolvidos na fase de anteprojeto e projeto de engenharia rodoviária através das instruções de serviços IS-204 e IS-205, respectivamente.

Segundo DNIT (2002a) e DNIT (2002b) o eixo locado deve ser nivelado e contra nivelado por nivelamento geométrico e apoiado a uma rede de RRNN implantada ao longo da faixa de domínio da rodovia, cujos marcos estejam espaçados de 500 metros.

A tolerância de erro de nivelamento é de $20 \mathrm{~mm} / \mathrm{km}$ entre os RRNN e a diferença acumulada $(e)$ deve atender a inequação: 


$$
e \leq 12,5 \mathrm{~mm} \cdot \sqrt{n}
$$

onde:

$n: \quad$ Extensão $(\mathrm{km})$

$e: \quad$ Diferença acumulada $(\mathrm{mm})$.

Apesar de destacar a utilização de estações totais como forma de aumentar a produtividade, melhorar a segurança da coleta dos dados dentre outras qualidades, as instruções não especificam o nivelamento trigonométrico com estação total para nivelamento do eixo de estradas, em nenhuma das fases, seja de projeto ou e anteprojeto. 


\section{Materiais e Métodos}

\subsection{Considerações Iniciais}

Neste capítulo apresentam-se as características da seção em que se realizou o nivelamento, objeto desta pesquisa, a estratégia dos levantamentos, os métodos de coleta de dados em campo e a estratégia e procedimentos dos cálculos.

\subsection{Definição da Seção de Estudo}

A localização da seção, sua dimensão, distância entre os pontos e seu perfil foram definidos de modo que as condições fossem o mais próximo possível das encontradas no cotidiano das atividades convencionais de topografia, fácil acesso e baixo custos de transportes e apoio às atividades de campo. As características topográficas para o local foram estabelecidas visando uma maior variação dos ângulos verticais, visibilidade entre todos os pontos e possibilidade da linha de visada passar próximo ao solo em determinadas posições.

O local escolhido fica no $\mathrm{km} 256$ da rodovia SP 318 - Eng. Thales de Lorena Peixoto Júnior, distante $20 \mathrm{~km}$ da cidade de São Carlos (SP). A rodovia encontra-se sob administração por concessão da empresa Autovias SA. Durante a seleção do local, foram considerados alguns trechos no centro da cidade de São Carlos (SP), entretanto árvores e placas de publicidade das lojas impossibilitavam a visão das extremidades da seção.

A seção apresenta um perfil côncavo, atendendo as condições de visibilidade entre todos os pontos e linha de visada próximo ao solo. Possui rampa máxima em torno 
de $5 \%$, o que implica em ângulo de inclinação da ordem de $3^{\circ}$. Uma seção que possibilitasse ângulos verticais de até $10^{\circ}$ seria útil para avaliar o comportamento da propagação da componente do erro devido ao ângulo vertical, no entanto ângulo desta magnitude implica em rampa em torno de 17\%, não é encontrada na margem de rodovia, nem em vias urbanas com a extensão pretendida. Este foi o local que mais se adequou aos critérios estabelecidos, num raio de $50 \mathrm{~km}$.

O comprimento da seção é de $680 \mathrm{~m}$, com pontos materializados a cada $40 \mathrm{~m}$, e numerados seqüencialmente de P0 ate P15, sendo que 40 metros antes do P0 foi materializado ponto de segurança PS1 e 40 metros após o P15 o ponto de segurança PS2, conforme ilustra a Figura 7.1. A Figura 7.2 apresenta uma visão panorâmica da seção.

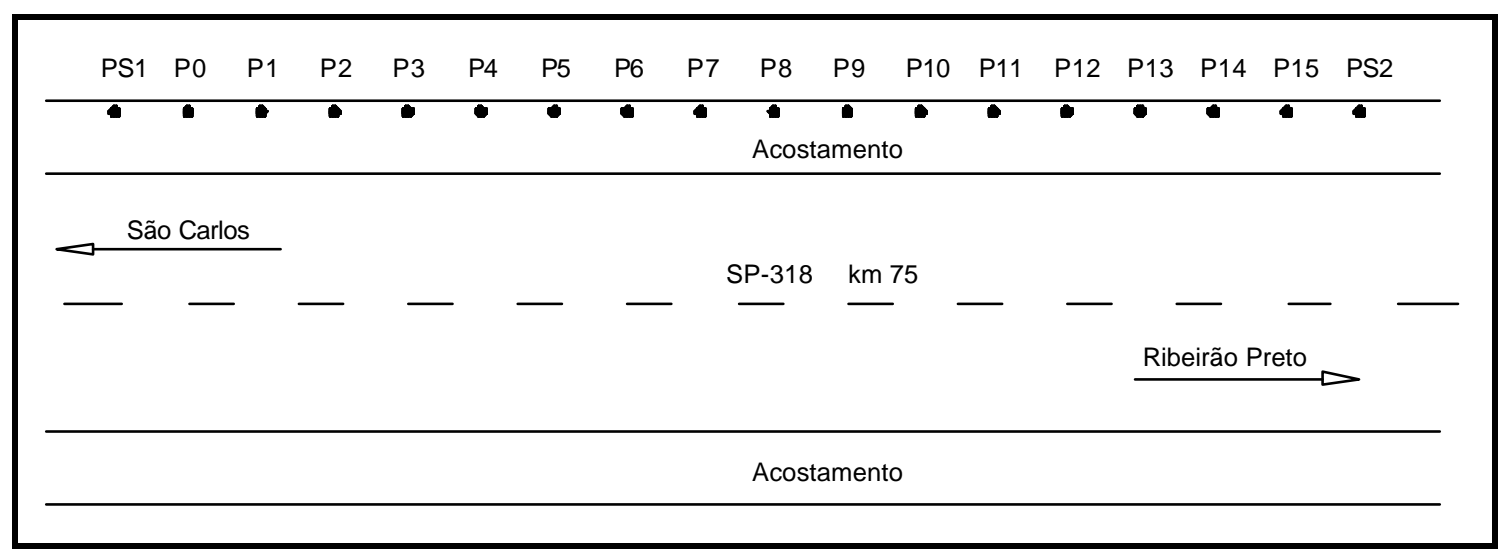

Figura 7.1 - Ilustração esquemática da seção de estudo.

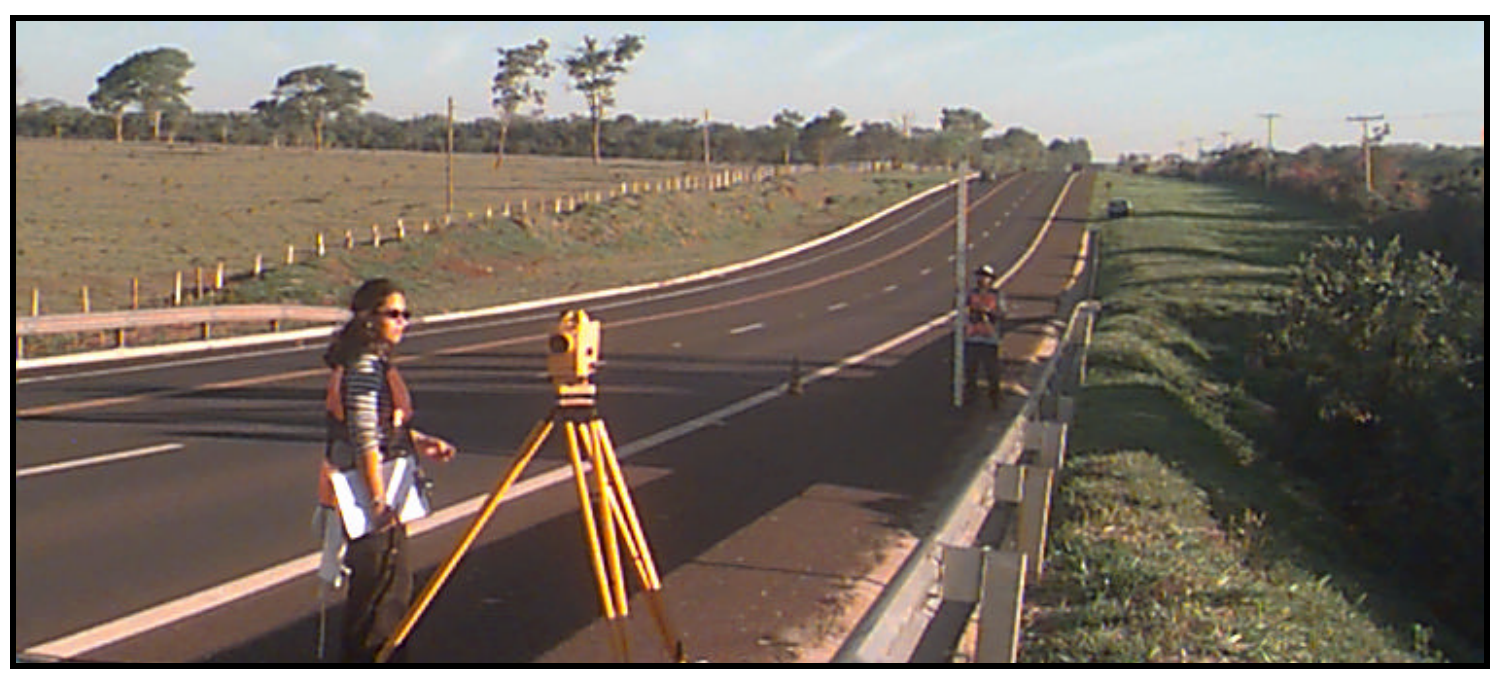

Figura 7.2 - Vista da seção com o nível entre os pontos P7 e P8 e a mira em P7 
Os pontos foram materializados na extremidade do acostamento por questão de segurança durante as operações de campo, e foram utilizados parafusos galvanizados de cabeças arredondadas, com 100mm de comprimento e bitola de $10 \mathrm{~mm}$. A Figura 7.3 mostra detalhes do ponto e de sua fixação no solo.

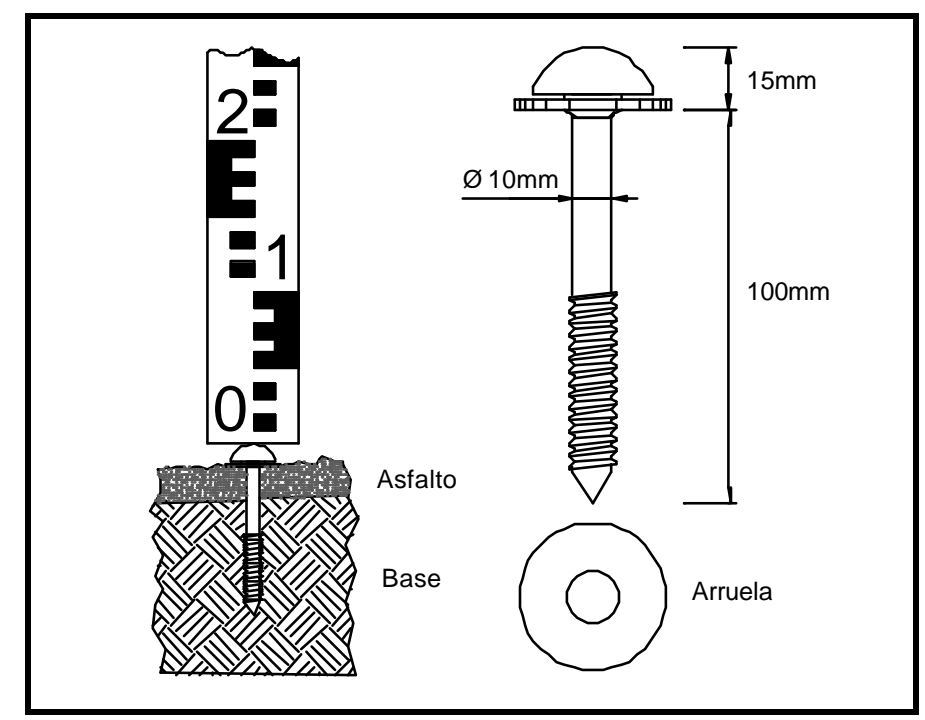

Figura 7.3 - Detalhe da materialização dos pontos.

\subsection{Levantamento de Campo}

Para avaliar a precisão de uma técnica de nivelamento torna-se necessário escolher um local, materializar os pontos em estudos, realizar o nivelamento com uma técnica de precisão reconhecidamente superior a que se quer verificar, de modo que as propagações dos erros residuais causem a menor interferência possível na precisão dos resultados da técnica que se está testando.

Com os pontos da seção materializados, realizou-se o nivelamento geométrico conforme as especificações dadas por IBGE, (1983) para o nivelamento geodésico de precisão. Em seguida realizou-se o nivelamento trigonométrico utilizando estações totais. Os pontos de segurança foram nivelados utilizando-se equipamento GPS (receptor e antena) de uma frequiência com o método de posicionamento estático, com tempo de observação de uma hora. 


\subsubsection{Nivelamento geométrico}

\subsubsection{Equipamentos utilizados}

Para este nivelamento foi utilizado o nível do Laboratório de Topografia do Departamento de Engenharia Civil da Universidade Federal de São Carlos - UFSCar e os acessórios do Laboratório de Mensuração do Departamento de Transportes da EESC/USP. Os equipamentos utilizados foram o nível NI 07, fabricado pela Carl Zeiss - JENA, com placa plana paralela, destinado a nivelamentos de média e alta precisão, com erro quadrático médio de até $0,5 \mathrm{~mm}$ por quilômetro de duplo nivelamento, uma mira de ínvar e acessórios. A Figura 7.4 apresenta o nível utilizado.

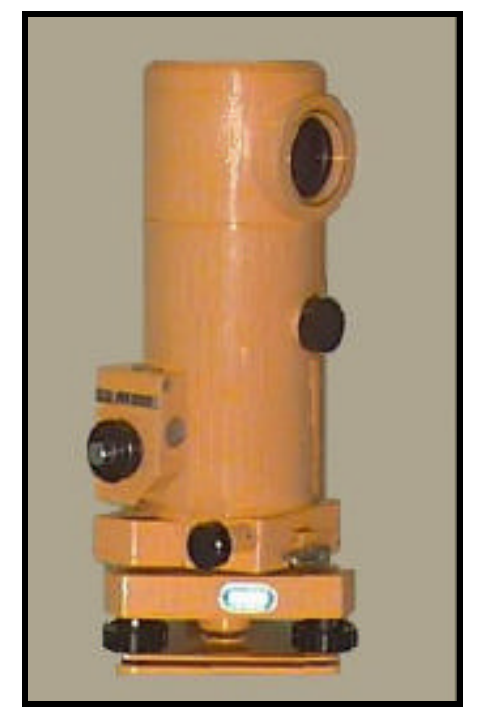

Figura 7.4 - Nível NI 07. Fabricação Karl Zeiss-Jena

\subsubsection{Estratégia de ocupação dos pontos e cálculo}

No processo de nivelamento foram adotadas as recomendações para levantamentos altimétricos estabelecidos pela Resolução - PR 22, Normas Gerais para Levantamentos Geodésicos do IBGE, que normaliza os levantamentos altimétricos de alta precisão, com o intuito de minimizar os efeitos e propagação de erros sistemáticos.

O comprimento das visadas foi de 20 metros e com uma diferença entre ré e vante menor que $50 \mathrm{~cm}$, de modo a compensar o efeito da curvatura terrestre e de erros sistemáticos devido à refração atmosférica. As mudanças de instrumento foram feitas sempre nos pontos estabelecidos, sem a necessidade de utilizar sapata como ponto auxiliar. 
As leituras na mira foram realizadas a $50 \mathrm{~cm}$ acima do solo para minimizar os efeitos da cintilação causada pela variação da densidade do ar, em decorrência da troca térmica. Utilizourse também apenas uma mira de modo a eliminar o erro de índice.

As diferenças de níveis entre pontos foram calculadas no programa Microsoft ${ }^{\circledR}$ Excel2002.

\subsubsection{Nivelamento com GPS}

Com o GPS determinou-se a altitude ortométrica dos pontos de segurança, PS1 e PS2, utilizando as ondulações geoidais obtidas do Mapa Geoidal do Brasil (1992) desenvolvido pelo IBGE em conjunto com a Escola Politécnica da Universidade de São Paulo (EPUSP/PTR). O mapa apresenta precisão absoluta de 3 metros e relativa de $1 \mathrm{~cm} / \mathrm{km}$, (SEGANTINE, 2002). Para a obtenção das altitudes foram usados os procedimentos descritos no Capítulo 5.

\subsubsection{Equipamentos utilizados}

Nesta etapa utilizou-se um sistema GPS de fabricação Leica, GPS System modelo SR9400, composto por um par de receptores com capacidade de observação da portadora L1 e código C/A. Duas antenas receptoras com bastão de 1,50 metros, dois bipés para dar apoio às antenas e dois coletores de dados.

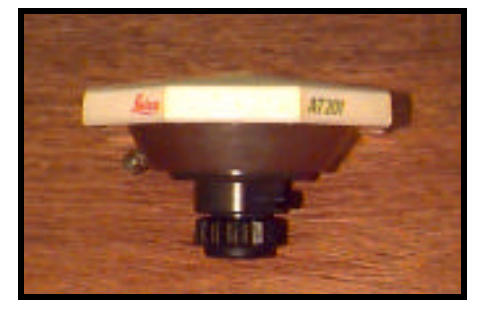

(a)

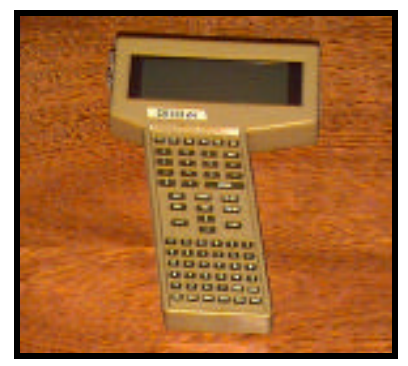

(b)

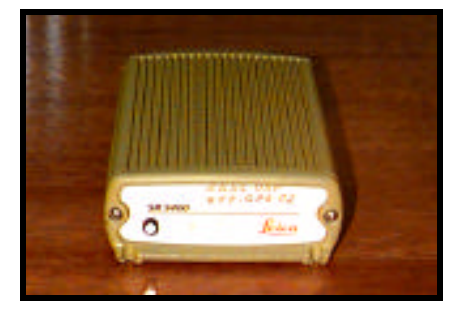

(c)

Figura 7.5 - Sistema GPS - Leica usado no nivelamento do PS1 e PS2 


\subsubsection{Estratégia de ocupação dos pontos e processamento}

Os pontos foram levantados no método de posicionamento relativo estático usando a fase da portadora, pois é a técnica mais precisa e mais usada em levantamentos de campo, (SEGANTINE, 2002). Os dois receptores foram posicionados nos pontos PS1 e PS2 rastreados por uma hora, com taxa de armazenamento de 15 segundos. A estação BASE-STT foi usada como vértice de referência. Esta estação monitora continuamente os satélites GPS e os seus dados estão disponibilizados para os usuários no endereço <http://143.107.234.58/default.htm>.

Os dados foram pós-processados no programa Ski-Pro. A diferença de nível entre os pontos PS1 e PS2 foram comparadas com os resultados do nivelamento geométrico.

\subsubsection{Nivelamento trigonométrico}

O nivelamento trigonométrico foi feito em duas etapas, na primeira com um equipamento de baixa precisão e na segunda com o equipamento de média precisão.

\subsubsection{Equipamentos utilizados}

Como equipamento de baixa precisão utilizou-se a estação total TC 400, Figura 7.6a, com precisão angular de 10 segundos e com precisão para distância de $5 \mathrm{~mm}+10$ ppm de fabricação da Leica. Utilizou-se um par de prismas, um par de bastões apoiados por bipés e acessórios. Todos os equipamentos pertencem ao Laboratório de Mensuração do Departamento de Transportes da EESC/USP.

O equipamento de média precisão usado foi a estação total TC 307, Figura 7.6b, com precisão angular de 7 segundos e distância de $2 \mathrm{~mm}+2 \mathrm{ppm}$, também de fabricação da Leica, emprestada da Wild Brasil S/A. 


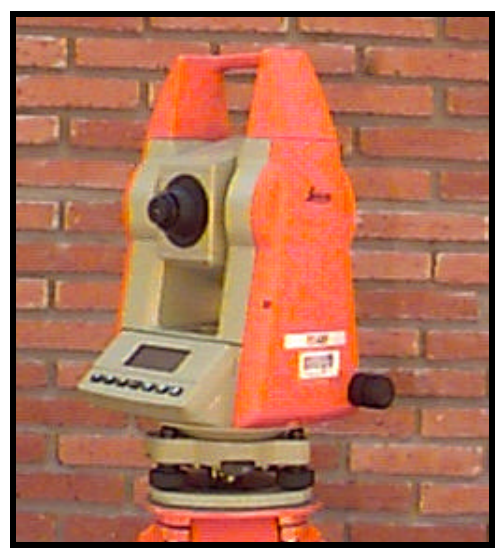

(a) - TC400

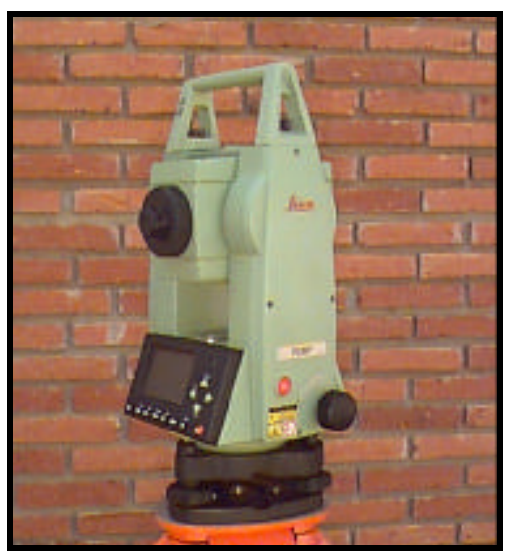

(b) - TC307

Figura 7.6 - Estações totais usada no nivelamento trigonométrico - Fabricação Leica.

\subsubsection{Coleta de dados atmosféricos}

Foram coletados os dados atmosféricos tais como: pressão, temperatura e umidade relativa do ar. A pressão atmosférica e a temperatura foram coletadas em média a cada quatro pontos nivelados, o que corresponde a intervalos de cerca de 20 minutos. A umidade relativa, no entanto, foi obtida de EMBRAPA (2003), que divulga os dados da estação meteorológica localizada a cerca de $7 \mathrm{~km}$ da seção em estudo. E conforme foi mostrado na Seção 4.4.1, o uso dos mesmos valores de umidade observados na estação meteorológica para o local do nivelamento não implica em erros significativos.

\subsubsection{Medição da altura do instrumento}

A determinação da altura do instrumento é um dos fatores que limita a precisão do nivelamento trigonométrico, pois geralmente este procedimento é realizado com uma trena, (MAIA, 1999). Neste trabalho a altura do instrumento foi determinada de duas maneiras diferentes:

$\checkmark$ Medição direta com uma trena;

Neste caso a altura foi obtida inclinada do ponto até a projeção do eixo de rotação da luneta na lateral da estação total. A altura vertical foi calculada aplicando o teorema de Pitágoras: 


$$
h_{V}=\sqrt{h_{I}^{2}-d^{2}}
$$

onde:

$h_{V}: \quad$ Altura vertical (m);

$h_{I}: \quad$ Altura inclinada $(\mathrm{m})$;

d: $\quad$ Distância horizontal entre a eixo vertical e a lateral da estação.

Para o valor de $d$ considerou-se a metade da largura dos equipamentos informada no manual do usuário destes: $d=0,10 \mathrm{~m}$ para a TC400 e $d=0,075 \mathrm{~m}$ para a TC307.

$\checkmark$ Por nivelamento trigonométrico de uma RN (referência de nível).

De acordo com a Figura 7.7 a medição da altura do instrumento por nivelamento trigonométrico é dada por:

$$
h i=d n_{E-R N}+h a-S \cdot \cos Z
$$

onde:

hi: $\quad$ Altura do instrumento a determinar;

$d n_{E-R N}$ :Diferença de nível entre estação e $\mathrm{RN}$ obtida por nivelamento geométrico;

ha: $\quad$ Altura do alvo conhecida;

S: $\quad$ Distância inclinada;

Z: $\quad$ Ângulo zenital.

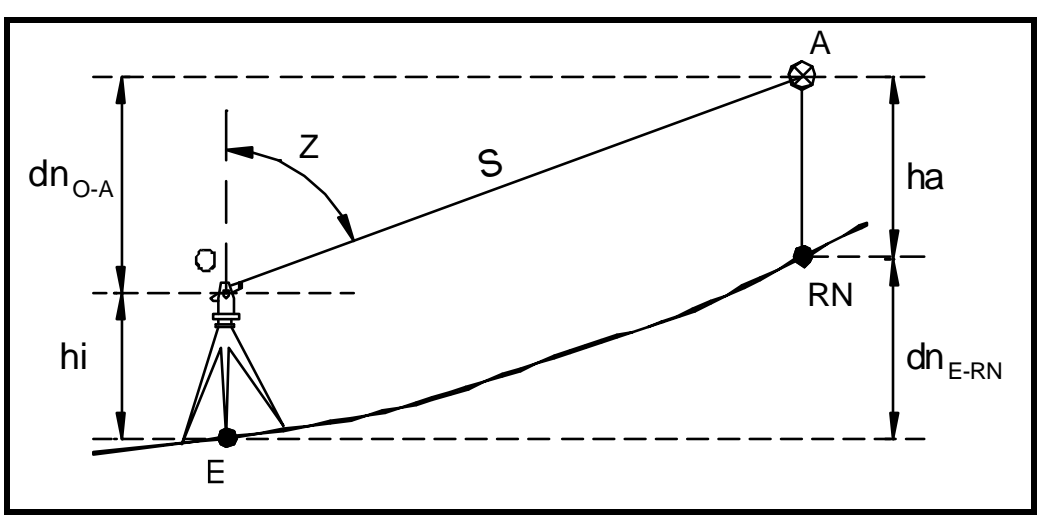

Figura 7.7 - Obtenção da altura por nivelamento 
No processamento dos dados foram consideradas as alturas do instrumento medidas das duas formas com o objetivo de avaliar quanto à medição com a trena influência na precisão da altitude.

\subsubsection{Posicionamento do alvo}

Os prismas foram fixados em bastões dotados de bolha de nível circular, devidamente aferida, e bipé que permitiu mantê-los na vertical e estáveis durante as medições. No entanto, algumas vezes durante os procedimentos os bastão foram aprumados apenas com o apoio das mãos. As alturas finais do alvo, considerando o centro geométrico do prisma foram de 1,560 metros.

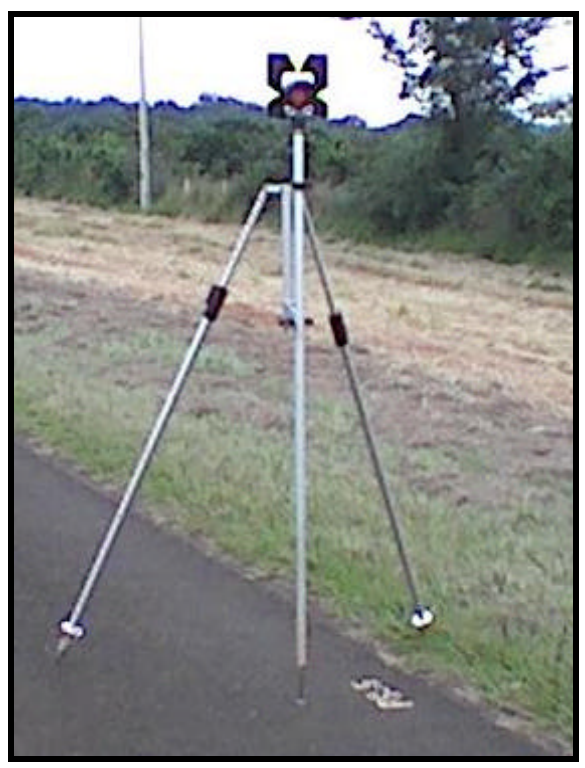

Figura 7.8 - Prisma em bastão apoiado com bipé.

\subsubsection{Estratégia de ocupação dos pontos}

Em cada um dos pontos visados foram realizadas três séries de leituras conjugadas, diretas e inversas, de ângulos zenitais e medição de distâncias, sendo que as duas primeiras séries foram realizadas com o bastão instalado sobre o ponto e devidamente sustentado pelo bipé e a última com o bastão seguro manualmente, sem o apoio destes.

$\mathrm{O}$ procedimento consistiu em instalar o equipamento no ponto $\mathrm{P} 0$, visar o ponto PS1 à ré e em seguida visar a vante os pontos P1, P2 até o PS2. Deslocar o equipamento 
para o ponto $\mathrm{P} 1$ e visar à ré o ponto $\mathrm{PS} 1$ e em seguida visar a vante os pontos $\mathrm{P} 0, \mathrm{P} 2, \mathrm{P} 3$ até o PS2. Repetiu-se este procedimento até estacionar no ponto P15 e visar todos os demais pontos, conforme ilustra a Figura 7.9.

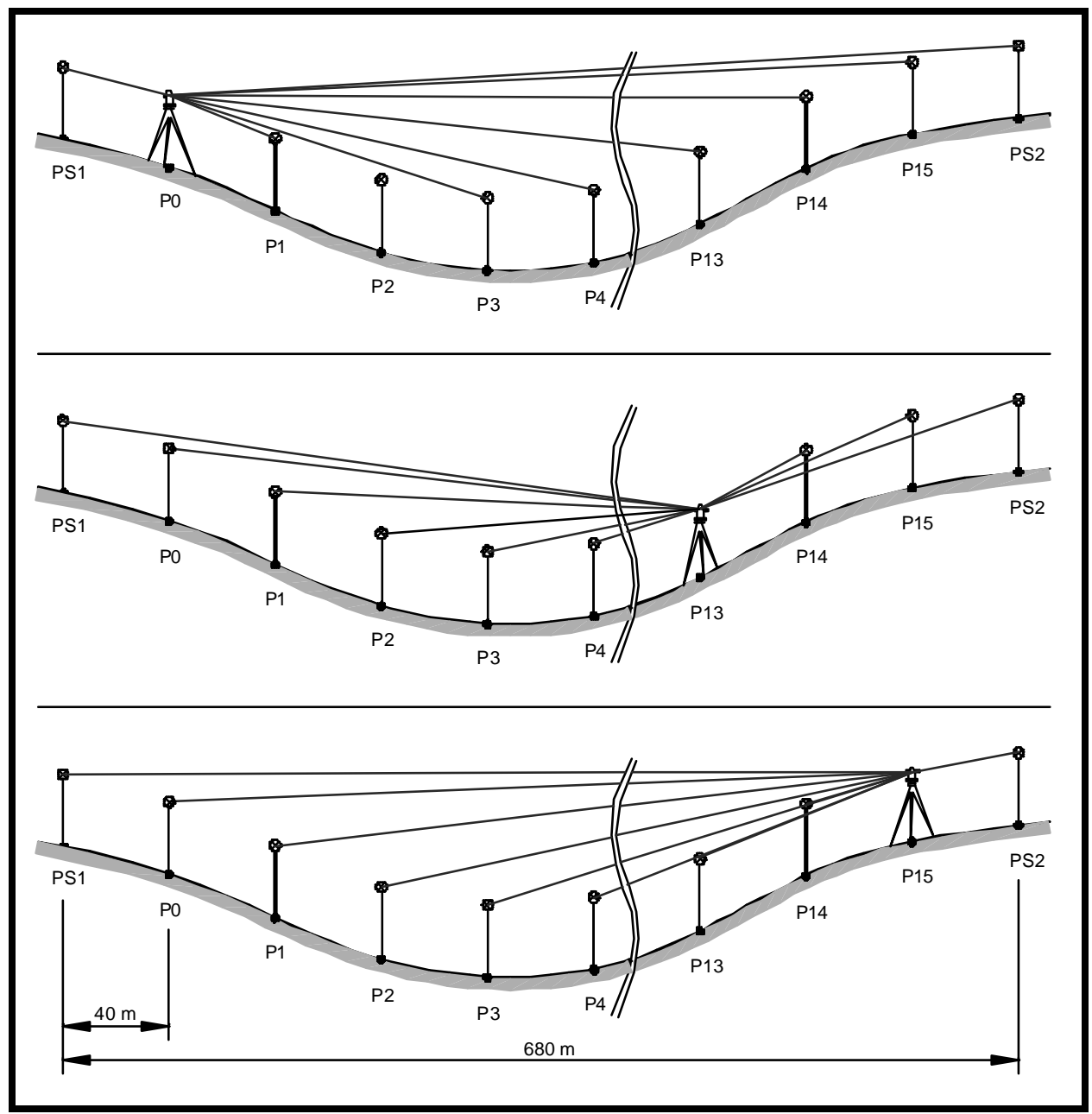

Figura 7.9 - Ilustração da estratégia para o nivelamento trigonométrico.

Desta forma dois pontos foram visados de $640 \mathrm{~m}$, são do P0 ao PS2 na ida e do P15 ao PS1 na volta, outros quatro foram visados de 60m, do P0 ao P15 e do P1 ao PS2 e vice-versa, até atingir o total de 32 pontos visados de $40 \mathrm{~m}$ de distâncias, formando um conjunto de dados cuja altitude dos pontos foram obtidas de diferentes distâncias, distribuídos conforme mostra a Tabela 7.1. Foram usados os dados com distância de até $520 \mathrm{~m}$, pois a partir daí a quantidade de pontos observados são menores que oito.

Tabela 7.1 - Número de pontos nivelados $\mathrm{x}$ distância de visada.

\begin{tabular}{lcccccccccccccccc}
\hline Distância (m) & 40 & 80 & 120 & 160 & 200 & 240 & 280 & 320 & 360 & 400 & 440 & 480 & 520 & 560 & 600 & 640 \\
\hline № Pontos & 32 & 30 & 28 & 26 & 24 & 22 & 20 & 18 & 16 & 14 & 12 & 10 & 8 & 6 & 4 & 2 \\
\hline
\end{tabular}


Um outro conjunto é formado pelas altitudes obtidas para o mesmo ponto com o instrumento instalado nos demais pontos. Como esclarecimento, o ponto P1 terá altitude determinada a partir do PS1, P0, P2, P3... até o PS2. Dessa forma cada ponto terá sua altitude determinada de 16 posições diferentes.

\subsubsection{Estratégia de processamento e avaliação dos dados}

Os dados de campo foram calculados em planilhas eletrônicas programadas no programa Microsoft Excel 2001. Nos cálculos considerou-se o nivelamento trigonométrico com visadas unilaterais e o "Leap-frog":

No nivelamento trigonométrico unilateral, as alturas dos pontos foram obtidas considerando-se a combinação das diferentes condições:

$\checkmark$ Altura do instrumento medida com trena;

$\checkmark$ Altura do instrumento medida por nivelamento trigonométrico;

$\checkmark$ Sem correção dos efeitos atmosféricos na medição eletrônica de distâncias;

$\checkmark$ Com correção dos efeitos atmosféricos na medição eletrônica de distâncias;

$\checkmark$ Sem correção da refração e da curvatura terrestre na diferença de nível ;

$\checkmark$ Com correção da refração e da curvatura terrestre na diferença de nível;

$\checkmark$ Média das duas séries de visadas diretas e inversas, com o bastão apoiado pelo bi-pé;

$\checkmark$ Média da série de visada direta e inversa, com o bastão seguro manualmente;

A Tabela 7.2 mostra as 16 combinações das condições que foram consideradas.

Tabela 7.2 - Combinação das diferentes condições para o cálculo do nivelamento trigonométrico

\begin{tabular}{|c|c|c|c|c|c|c|c|c|c|c|c|c|c|c|c|c|c|}
\hline Considerações & & 1 & 2 & 3 & 4 & 5 & 6 & 7 & 8 & 9 & 10 & 11 & 12 & 13 & 14 & 15 & 16 \\
\hline \multirow{2}{*}{ Altura da Estação } & Trena & $\bullet$ & $\bullet$ & $\bullet$ & $\bullet$ & $\bullet$ & $\bullet$ & $\bullet$ & $\bullet$ & & & & & & & & \\
\hline & Nivelamento & & & & & & & & & $\bullet$ & $\bullet$ & $\bullet$ & $\bullet$ & $\bullet$ & $\bullet$ & $\bullet$ & $\bullet$ \\
\hline \multirow{2}{*}{$\begin{array}{l}\text { Correção do efeito da refração } \\
\text { na distância }\end{array}$} & Não & $\bullet$ & $\bullet$ & $\bullet$ & $\bullet$ & & & & & $\bullet$ & $\bullet$ & $\bullet$ & $\bullet$ & & & & \\
\hline & Sim & & & & & $\bullet$ & $\bullet$ & $\bullet$ & $\bullet$ & & & & & $\bullet$ & $\bullet$ & $\bullet$ & $\bullet$ \\
\hline \multirow{2}{*}{$\begin{array}{l}\text { Correção do ângulo de refração } \\
\text { e curvatura da terra }\end{array}$} & Não & $\bullet$ & $\bullet$ & & & $\bullet$ & $\bullet$ & & & $\bullet$ & $\bullet$ & & & $\bullet$ & $\bullet$ & & \\
\hline & Sim & & & $\bullet$ & $\bullet$ & & & $\bullet$ & $\bullet$ & & & $\bullet$ & $\bullet$ & & & $\bullet$ & $\bullet$ \\
\hline \multirow{2}{*}{ Bastão com o Prisma } & Manual & $\bullet$ & & $\bullet$ & & $\bullet$ & & $\bullet$ & & $\bullet$ & & $\bullet$ & & $\bullet$ & & $\bullet$ & \\
\hline & Apoiado & & $\bullet$ & & $\bullet$ & & $\bullet$ & & $\bullet$ & & $\bullet$ & & $\bullet$ & & $\bullet$ & & $\bullet$ \\
\hline
\end{tabular}


No nivelamento trigonométrico Leap-frog foi calculado a diferença de nível entre os pontos mostrados na Tabela 7.3, que apresenta as combinações de posição do equipamento e do alvo e as distâncias de visadas em que foram feitos os cálculos. A diferença de nível entre os pontos PS1 e P15, na primeira linha, considerando o símbolo “\#” como a posição do equipamento e a letra "A" como a posição do alvo, foi calculada aplicando a equação (4.11) do ponto PS1 a P1, de P1 a P3 e assim sucessivamente até P13 a P15.

Quanto às combinações da Tabela 7.2, considerou-se apenas as visadas com o alvo apoiado, pois a avaliação da diferença de altura entre o alvo fixo ou móvel foi feita com o nivelamento unilateral. As demais: altura do instrumento, correções da refração, correção da curvatura se anulam como mostra as equações (4.7) a (4.11).

Tabela 7.3 - Pontos de estação e alvo nos cálculos do Leap-frog

\begin{tabular}{|c|c|c|c|c|c|c|c|c|c|c|c|c|c|c|c|c|c|c|c|c|c|}
\hline Item & PS1 & P0 & P1 & P2 & P3 & P4 & P5 & P6 & P7 & P8 & P9 & P10 & P11 & P12 & P13 & P14 & P15 & PS2 & $\begin{array}{c}\text { Distância } \\
\text { Visada }\end{array}$ & Início & Fim \\
\hline 1 & A & \# & A & \# & A & \# & A & \# & A & \# & A & $\#$ & A & \# & A & \# & A & & \multirow{2}{*}{40} & PS1 & P15 \\
\hline 2 & & $A$ & \# & $A$ & $\#$ & $A$ & \# & A & \# & $A$ & $\#$ & $A$ & \# & A & $\#$ & A & $\#$ & A & & P0 & PS2 \\
\hline 3 & A & & \# & & A & & $\#$ & & A & & $\#$ & & A & & \# & & A & & \multirow{2}{*}{80} & PS1 & P15 \\
\hline 4 & & A & & \# & & A & & \# & & A & & \# & & A & & $\#$ & & A & & P0 & PS2 \\
\hline 5 & A & & & \# & & & A & & & \# & & & A & & & & & & \multirow{5}{*}{120} & PS1 & P11 \\
\hline 6 & & A & & & $\#$ & & & A & & & $\#$ & & & A & & & & & & P0 & P12 \\
\hline 7 & & & A & & & \# & & & A & & & \# & & & A & & & & & $\mathrm{P} 1$ & $\mathrm{P} 13$ \\
\hline 8 & & & & A & & & $\#$ & & & A & & & $\#$ & & & A & & & & $\mathrm{P} 2$ & P14 \\
\hline 9 & & & & & A & & & $\#$ & & & A & & & $\#$ & & & A & & & $\mathrm{P} 3$ & P15 \\
\hline 10 & A & & & & \# & & & & A & & & & \# & & & & A & & \multirow{2}{*}{160} & PS1 & $\mathrm{P} 15$ \\
\hline 11 & & A & & & & $\#$ & & & & A & & & & \# & & & & A & & $\mathrm{PO}$ & PS2 \\
\hline 12 & A & & & & & $\#$ & & & & & A & & & & & & & & \multirow{8}{*}{200} & PS1 & P9 \\
\hline 13 & & A & & & & & $\#$ & & & & & A & & & & & & & & P0 & P10 \\
\hline 14 & & & A & & & & & $\#$ & & & & & A & & & & & & & $\mathrm{P} 1$ & $\mathrm{P} 11$ \\
\hline 15 & & & & A & & & & & \# & & & & & A & & & & & & $\mathrm{P} 2$ & $\mathrm{P} 12$ \\
\hline 16 & & & & & A & & & & & $\#$ & & & & & A & & & & & $\mathrm{P} 3$ & $\mathrm{P} 13$ \\
\hline 17 & & & & & & A & & & & & \# & & & & & A & & & & P4 & P14 \\
\hline 18 & & & & & & & A & & & & & \# & & & & & A & & & P5 & $\mathrm{P} 15$ \\
\hline 19 & & & & & & & & A & & & & & $\#$ & & & & & A & & P6 & PS2 \\
\hline 20 & A & & & & & & \# & & & & & & A & & & & & & \multirow{6}{*}{240} & PS1 & P11 \\
\hline 21 & & A & & & & & & $\#$ & & & & & & A & & & & & & $\mathrm{Po}$ & $\mathrm{P} 12$ \\
\hline 22 & & & A & & & & & & \# & & & & & & A & & & & & $\mathrm{P} 1$ & $\mathrm{P} 13$ \\
\hline 23 & & & & A & & & & & & \# & & & & & & A & & & & $\mathrm{P} 2$ & P14 \\
\hline 24 & & & & & A & & & & & & \# & & & & & & A & & & P3 & $\mathrm{P} 15$ \\
\hline 25 & & & & & & A & & & & & & \# & & & & & & A & & P4 & PS2 \\
\hline 26 & A & & & & & & & \# & & & & & & & A & & & & \multirow{4}{*}{280} & PS1 & P13 \\
\hline 27 & & A & & & & & & & \# & & & & & & & A & & & & $\mathrm{PSO}$ & P14 \\
\hline 28 & & & A & & & & & & & $\#$ & & & & & & & A & & & $\mathrm{P} 1$ & $\mathrm{P} 15$ \\
\hline 29 & & & & A & & & & & & & $\#$ & & & & & & . & A & & $\mathrm{P} 2$ & PS2 \\
\hline 30 & A & & & & & & & & \# & & & & & & & & A & & \multirow{2}{*}{320} & PS1 & P14 \\
\hline 31 & & A & & & & & & & & \# & & & & & & & & A & & P0 & PS2 \\
\hline
\end{tabular}




\section{Resultados e Discussão}

\subsection{Nivelamento Geométrico}

Os valores das cotas arbitrárias dos pontos são mostrados na Tabela 8.1 e serão chamadas de cotas de referência na comparação com o nivelamento trigonométrico. $\mathrm{O}$ erro cometido entre o nivelamento e o contra nivelamento foi de $0,2 \mathrm{~mm}$, que equivale a precisão de $0,25 \mathrm{~mm} \sqrt{L(\mathrm{~km})}$, e ficou abaixo da tolerância para o nivelamento geodésico de alta precisão estabelecidos pelo IBGE:

$$
\begin{aligned}
& T=3 \mathrm{~mm} \cdot \sqrt{L(\mathrm{~km})} \\
& e \leq T \\
& e=d n_{\text {Ida }}-d n_{\text {Volta }}=0,2 \mathrm{~mm} \\
& T=3 \mathrm{~mm} \cdot \sqrt{0,68}=2,4 \mathrm{~mm}
\end{aligned}
$$

onde:

$e: \quad$ Erro entre o nivelamento e o contranivelamento $(\mathrm{mm})$

$T: \quad$ Tolerância de fechamento (mm).

A diferença de nível encontrada para os pontos PS1 e PS2 foi de 1,563 metros. A maior diferença entre os desníveis obtidos no nivelamento e no contranivelamento foi de $0,6 \mathrm{~mm}$, conforme apresentado no Gráfico 8.1. 
Tabela 8.1 - Resultados do nivelamento geométrico

\begin{tabular}{|c|c|c|c|c|c|c|c|c|c|c|c|c|c|c|c|c|c|c|}
\hline Pontos & $\bar{\infty}$ & ㅇ & $\bar{a}$ & $\stackrel{\sim}{\alpha}$ & $\stackrel{m}{a}$ & $\stackrel{+}{a}$ & $\stackrel{L}{\alpha}$ & $\begin{array}{l}0 \\
\alpha\end{array}$ & $\hat{a}$ & $\stackrel{\infty}{\square}$ & $\stackrel{\circ}{\square}$ & $\frac{0}{2}$ & $\bar{\Sigma}$ & $\frac{N}{\square}$ & $\frac{m}{\alpha}$ & $\frac{+}{a}$ & $\frac{10}{2}$ & ల్ \\
\hline Cotas (m) & $\begin{array}{l}8 \\
8 \\
8\end{array}$ & $\begin{array}{l}\infty \\
\infty \\
\infty \\
\infty \\
\infty\end{array}$ & 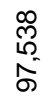 & $\frac{10}{\frac{10}{n}}$ & $\begin{array}{l}\text { ర్ } \\
\text { లু } \\
\text { '. }\end{array}$ & $\begin{array}{l}\text { ণ } \\
\text { চ }\end{array}$ & $\begin{array}{l}\infty \\
\text { ల } \\
\text { ळ }\end{array}$ & $\begin{array}{c}\stackrel{n}{\wedge} \\
\stackrel{\infty}{\infty}\end{array}$ & $\begin{array}{l}\bar{\sigma} \\
\text { o } \\
\infty \\
\infty\end{array}$ & 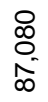 & 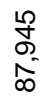 & $\begin{array}{l}\overline{6} \\
\varnothing \\
\infty\end{array}$ & $\begin{array}{l}\text { N } \\
\text { б }\end{array}$ & $\begin{array}{l}\infty \\
\stackrel{\infty}{\infty} \\
\text { లో }\end{array}$ & 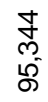 & $\begin{array}{l}\mathscr{8} \\
\mathscr{8} \\
\mathscr{8}\end{array}$ & 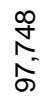 & \begin{tabular}{l}
$\hat{m}$ \\
\multirow{\sigma}{\sigma}{} \\
$\mathscr{o}^{\prime}$
\end{tabular} \\
\hline
\end{tabular}

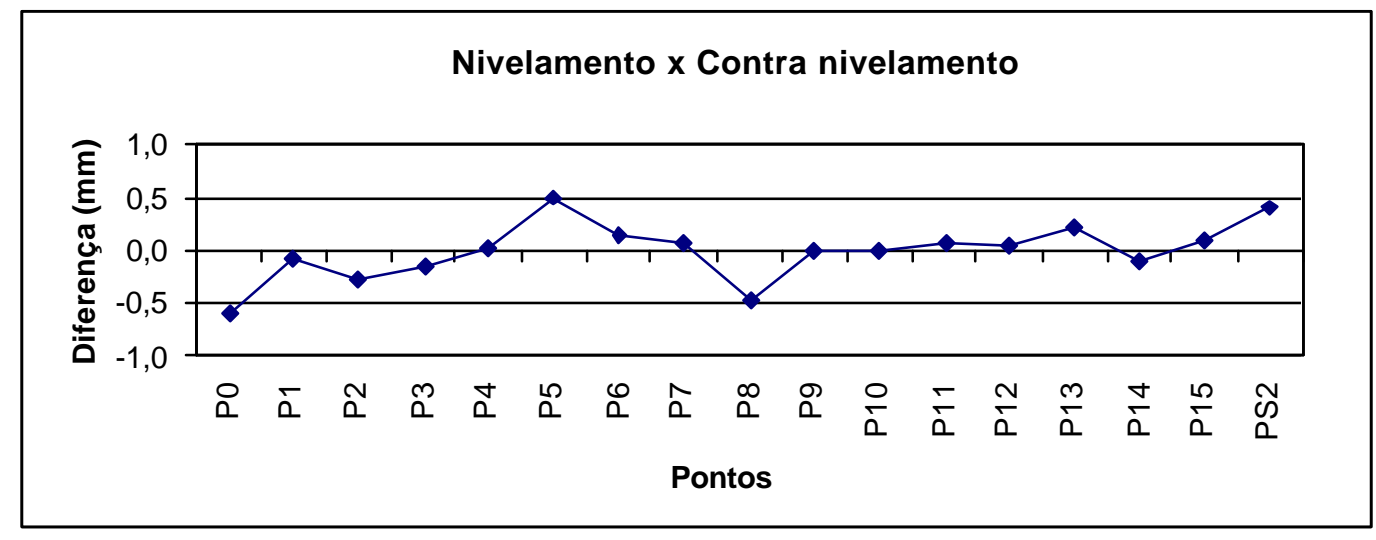

Gráfico 8.1 - Diferença dos desníveis do nivelamento e contranivelamento.

\subsection{Nivelamento com GPS}

Os resultados de posicionamento dos pontos de segurança nos sistemas WGS-84 e SAD-69 e os valores das altitudes e ondulações geoidais determinados como descrito na seção 7.3.2. são apresentados nas Tabela 8.2 e 8.3.

Observou-se que a diferença entre os desníveis obtidos por nivelamento geométrico e os obtidos por GPS, com a ondulação geoidal interpolada através do programa Mapgeo, foi de $26 \mathrm{~mm}$ o que significa uma precisão de $32 \mathrm{~mm} \cdot \sqrt{L(\mathrm{~km})}$, maior que a tolerância para o nivelamento IIN, $20 \mathrm{~mm} \cdot \sqrt{K(\mathrm{~km})}=16,4 \mathrm{~mm}$.

Tabela 8.2 - Coordenadas geodésicas

\begin{tabular}{|c|c|c|c|c|c|c|}
\hline \multirow[b]{2}{*}{ Pontos } & \multicolumn{3}{|c|}{ Sistema WGS-84 } & \multicolumn{3}{|c|}{ Sistema SAD-69 } \\
\hline & Latitude & Longitude & $\begin{array}{c}\text { Altura } \\
\text { Geométrica } \\
\end{array}$ & Latitude & Longitude & $\begin{array}{c}\text { Altura } \\
\text { Geométrica }\end{array}$ \\
\hline PS1 & $-21^{\circ} 48^{\prime} 30,739 "$ & $47^{\circ} 54^{\prime} 19,263^{\prime \prime}$ & 696,497 & $-21^{\circ} 48^{\prime} 29,010^{\prime \prime}$ & $-47^{\circ} 54^{\prime} 17,638^{\prime \prime}$ & 703,898 \\
\hline \multirow[t]{2}{*}{ PS2 } & $-21^{\circ} 48^{\prime} 08,922 "$ & $-47^{\circ} 54^{\prime} 15,448^{\prime \prime}$ & 694,922 & $-21^{\circ} 48^{\prime} 07,192 "$ & $-47^{\circ} 54^{\prime} 13,823^{\prime \prime}$ & 702,329 \\
\hline & & Dif. de Nível = & $-1,575$ & & Dif. de Nível = & $-1,569$ \\
\hline
\end{tabular}


Tabela 8.3 - Altura geométrica e altitude ortométrica

\begin{tabular}{cccc}
\hline Pontos & $\begin{array}{c}\text { Altura } \\
\text { Geométrica } \\
\text { SAD-69 }\end{array}$ & $\begin{array}{c}\text { Ondulação } \\
\text { Geoidal }\end{array}$ & $\begin{array}{c}\text { Altitude } \\
\text { Ortométrica }\end{array}$ \\
\hline PS1 & 703,898 & $-3,35$ & 707,248 \\
PS2 & 702,329 & $-3,33$ & 705,659 \\
\hline & & Dif. De Altitude $=$ & $-1,589$ \\
\hline
\end{tabular}

\subsection{Nivelamento Trigonométrico}

Os levantamentos de campo com a estação TC400 foram feitos durante o mês de setembro/2002 e início de dezembro/2002, num total de 5 dias em que a temperatura variou de 16,5 a $34^{\circ} \mathrm{C}$, sendo que dois terço do tempo foi superior a $25 \mathrm{C}$ e $70 \%$ das observações foram feitas com intensidade solar média a forte e o restante com sol fraco e nublado.

Com a estação TC307 os dados foram obtidos em abril/2003, durante dois dias em que a variação temperatura foi 20 a $31^{\circ} \mathrm{C}$ e em $70 \%$ do tempo superior a $25^{\circ} \mathrm{C}$. Durante as observações, $43 \%$ delas foram feitas com céu nublado e o restante com média intensidade solar.

\subsubsection{Visadas unilaterais}

\subsubsection{Altura do instrumento}

A Tabela 8.4 e o Gráfico 8.2 mostram a diferença na altura do instrumento obtida por trena e por nivelamento, conforme descrito na seção 7.3.3.3. Observou-se uma certa uniformidade nas alturas para a estação TC307.

Isso ocorreu por que no nivelamento realizado com a estação total TC400, utilizou-se uma trena convencional com fita de fibra e o posicionamento do "zero de referência" no ponto é mais susceptível a erros como mostra a Figura 8.1, já durante o levantamento com a TC307 utilizou-se uma trena de aço em que o "zero" é no topo da fita, não necessitando dobrá-la sobre o ponto. Esse deve ser um dos cuidados a serem tomados na obtenção da altura do instrumento com trena. 
De um modo geral o desvio em relação a altura do instrumento obtida por nivelamento ficou em torno de $1 \mathrm{~mm}$ para a estação TC400 e $0,7 \mathrm{~mm}$ para a TC307. A variação abrupta que aparece no ponto P13 ocorreu porque este ponto foi deslocado e isso influenciou também as diferenças de níveis para este ponto e as obtidas a partir dele.

Tabela 8.4 - Diferença entre altura do instrumento medida à trena e por nivelamento

\begin{tabular}{|c|c|c|c|c|c|c|c|c|c|c|c|c|c|c|c|c|c|c|}
\hline \multirow{2}{*}{ Estação } & P0 & P1 & P2 & P3 & P4 & P5 & P6 & P7 & P8 & P9 & P10 & P11 & P12 & P13 & P14 & P15 & \multicolumn{2}{|c|}{ Desvio } \\
\hline & \multicolumn{16}{|c|}{ Diferença $(\mathrm{mm})$} & Todos & sem $\mathrm{P} 13$ \\
\hline TC400 & 0,9 & 0,2 & $-1,9$ & 0,4 & $-0,6$ & 0,5 & $-0,9$ & $-0,6$ & 1,8 & 1,2 & $-0,8$ & 0,9 & $-0,1$ & 5,0 & 1,2 & $-0,3$ & 1,6 & 1,0 \\
\hline TC307 & $-0,8$ & $-0,9$ & $-0,7$ & $-0,5$ & $-0,1$ & $-0,7$ & $-0,3$ & $-0,3$ & $-0,2$ & $-0,5$ & 0,0 & $-0,3$ & $-1,8$ & 2,5 & 0,1 & $-0,5$ & 0,9 & 0,7 \\
\hline
\end{tabular}

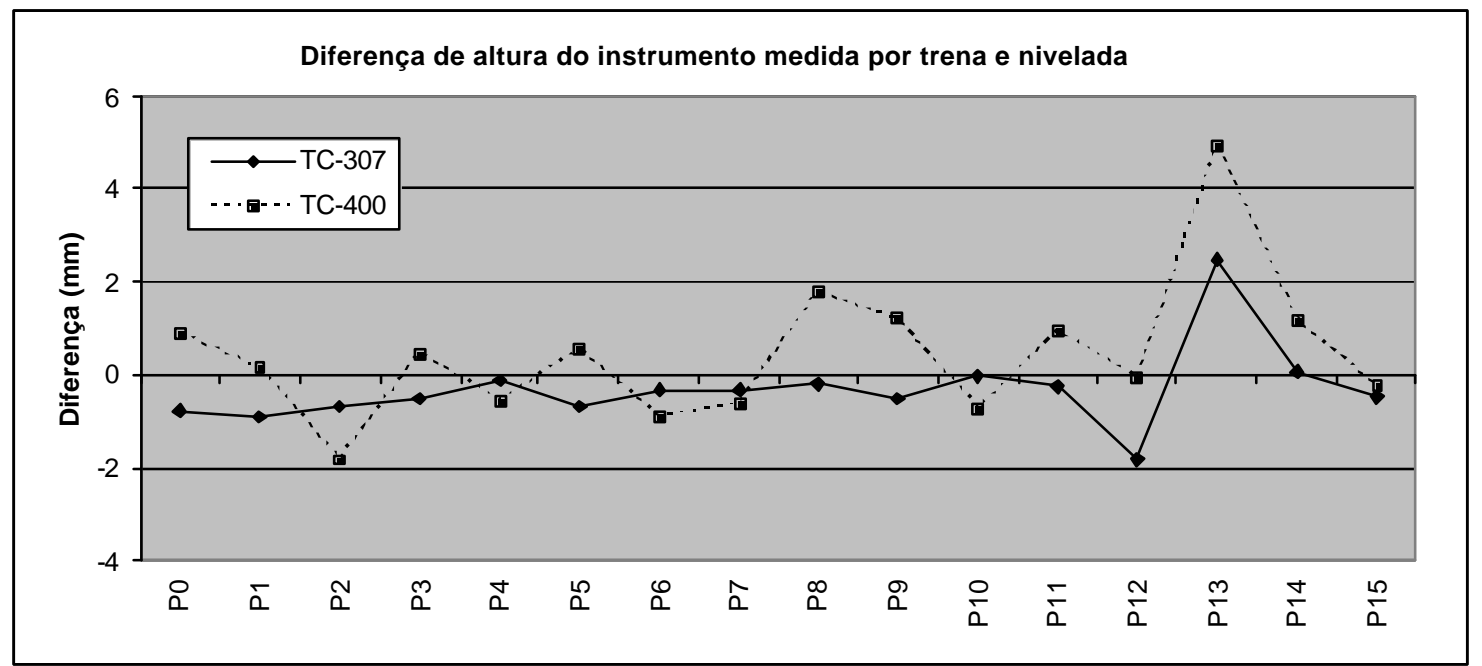

Gráfico 8.2 - Diferença de altura do instrumento medida por trena e nivelada

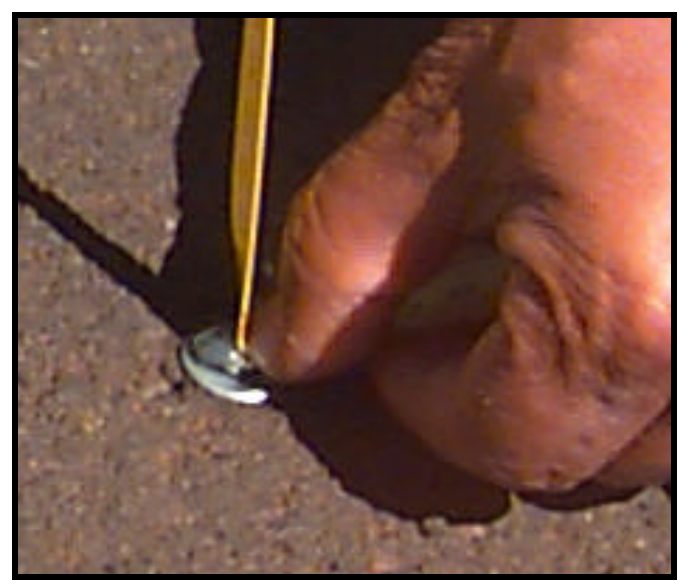

(a)

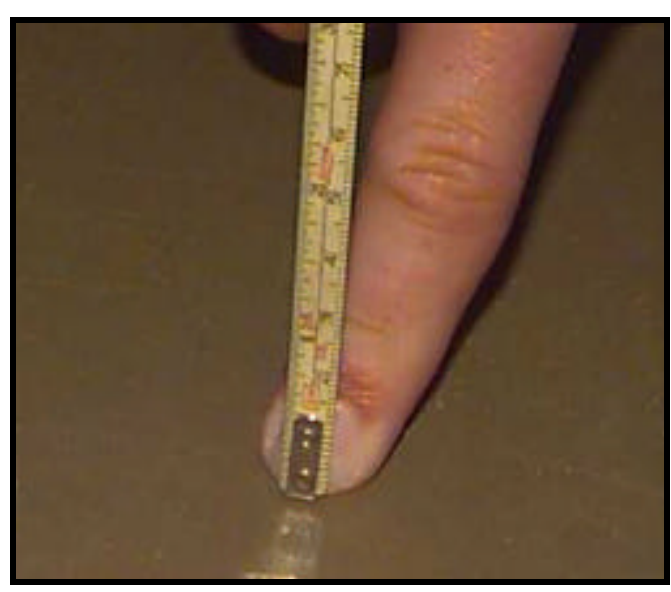

(b)

Figura 8.1 - Detalhe do posicionamento do "zero de referência" da trena no ponto. 


\subsubsection{Linha de visada próxima do solo}

Na Tabela 8.5 apresentam-se as alturas em que a linha de visada de alguns segmentos encontra-se acima do solo em determinados pontos. Os valores foram obtidos considerando a altura do instrumento e do alvo com 1,55 metros. Essas informações ajudaram a compreender algumas diferenças bruscas entre as cotas do nivelamento trigonométrico e as cotas de referências. A Figura 8.2 ilustra a situação mais crítica em que a linha de visada passou a apenas $9 \mathrm{~cm}$ acima do solo.

Tabela 8.5 - Altura da linha de visada em relação ao solo

\begin{tabular}{|c|c|c|c|c|c|c|c|}
\hline \multirow{2}{*}{\multicolumn{2}{|c|}{ Linha de Visada }} & \multicolumn{5}{|c|}{ Altura do solo $(\mathrm{cm})$} & \multirow{3}{*}{$\begin{array}{c}\begin{array}{c}\text { Distância } \\
\text { (m) }\end{array} \\
160\end{array}$} \\
\hline & & \multirow{2}{*}{$\frac{\mathbf{P 0}}{101}$} & \multirow{2}{*}{$\frac{\mathbf{P 1}}{76}$} & \multirow{2}{*}{$\frac{\mathbf{P 2}}{99}$} & \multirow[t]{2}{*}{ P3 } & \multirow[t]{2}{*}{ P4 } & \\
\hline P3 & - PS1 & & & & & & \\
\hline P4 & - PS1 & 52 & 63 & 102 & & & 200 \\
\hline P5 & - PS1 & 83 & 40 & 44 & 77 & & 240 \\
\hline P6 & - PS1 & 87 & 47 & 55 & 90 & & 280 \\
\hline \multirow[t]{2}{*}{$\mathrm{P} 7$} & - PS1 & 98 & 70 & 89 & 139 & & 320 \\
\hline & & P11 & P12 & P13 & P14 & P15 & \\
\hline P12 & - PS2 & & & 95 & 80 & 95 & 160 \\
\hline P11 & - PS2 & & 95 & 53 & 53 & 83 & 200 \\
\hline P10 & - PS2 & 95 & 50 & 20 & 31 & 72 & 240 \\
\hline P9 & - PS2 & 76 & 36 & 9 & 23 & 69 & 280 \\
\hline P8 & - PS2 & & 67 & 33 & 39 & 77 & 320 \\
\hline P7 & - PS2 & & & 77 & 68 & 91 & 360 \\
\hline P10 & - P15 & & 80 & 66 & 92 & & 200 \\
\hline P9 & - P15 & 103 & 76 & 64 & 90 & & 240 \\
\hline
\end{tabular}

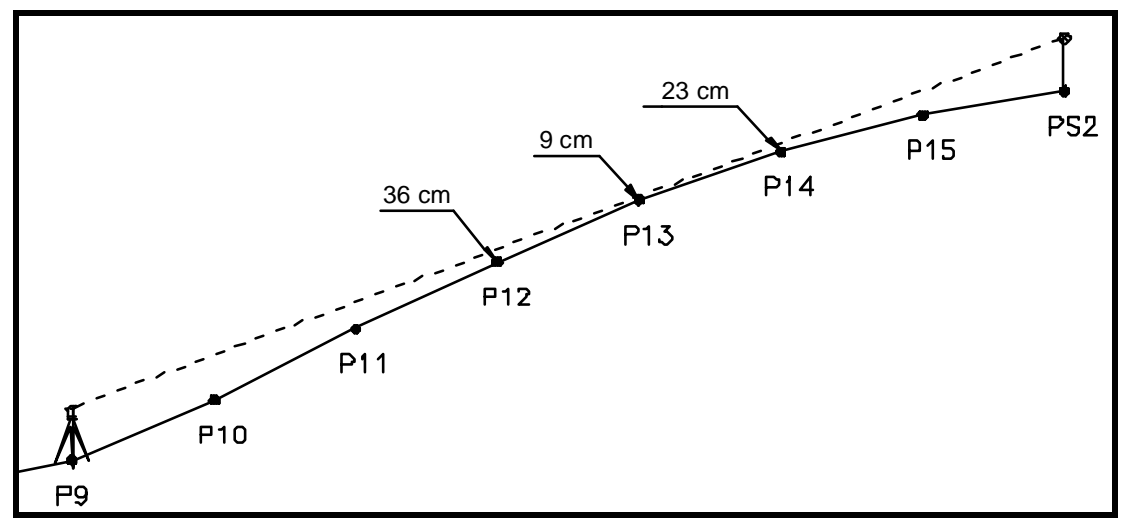

Figura 8.2 - Altura da linha de visada da estação P9 ao ponto PS2 


\subsubsection{Avaliação das condições}

O erro padrão das cotas do nivelamento trigonométrico em relação às cotas de referências, em função das distâncias de visadas e das condições avaliadas, são mostrados nas Tabelas 8.6 e 8.7. Observou-se que a condição que apresenta menor média dos erros padrão é a condição C15 e a maior é a C2. Estes resultados estão em conformidade com a situação de melhor e pior condição, conforme apresentado na Tabela 7.2.

A correção atmosférica do ângulo de refração e a curvatura da terra são os mais significativos, ao passo que a correção atmosférica da distância não influenciou nos desníveis nem para distância de 520m, conforme demonstrado na seção 4.3.1.3, como foi observado comparando as condições C1, C2, C3, C4, C9, C10, C11 e C12, a C5, C6, C7; C8, C13, C14, C15 e C16 respectivamente.

As condições C13, C14, C15 e C16 comparadas com as C5, C6, C7 e C8 respectivamente refletem a diferença da altura do instrumento medido por nivelamento e com trena, como retrata a Tabela 8.4. O Gráfico 8.3 mostrou que a estação TC307 apresentou erro médio menor que a TC400, resultado coerente com a precisão angular dos equipamentos.

Tabela 8.6 - Erro padrão x distância x condição avaliada TC400

\begin{tabular}{|c|c|c|c|c|c|c|c|c|c|c|c|c|c|c|c|c|}
\hline \multirow{2}{*}{ Distância } & \multicolumn{16}{|c|}{ Condições } \\
\hline & C1 & $\mathrm{C} 2$ & C3 & C4 & C5 & C6 & C7 & $\mathrm{C} 8$ & $C 9$ & C10 & C11 & C12 & C13 & C14 & C15 & C16 \\
\hline 40 & 2,2 & 2,2 & 2,2 & 2,2 & 2,2 & 2,2 & 2,2 & 2,2 & 1,5 & 1,7 & 1,6 & 1,7 & 1,5 & 1,7 & 1,6 & 1,7 \\
\hline 80 & 2,6 & 2,6 & 2,6 & 2,5 & 2,6 & 2,6 & 2,5 & 2,5 & 1,9 & 1,9 & 1,9 & 1,8 & 1,8 & 1,9 & 1,8 & 1,8 \\
\hline 120 & 2,7 & 3,3 & 2,5 & 3,0 & 2,7 & 3,2 & 2,4 & 3,0 & 2,1 & 2,6 & 1,8 & 2,3 & 2,0 & 2,5 & 1,8 & 2,2 \\
\hline 160 & 3,7 & 3,7 & 3,0 & 3,1 & 3,6 & 3,7 & 2,9 & 3,1 & 3,3 & 3,4 & 2,5 & 2,8 & 3,2 & 3,3 & 2,4 & 2,7 \\
\hline 200 & 4,8 & 4,7 & 3,4 & 4,0 & 4,8 & 4,7 & 3,4 & 4,0 & 4,4 & 4,3 & 3,0 & 3,6 & 4,4 & 4,3 & 3,0 & 3,5 \\
\hline 240 & 6,2 & 6,7 & 4,2 & 4,9 & 6,2 & 6,7 & 4,2 & 4,9 & 5,4 & 6,0 & 3,3 & 4,1 & 5,4 & 6,0 & 3,3 & 4,1 \\
\hline 280 & 7,4 & 8,3 & 4,7 & 5,6 & 7,4 & 8,4 & 4,8 & 5,7 & 6,8 & 8,0 & 3,9 & 5,3 & 6,8 & 8,0 & 3,9 & 5,3 \\
\hline 320 & 10,3 & 10,2 & 4,9 & 5,0 & 10,3 & 10,2 & 5,0 & 5,0 & 10,1 & 10,0 & 4,5 & 4,8 & 10,1 & 10,0 & 4,6 & 4,9 \\
\hline 360 & 12,1 & 14,0 & 5,8 & 7,2 & 12,0 & 13,9 & 5,7 & 7,1 & 11,6 & 13,6 & 5,1 & 6,6 & 11,5 & 13,5 & 5,0 & 6,5 \\
\hline 400 & 15,8 & 14,1 & 7,6 & 8,4 & 15,7 & 14,0 & 7,6 & 8,4 & 15,5 & 13,7 & 7,3 & 8,1 & 15,4 & 13,7 & 7,2 & 8,1 \\
\hline 440 & 16,7 & 16,7 & 7,9 & 8,4 & 16,7 & 16,7 & 7,9 & 8,5 & 16,2 & 16,2 & 7,3 & 7,8 & 16,2 & 16,2 & 7,3 & 7,8 \\
\hline 480 & 18,7 & 19,0 & 8,5 & 10,4 & 18,7 & 18,9 & 8,5 & 10,4 & 18,3 & 18,6 & 8,4 & 10,5 & 18,3 & 18,6 & 8,5 & 10,5 \\
\hline 520 & 26,1 & 28,9 & 12,0 & 15,1 & 26,0 & 28,9 & 12,0 & 15,1 & 25,1 & 28,2 & 11,0 & 14,6 & 25,1 & 28,2 & 10,9 & 14,6 \\
\hline Média & 9,9 & 10,3 & 5,3 & 6,1 & 9,9 & 10,3 & 5,3 & 6,1 & 9,4 & 9,9 & 4,7 & 5,7 & 9,4 & 9,8 & 4,7 & 5,7 \\
\hline
\end{tabular}


Tabela 8.7 - Erro padrão x distância x condição avaliada - TC307

\begin{tabular}{|c|c|c|c|c|c|c|c|c|c|c|c|c|c|c|c|c|}
\hline \multirow{2}{*}{ Distância } & \multicolumn{16}{|c|}{ Condições } \\
\hline & C1 & C2 & C3 & C4 & C5 & C6 & C7 & C8 & C9 & C10 & C11 & C12 & C13 & C14 & C15 & C16 \\
\hline 40 & 1,7 & 1,8 & 1,7 & 1,8 & 1,7 & 1,8 & 1,7 & 1,8 & 1,2 & 1,3 & 1,2 & 1,3 & 1,2 & 1,3 & 1,2 & 1,3 \\
\hline 80 & 1,8 & 1,7 & 1,9 & 1,9 & 1,8 & 1,7 & 1,9 & 1,9 & 1,3 & 1,3 & 1,5 & 1,4 & 1,3 & 1,2 & 1,4 & 1,4 \\
\hline 120 & 2,0 & 2,3 & 2,0 & 2,2 & 2,0 & 2,3 & 2,0 & 2,2 & 1,7 & 1,8 & 1,6 & 1,7 & 1,8 & 1,9 & 1,7 & 1,7 \\
\hline 160 & 2,5 & 2,8 & 2,4 & 2,6 & 2,6 & 2,8 & 2,5 & 2,6 & 2,3 & 2,6 & 2,0 & 2,2 & 2,4 & 2,6 & 2,1 & 2,3 \\
\hline 200 & 4,2 & 4,5 & 3,3 & 3,4 & 4,2 & 4,6 & 3,3 & 3,5 & 4,1 & 4,6 & 3,1 & 3,4 & 4,1 & 4,6 & 3,1 & 3,5 \\
\hline 240 & 5,7 & 6,1 & 3,7 & 4,1 & 5,7 & 6,1 & 3,7 & 4,1 & 5,6 & 6,0 & 3,3 & 3,8 & 5,6 & 5,9 & 3,4 & 3,8 \\
\hline 280 & 6,9 & 6,5 & 4,2 & 3,9 & 6,9 & 6,5 & 4,2 & 3,9 & 6,9 & 6,4 & 4,0 & 3,6 & 6,9 & 6,5 & 4,0 & 3,6 \\
\hline 320 & 7,8 & 9,2 & 4,3 & 5,1 & 7,8 & 9,2 & 4,2 & 5,0 & 7,8 & 9,3 & 4,1 & 5,0 & 7,8 & 9,3 & 4,1 & 5,0 \\
\hline 360 & 10,3 & 9,4 & 4,9 & 4,7 & 10,2 & 9,3 & 4,8 & 4,6 & 10,3 & 9,5 & 4,7 & 4,6 & 10,3 & 9,4 & 4,7 & 4,5 \\
\hline 400 & 9,9 & 10,0 & 5,6 & 5,6 & 9,9 & 10,0 & 5,6 & 5,7 & 9,9 & 10,2 & 5,3 & 5,8 & 9,9 & 10,2 & 5,4 & 5,9 \\
\hline 440 & 11,2 & 13,2 & 4,9 & 6,4 & 11,1 & 13,2 & 5,0 & 6,3 & 11,3 & 13,2 & 4,7 & 5,9 & 11,3 & 13,2 & 4,7 & 5,8 \\
\hline 480 & 14,4 & 14,8 & 4,3 & 6,7 & 14,4 & 14,8 & 4,3 & 6,8 & 14,5 & 15,2 & 3,6 & 7,0 & 14,5 & 15,2 & 3,7 & 7,1 \\
\hline 520 & 15,9 & 20,8 & 5,8 & 5,7 & 15,9 & 20,7 & 5,9 & 5,8 & 16,0 & 20,9 & 5,1 & 5,4 & 16,0 & 20,9 & 5,2 & 5,5 \\
\hline Média & 7,2 & 7,9 & 3,7 & 4,2 & 7,2 & 7,9 & 3,8 & 4,2 & 7,1 & 7,9 & 3,4 & 3,9 & 7,2 & 7,9 & 3,4 & 4,0 \\
\hline
\end{tabular}

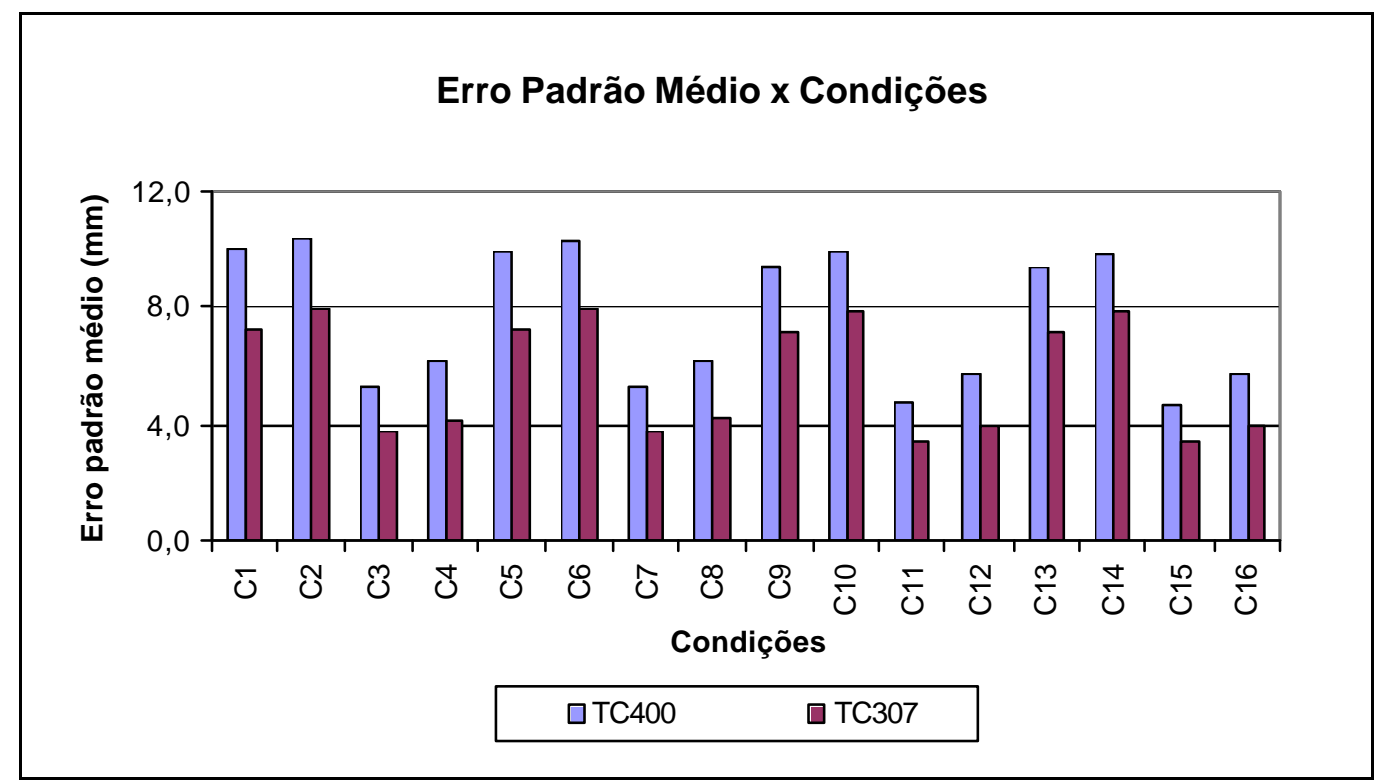

Gráfico 8.3 - Média dos erros padrões do nivelamento com TC400 e TC307

Os Gráficos 8.4 e 8.5 apresentam as diferenças entre as médias dos erros padrões mostrados nas Tabelas 8.6 e 8.7, considerando as combinações em que apenas uma condição foi alterada e as outras três condições foram mantidas.

Observou-se que fazer ou não a correção da refração atmosférica da distância não implica em diferenças no nivelamento para distâncias até 520 metros, confirmando o que foi discutido na seção 4.3.1.3, já a correção atmosférica do ângulo de refração e a curvatura da terra tem os efeitos mais significativos. 
Manter o Bastão apoiado por bipé ou segurá-lo com as mãos apresenta diferença inferior à $1 \mathrm{~mm}$ para distâncias até 240 metros e menor que $2 \mathrm{~mm}$ em distâncias de até 480 metros. Esse efeito pode estar associado também à visibilidade do alvo, considerando que a definição do centro do prisma fica indefinido para distâncias superiores a 280 metros e o movimento pode causar erro de pontaria.

Para a avaliação dos comprimentos de visadas consideroutse as combinações que foram realizadas a correção atmosférica e curvatura da terra, reduzindo-se a oito combinações. Dessas escolheu-se as duas que apresentavam a combinação mais favorável, C15, e a mais desfavorável, C4.

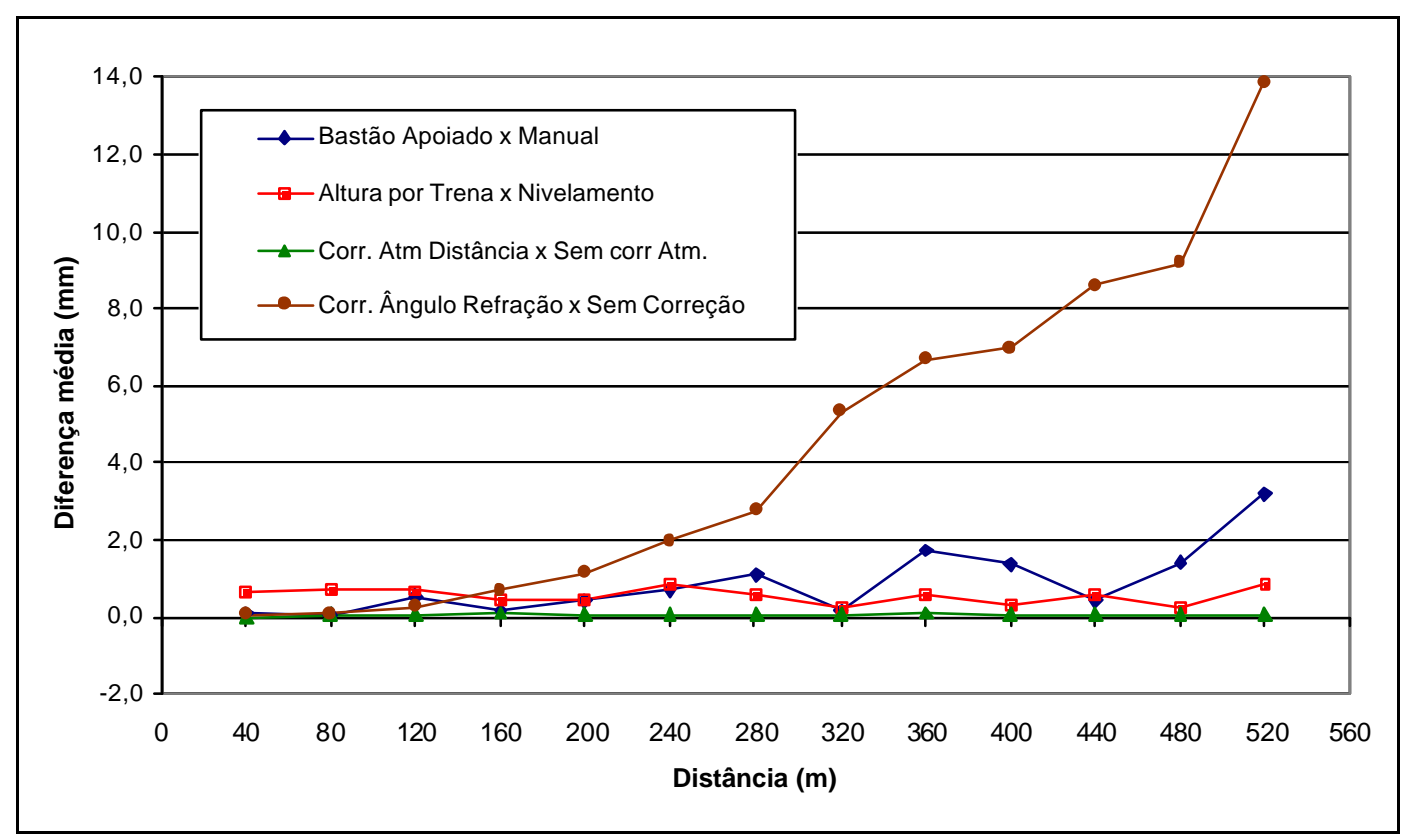

Gráfico 8.4 - Diferença média x distância x combinação - TC400 


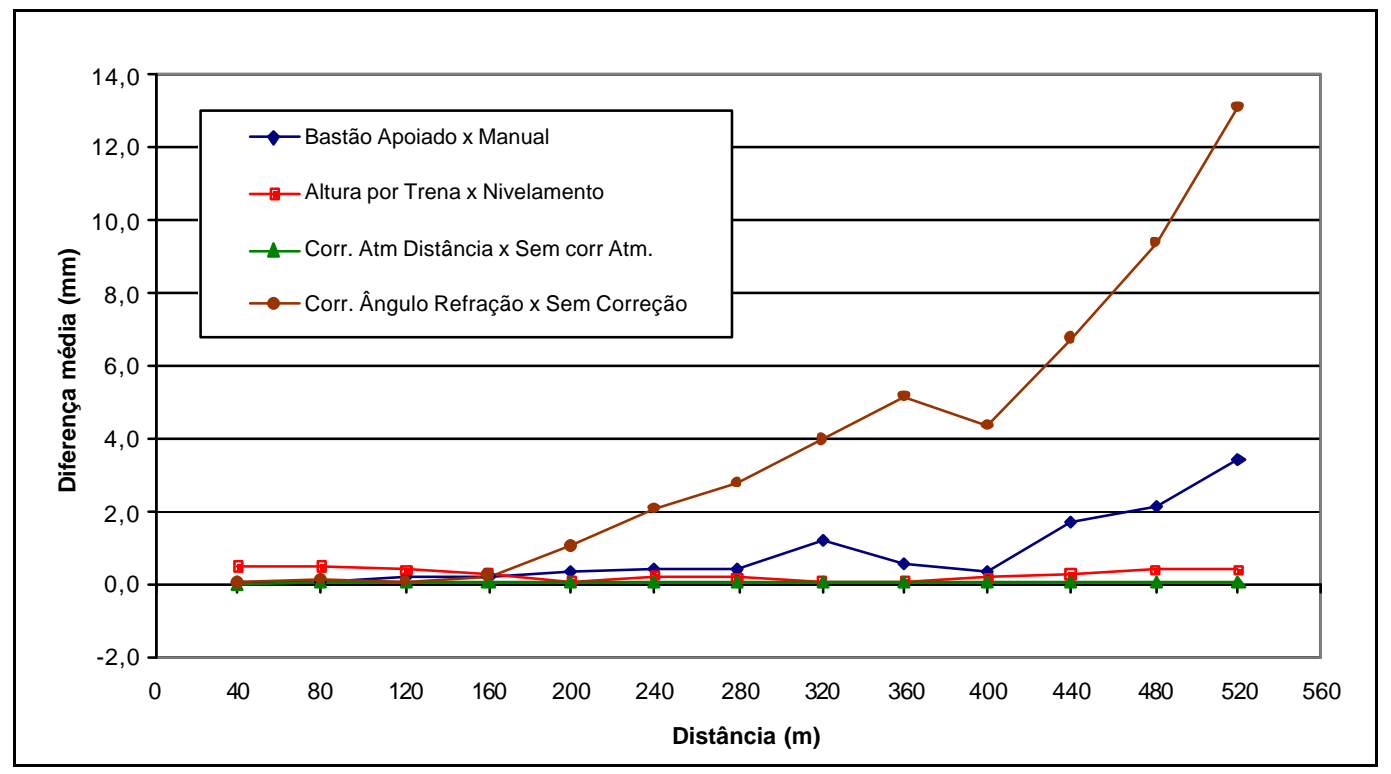

Gráfico 8.5 - Diferença média x distância x conbinação - TC307

\subsubsection{Avaliação das distâncias}

As diferenças entre as cotas do nivelamento trigonométrico e as cotas de referências para diferentes distâncias de visadas, com as duas estações totais, nas condições C4 e C15 são apresentadas nos Gráficos 9.1a, 9.1b, 9.1c, 9.2a, 9.2b e 9.2c no apêndice A.

Nas visadas de 200, 240 e 280 metros aos pontos PS1 e PS2 a linha de visada passou a menos de $60 \mathrm{~cm}$ acima do solo, como mostra a Tabela 8.5. O mesmo aconteceu com o ponto P9 e PS2 nas visadas de 240 e 320 metros, respectivamente. Isso explica os picos que ocorreram nestes pontos, pois muito próximo do solo o índice de refração é muito mais inconstante.

Os pontos P7, P6, P5, P4, P3, P2, P2, P1, P0 e PS1 visados com distâncias de 160, 200, 240, 280, 320, 360, 400, 440 e 480m respectivamente, com a estação TC307 estacionada no P11 apresentaram forte desvio. Esses pontos foram nivelados das 16:44h até as $17: 54 \mathrm{~h}$ e a temperatura variou de $20^{\circ} \mathrm{C}$ a $16,5^{\circ} \mathrm{C}$ ocasionando alteração rápida no fluxo de calor e conseqüentemente do índice de refração. Estes resultados estão de acordo com MEDEIROS (1999) que sugere evitar os nivelamentos nas duas primeiras horas após o sol nascer e nas duas horas que antecede o por do sol.

Deve-se então estar atento, pois no anseio de concluir uma atividade de nivelamento trigonométrico ao final da tarde, para evitar um retorno no dia seguinte, 
pode-se estar adicionando erros, que a depender da magnitude, exija uma nova volta ao campo com muito mais custos.

O Gráfico 8.6 apresenta a avaliação da distância para o nivelamento trigonométrico considerando a tolerância do nivelamento geométrico IIN definida pela plotagem dos valores da Tabela 4.8, calculados pela equação (4.39). O erro do nivelamento trigonométrico obtido pela propagação de erros, conforme equação (4.31), para as estações TC307 e TC400, conforme apresentado na Tabelas 4.9 e 4.10.

Observou-se neste gráfico que a distância máxima de visada em que o erro do nivelamento trigonométrico é inferior a tolerância do nivelamento geométrico IIN é de 160 e 320 metros para estações com precisão equivalente a TC400 e TC307, respectivamente.

As avaliações da distância considerando os resultados experimentais estão apresentadas nos Gráficos 8.7, 8.8, 8.9 e 8.10. Em cada gráfico são mostradas três curvas por equipamentos, $1 \mathrm{~S}, 2 \mathrm{~S}$ e $3 \mathrm{~S}$, que correspondem a uma, duas e três vezes, respectivamente, o erro padrão encontrado A Tabela 8.8 resume os valores encontrados nestes gráficos para as duas estações em cada uma das situações avaliadas. $\mathrm{O}$ valor de 3S da estação TC307 na condição C15 pode até ser considerado 240, mas a curva corta a curva tolerância perto de 200 metros.

Tabela 8.8 - Distâncias de visadas obtidas dos Gráficos 8.7, 8.8, 8.9 e 8.10

\begin{tabular}{cccc|ccc}
\hline \multicolumn{7}{c}{ Distância Máxima de Visada (m) } \\
\hline \multirow{2}{*}{ Estação } & \multicolumn{7}{c}{ C15 } \\
\cline { 2 - 7 } & $1 \mathrm{~S}$ & $2 \mathrm{~S}$ & $3 \mathrm{~S}$ & $1 \mathrm{~s}$ & $2 \mathrm{~S}$ & $3 \mathrm{~S}$ \\
\hline TC400 & $>520$ & 360 & 200 & 480 & 240 & - \\
TC307 & $>520$ & 520 & 200 & 520 & 480 & 160 \\
\hline
\end{tabular}

Considerando que os levantamentos representam um período curto de poucos dias, apesar de feitos em meses diferentes, e com variação das condições atmosférica não muito intensa, é possível conseguir a precisão do nivelamento IIN com visadas de 160 e 320 metros para equipamentos de baixa e média precisão conforme Gráfico 8.6.

Apesar dos resultados experimentais evidenciarem que com distâncias de 360 e 520 metros, para equipamentos de 10" e 7" de precisão, respectivamente, os erros não ultrapassaram a tolerância do nivelamento geométrico IIN, deve-se ser conservador na 
definição do limite de distância, pois as condições ambientais são imprevisíveis e o valor constante do coeficiente de refração "k" é válido nas situação de atmosfera sem turbulência ou no estado neutro. (SCHAAL, 1995).

No entanto, mesmo não sendo possível extrapolar os resultados obtidos para qualquer situação, eles confirmam com folga a avaliação teórica, em que é possível obter a precisão do nivelamento trigonométrico com distâncias de visadas de 160 e 320 metros com equipamentos de baixa e média precisão, respectivamente.

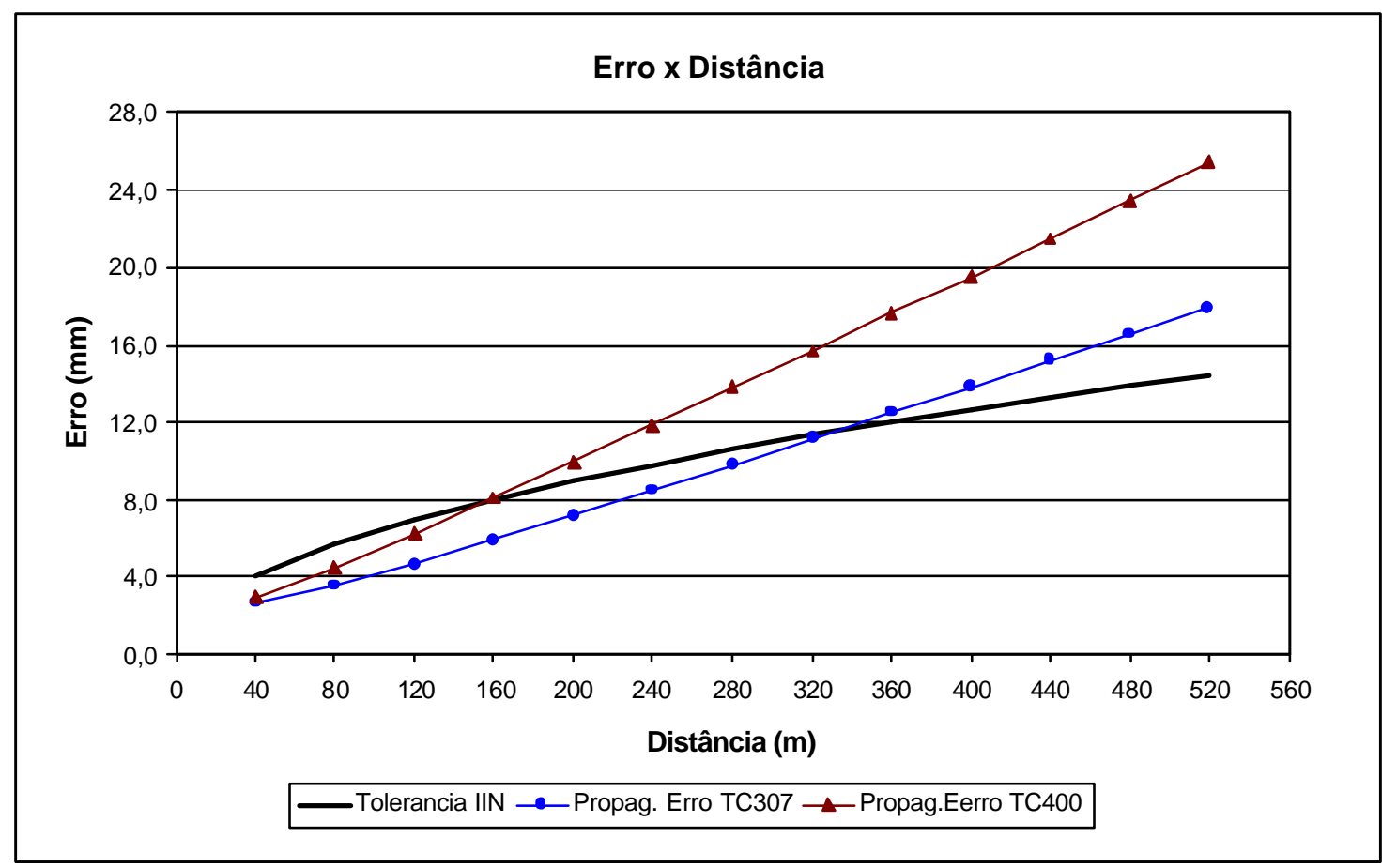

Gráfico 8.6 - Erro do nivelamento trigonométrico e tolerância do nivelamento geométrico IIN 
Erro Padrão x Distância - C15

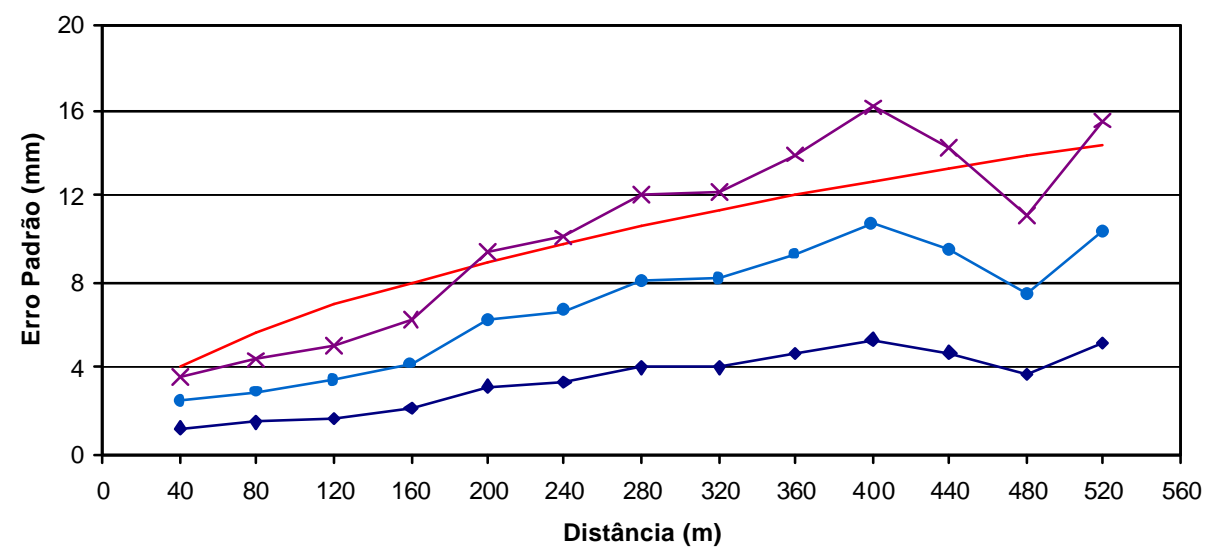

Tolerancia IIN ๑ャTC307 1S •-TC307 2S * TC307 3S

Gráfico 8.7 - Erro padrão do nivelamento trigonométrico na condição C15 - TC307

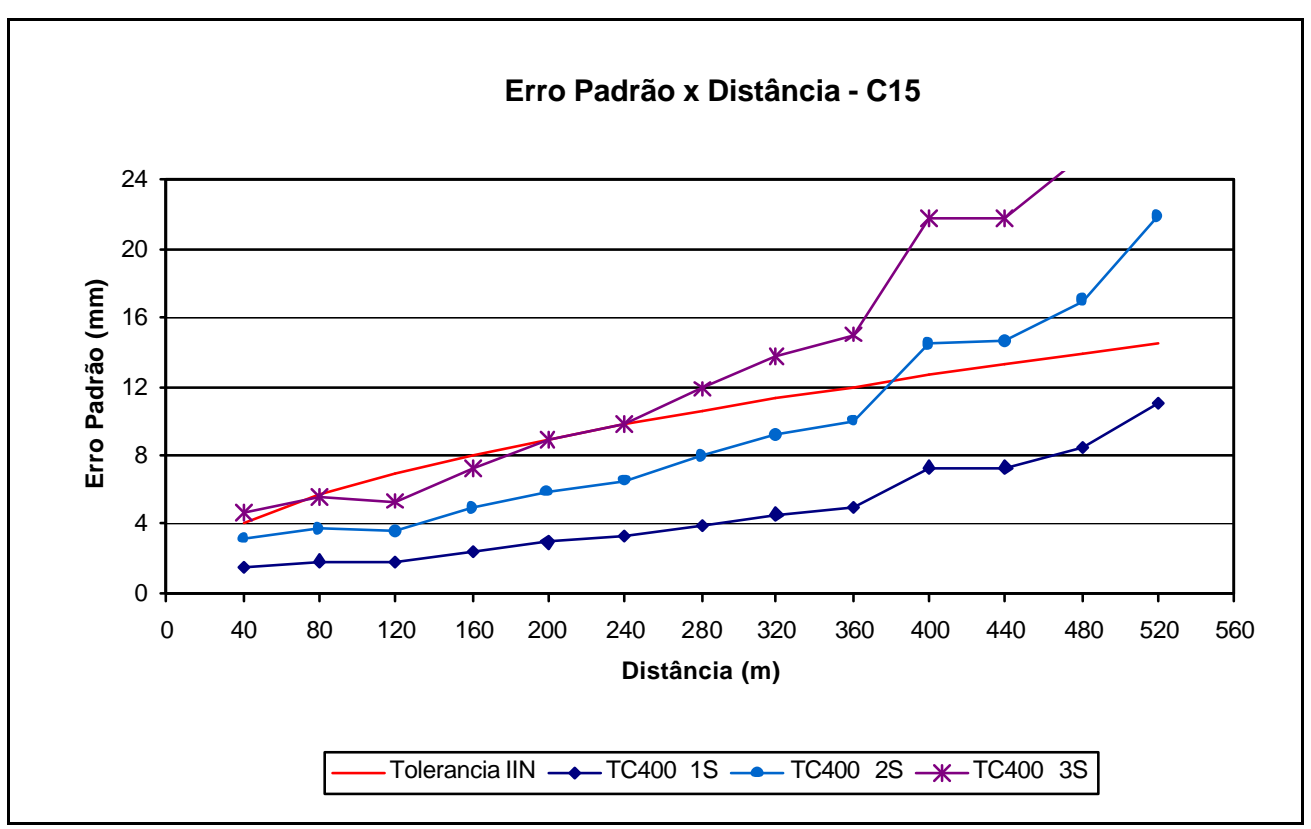

Gráfico 8.8 - Erro padrão do nivelamento trigonométrico na condiçãa C15 - TC400 


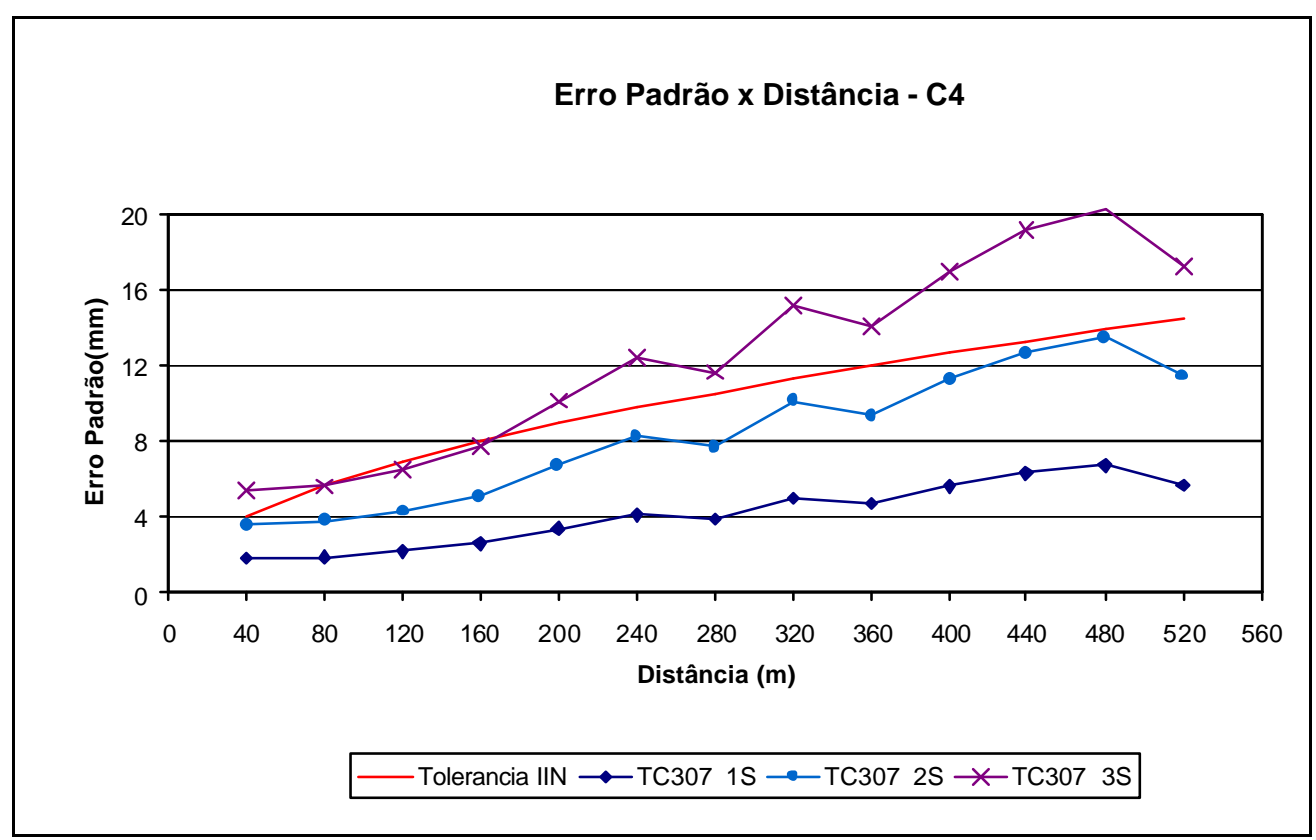

Gráfico 8.9 - Erro padrão do nivelamento trigonométrico na condição C4 - TC400

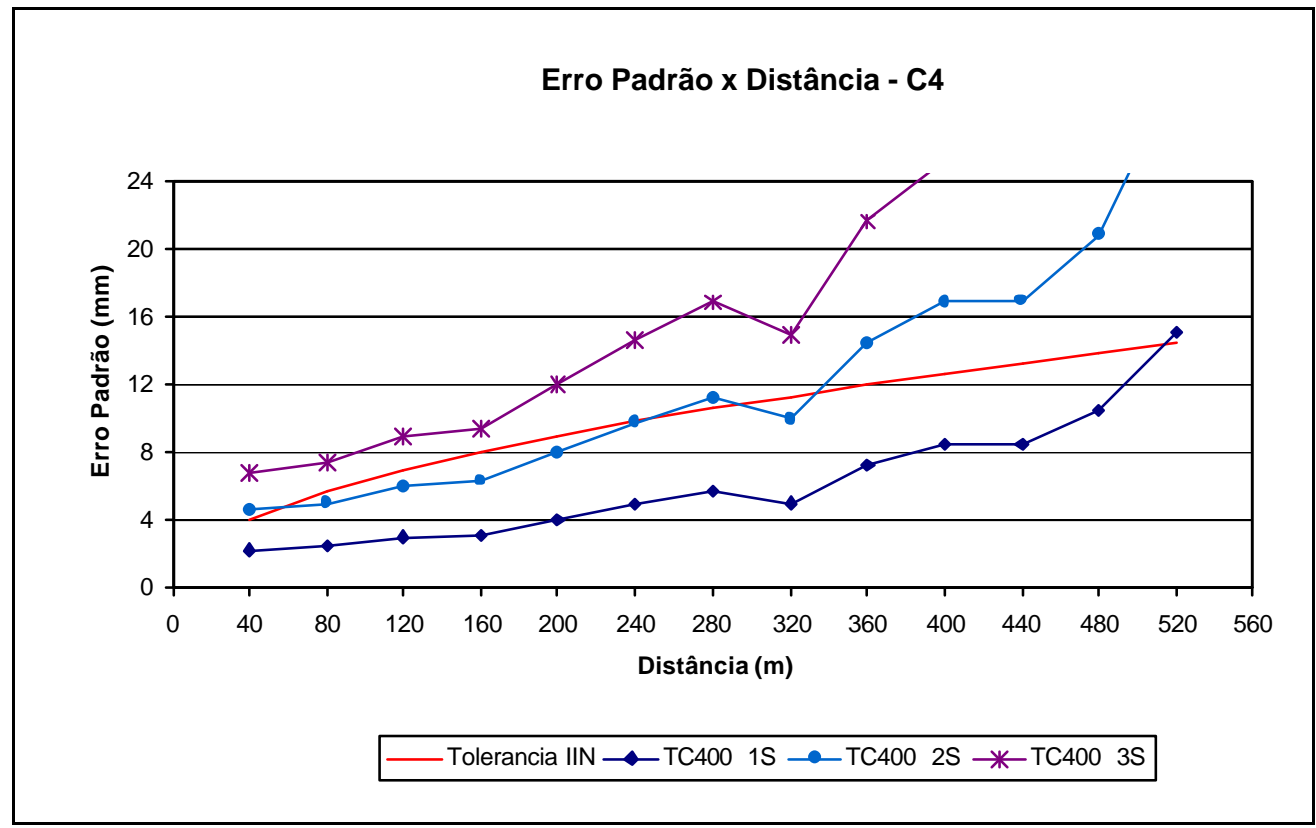

Gráfico 8.10 - Erro padrão do nivelamento trigonométrico na condição C4 - TC400 


\subsubsection{Leap-frog}

Todos os resultados obtidos por nivelamento trigonométrico, nas 31 combinações mostradas na Tabela 5.8, foram comparados com as diferenças de níveis do nivelamento geométrico. Em função do comportamento dos erros frente às condições impostas, foram estabelecidos os limites em que os dois métodos de nivelamento apresentaram precisões equivalentes.

\subsubsection{Seções niveladas}

No nivelamento "Leap-frog" calculou-se o desnível entre dois pontos extremos considerando visadas de 40, 80120 e 160 metros com 8, 4, 2 e 2 lances respectivamente. Os resultados mostram que os erros ficaram bem abaixo da tolerância para o nivelamento geométrico IIN com os dois equipamentos, conforme apresentado na Tabela 8.9.

Os resultados mostraram que para distâncias de até 160 metros os valores das duas estações concordaram até com o nivelamento IN, cuja tolerância é $8,3 \mathrm{~mm}$ para seção de 480 metros e 9,6mm para seção de 640 metros.

Tabela 8.9 - Ni velamento de uma seção com Leap-frog

\begin{tabular}{|c|c|c|c|c|c|}
\hline \multirow{2}{*}{$\begin{array}{l}\text { Distância } \\
\text { de Visada }\end{array}$} & \multirow{2}{*}{$\begin{array}{l}\mathrm{N}^{\circ} \text { de } \\
\text { Lances }\end{array}$} & \multirow{2}{*}{$\begin{array}{c}\text { Seção } \\
\text { (m) }\end{array}$} & \multicolumn{2}{|c|}{ Erro (mm) } & \multirow{2}{*}{$\begin{array}{c}\text { Tolerância } \\
\text { IIN }\end{array}$} \\
\hline & & & TC307 & TC400 & \\
\hline \multirow{2}{*}{40} & \multirow{2}{*}{8} & \multirow{2}{*}{640} & 1,2 & 1,6 & \multirow{2}{*}{16,4} \\
\hline & & & $-0,8$ & $-3,6$ & \\
\hline \multirow{2}{*}{80} & \multirow{2}{*}{4} & \multirow{2}{*}{640} & $-0,9$ & 4,3 & \multirow{2}{*}{16,4} \\
\hline & & & 1,8 & $-0,4$ & \\
\hline \multirow{5}{*}{120} & \multirow{5}{*}{2} & \multirow{5}{*}{480} & 0,6 & 7,5 & \multirow{5}{*}{13,8} \\
\hline & & & 3,1 & 1,0 & \\
\hline & & & 6,1 & 0,5 & \\
\hline & & & 3,3 & 0,9 & \\
\hline & & & 4,6 & 0,4 & \\
\hline \multirow{2}{*}{160} & \multirow{2}{*}{2} & \multirow{2}{*}{640} & $-1,4$ & 2,4 & \multirow{2}{*}{16,4} \\
\hline & & & 7,0 & 4,2 & \\
\hline
\end{tabular}




\subsubsection{Distâncias visadas}

A partir de distâncias de 200 metros não foi possível preparar uma seção com visadas seqüenciais como feito para as distâncias menores, entretanto a forma de avaliação será semelhante à utilizada no nivelamento com visadas unilaterais. Os valores de tolerâncias do nivelamento geométrico IN e IIN são os apresentados na Tabela 4.13 conforme discutido na seção 4.5.

Para as visadas de 200 e 240 metros comparou-se o erro padrão, pois foram feitas mais de 6 medições, já para as distâncias de 280 e 320 metros comparou-se com o maior erro observado. Entretanto na distância de 280 metros foi usado o segundo maior erro, pois o primeiro foi influenciado pela linha de visada passando a $9 \mathrm{~cm}$ do solo.

Conforme mostrado na Tabela 8.10, os resultados ficaram abaixo da tolerância para o nivelamento IIN em distâncias de até 320 metros com as duas estações. Para o nivelamento IN o mesmo ocorreu em distâncias de até 200 metros com os dois equipamentos. Os resultados foram melhores que os da avaliação da propagação de erro para o nivelamento IIN feito na seção 4.5 em que a distância de visada máxima foi de 160 e 320 metros para a TC400 e TC307, respectivamente.

Tabela 8.10 - Erros observado no nivelamento Leap-frog

\begin{tabular}{|c|c|c|c|c|c|c|}
\hline \multirow{2}{*}{ Estação } & \multirow{2}{*}{$\begin{array}{c}\text { Distância } \\
\text { visada }(m)\end{array}$} & \multirow{2}{*}{$\begin{array}{c}N^{\circ} \text { de } \\
\text { Medições }\end{array}$} & \multirow{2}{*}{$\begin{array}{l}\text { Erro Padrão } \\
(\mathrm{mm})\end{array}$} & \multirow{2}{*}{$\begin{array}{c}\text { Erro } \\
\text { Máximo } \\
(\mathrm{mm})\end{array}$} & \multicolumn{2}{|c|}{ Tolerância $(\mathrm{mm})$} \\
\hline & & & & & IN & IIN \\
\hline \multirow{4}{*}{ TC 400} & 200 & 8 & 7,1 & & 7,6 & 12,6 \\
\hline & 240 & 6 & 8,8 & & 8,3 & 13,9 \\
\hline & 280 & 4 & & 12,2 & 9,0 & 15,0 \\
\hline & 320 & 2 & & $-5,0$ & 9,6 & 16,0 \\
\hline \multirow{4}{*}{ TC 307} & 200 & 8 & 4,2 & & 7,6 & 12,6 \\
\hline & 240 & 6 & 9,4 & & 8,3 & 13,9 \\
\hline & 280 & 4 & & 8,2 & 9,0 & 15,0 \\
\hline & 320 & 2 & & $-7,5$ & 9,6 & 16,0 \\
\hline
\end{tabular}




\section{Considerações Finais e Conclusões}

Dentro do limite deste trabalho conclui-se que os resultados obtidos evidenciam ser possível realizar nivelamento trigonométrico com visadas unilaterais, com estações totais de baixa e média precisão, e obter resultados com erros inferiores às tolerâncias estabelecidas pela NBR 13.133 para o nivelamento geométrico classe IIN.

Os resultados também sugerem distâncias de visadas de aproximadamente 200 e 450 metros, para estação total de 10" e 7" de precisão angular, respectivamente.

Para alcançar resultados semelhantes, recomenda-se:

- O uso de equipamentos com precisão angular menor ou igual a 10";

- Posicionar o bastão com o prisma apoiado por bipé ou por outro artifício que o mantenha imobilizado;

- Fazer as observações de campo entre duas horas após o nascer do sol e duas horas antes do poente;

- Evitar observações quando ocorrer variação brusca de temperatura e ventos fortes de modo a ter variações moderadas no índice de refração.

A altura do instrumento medida com trena é uma fonte de erro sistemático, e deve-se ter atenção especial na sua determinação. A sua obtenção por nivelamento mostrou-se precisa e confiável, entretanto a distância de visada para a RN deve ser inferior a 40m, de modo a obter boa visibilidade do alvo minimizando os erros de pontaria e poder desconsiderar os efeitos atmosféricos e de curvatura.

O nivelamento "Leap-frog" apresentou resultados melhores que o nivelamento com visadas unilaterais com os dois equipamentos, e pode ser uma alternativa rápida ao nivelamento geométrico no transporte de RRNN. A não necessidade de medir altura do 
instrumento e nem fazer uso de modelos para correção da refração atmosférica elimina os efeitos dos erros decorrentes destas operações.

As distâncias de visadas devem ser equilibradas e não superior a 240 metros, para que as correções de refração e curvatura possam ser admitidas iguais. Recomendase o uso do bastão apoiado aplicando-se sempre três séries de leituras nas posições diretas e inversas da luneta e equipamentos com precisão angular menor ou igual a 10”.

Os resultados evidenciam os erros cometidos quando a linha de visada passa próximo do solo, mesmo com a atmosfera no estado neutro. Deve-se portanto evitar visadas cuja altura fique abaixo de $60 \mathrm{~cm}$ do solo.

Por fim considera-se oportuna a reavaliação por parte da ABNT dos limites estabelecidos para o nivelamento trigonométrico com estação total. Entretanto outros experimentos devem ser conduzidos em situações diferentes para ofe recer maiores subsídios a uma normalização.

Como complementação deste trabalho de pesquisa sugere-se realizar nivelamento trigonométrico com visadas unilaterais e Leap-frog, com as distâncias de visadas estabelecidas, em uma linha de alguns quilômetros para verificar a validade das distâncias definidas. É interessante que a linha possua trechos planos, onde a altura de visada permaneça aproximadamente constante, e trechos inclinados que permitam ângulos verticais da ordem de $10^{\circ}$ e que apresentem superfície com e sem cobertura vegetal.

Repetir o experimento com equipamentos de outros fabricantes com precisão semelhantes, e avaliar as observações com mais de um operador de modo quantificar o efeito do erro pessoal nas observações.

Realizar testes com o nivelamento "Leap-frog" com as distâncias de 160, 200, 240, 280 e 320 metros mantendo a estação em um único ponto e realizar observações em diferentes horários, inclusive à noite, em pontos da rede de referência cadastral do Campus I da USP - São Carlos (SP).

Implantar uma rede de nivelamento no Campus II da USP - São Carlos-SP, que possa ser usada no desenvolvimento de novos estudos sobre as técnicas de nivelamento geométrico, trigonométrico e com GPS. 


\section{Referências Bibliográficas}

ANDERSON, J.M.; MIKHAIL, E.M. (1998). Surveyng: Theory and practice. 7th ed. New York: Wcb McGraw-Hill.

ARABATZI, O; MAVRELLIS, G; STATHAS, D. (1993). Testing the digital level Wild-NA2000 in laboratory and field conditions. Survey Review, v.32, n.248, p.99-108, dez, 1973.

ASSOCIAÇÃO BRASILEIRA DE NORMAS TÉCNICAS (1994). NBR 13.133: Execução de levantamento topográfico. Rio de Janeiro.

BRASIL (1975). Manual técnico T34-410: Nivelamento trigonométrico. 1.ed. Ministério do Exército. Diretoria do Serviço Geográfico. Brasília. 1975.

BRINKER, C.R; TAYLOR, W.C. (1961). Elementary surveying. Scranton: International Textbook Company. 621p.

BRUNNER, F.K. (1984). Overview of Geodetic refraction studies. In BRUNNER, F.K. et al. Geodetic refraction: Effects of electromagnetic wave propagation through the atmosphere. Berlin: Spring-Verlag. Cap. 1, p.1-6.

CHRZANOWSKI, A. (1989). Implementation of trigonometric height traversing in geodetic levelling of high precision. Technical Report n.142. Geodesy and geomatics engineering, University of New Brunswick, Canada. 1989.

D’ALGE, J.C.L. (1986). Estabelecimento de um sistema de altitudes a aprtir do nivelamento geométrico. Dissertação (Mestrado) - Universidade Federal do Paraná. Curitiba. 1986. 
DEAKIN, R.E. (1996). The geoid what's it got to do with me?. The Australian Surveyor, Melbourne, p.294-305, dez.

DEPARTAMENTO NACIONAL DE INFRA-ESTRURURA DE TRANSPORTES-DNIT (2002a). IS-204: Instruções de serviços para estudos topográficos para anteprojeto. In: Diretrizes básicas para elaboração de estudos e projetos 1odoviários. Rio de Janeiro. P.137-40. Disponível em: <http://www.dnit.gov.br>. Acesso em: 04 set.

DEPARTAMENTO NACIONAL DE INFRA-ESTRURURA DE TRANSPORTESDNIT (2002b). IS-205: Instruções de serviços para estudos topográficos para projeto. In: Diretrizes básicas para elaboração de estudos e projetos rodoviários. Rio de Janeiro. P.141-46. Disponível em: <http://www.dnit.gov.br>. Acesso em: 04 set.

DREWES, H. SANCHES, L.; BLITZKOW, D.; FREITAS, S. (2002). Documento técnico sobre o sistema de referência vertical para a América do Sul. Boletim Informativo do Sistema de Referência Geocêntrico para as Américas, IBGE,. Rio de Janeiro, n.6, p.24 -31.

EMPRESA BRASILEIRA DE PESQUISA AGROPECUÁRIA. (2003). Pecuária Sudeste. São Carlos. Apresenta dados meteorológicos diários. Disponível em: <https://www.cppse.embrapa.br/meteoro/meteorodiario.htm>. Acesso em: 06 jan.

GEMAEL, C. (1994). Introdução ao ajustamento de observações: Aplicações geodésicas. Curitiba. UFPR. 319p.

INSTITUTO BRASILEIRO DE GEOGRAFIA E ESTATÍSTICA. (1983). Especificações e normas gerais para levantamentos geodésicos. Resolução PR no 22. Rio de Janeiro.

INSTITUTO BRASILEIRO DE GEOGRAFIA E ESTATÍSTICA. (2003). Disponível em: <http://www.ibge.gov.br/geodesia/altimetria>. Acesso em: 13 mai.

KHARAGHANI, G.A. (1987). Propagation of refraction errors in the trigonometric height traversing and geodetic leveling. Thesis (master's degree in science) - Geodesy and geomatics engineering, University of New Brunswick, Canada. 1987.

LIBAULT, A. (1975). Geocartografia. São Paulo: Edusp. 
LOPES, S.C. (1996). GPS e o perfil vertical de rodovias. Tese (Doutorado) - Escola de Engenharia de São Carlos, Universidade de São Paulo. São Carlos. 1996.

MAIA, T.C.B. (1999). Estudo e análise de poligonais segundo a NBR 13.133 e o sistema de posicionamento global. 175p. Dissertação (Mestrado) - Escola de Engenharia de São Carlos, Universidade de São Paulo, São Carlos. 1999.

MEDEIROS, Z.F. (1999). Considerações sobre a metodologia de levantamentos altimétricos de alta precisão e propostas para sua implantação. Dissertação (Mestrado) - Universidade Federal do Paraná. Curitiba. 1986.

MEDEIROS, Z.F.; FREITAS, S.R.C.; FAGGION, P.L. (2001). Estudos sobre a metodologia utilizada em nivelamento geométrico de alta precisão: Proposta para sua implantação. In: CONGRESSO BRASILEIRO DE CARTOGRAFIA, 20., 2001, Porto Alegre. Anais... Porto Alegre: SBC. 1 CD-ROM.

MONICO, G.J.F.; CHAVES, J.C.; ISHIKAWA, M.I. (1996). Nivelamento de precisão usando o GPS e interpolação geométrica do geóide. In. CONGRESSO NACIONAL DE ENGENHARIA DE AGRIMENSURA, 7. 1996, Salvador. Anais... Salvador: FENEA.

MOREIRA, A.P. (1998). Métodos de cálculos de coordenadas tridimensionais para controle de obras de engenharia. Dissertação (Mestrado) - Escola de Engenharia de São Carlos, Universidade de São Paulo. São Carlos. 1998.

PACILEO NETTO, N.; BLITZKOW, D.; CINTRA, J.P.; FONSECA JÚNIOR, E.S.; SCHAAL, R.E.; BUENO, R.F. (1996). Altitude ortométrica e o GPS - resultados parciais na grande São Paulo. In. CONGRESSO NACIONAL DE ENGENHARIA DE AGRIMENSURA, 7., 1996, Salvador. Anais... Salvador: FENEA.

PEREIRA, K.D.; OLIVEIRA, L.C. (1999). Emprego do mapa geoidal após o reajustamento da rede planimétrica brasileira. In: CONGRESSO BRASILEIRO DE CARTOGRAFIA, 19., 1999, Recife. Anais... Recife: SBC. 1 CD-ROM.

PESSOA, L.M.C. (1998). Altitude com GPS: Revisando conceitos fundamentais. Revista Fator GIS, Curitiba, n.21, jan. 
RODRIGUES, V (1988). O nivelamento trigonométrico como apoio altimétrico a densificação gravimétrica. Dissertação (Mestrado) - Universidade Federal do Paraná. Curitiba. 1988.

SCHAAL, R.E. (1995). Efeitos da refração na atmosfera em observações geodésicas próximas ao solo. 120p. Dissertação (Mestrado) - Escola Politécnica, Universidade de São Paulo, São Paulo. 1995.

SCHOFIELD, W. (1993). Engineering surveying: Theory and examination problems for Students. 4th ed. London: Butterworth-Heinemann Ltd.

SEGANTINE, P.C.L.(2002). Sistema de posicionamento global. São Carlos: Publicação do Departamento de Transportes da EESC/USP.

SILVA, N.C.C; SANTOS, M.C.; OLIVEIRA, LC.. (1998). Estudo comparativo sobre o efeito da refração troposférica no posicionamento geodésico. In. CONGRESSO BRASILEIRO DE CADASTRO TÉCNICO MULTIFINALITÁRIO, 3., 1998, Florianópolis. Anais...Florianópolis: UFSC. 1 CD-ROM.

SOARES, S.M. (1996). Nivelamento de precisão com técnica GPS. Revista A Mira, Criciúma, n.53, p.19-27.

TEDESCO. A; LANDOVSKY, G.; CAVALLI, J.; SANTOS, M.M.; PEDRO, P.C.; KRUGER, C.P.; FAGION, P.L. (2000). Nivelamento, GPS e gravimetria em Pontal do Sul - Resultados. In. CONGRESSO BRASILEIRO DE CADASTRO TÉCNICO MULTIFINALITÁRIO, 4., 2000, Florianópolis. Anais...Florianópolis: UFSC. 1 CDROM.

TORGE, W. (1991). Geodesy. 2nd ed. Berlin-New York: Walter de Gruyter.

VANICEK, P.; KRAKIWSKY, E.J. (1986). Geodesy: The concepts. 2 nd ed. Amsterdam-New York-Oxford: North-Holland Publishing Company. 697p.

VERONEZ, M.R. (1998). Proposta de parâmetros de transformação entre os sistemas WGS-84 e o SAD-69 para a região de São Carlos-SP. 111p. Dissertação (Mestrado) Escola de Engenharia de São Carlos, Universidade de São Paulo, São Carlos. 1998. 
VERONEZ, M.R.; LEANDRO, R.F.; ERBA, D.A.; SEGANTINE, P.C.L.; THUM, A.B. (2001). Ajuste automatizado de um modelo matemático para a determinação de ondulações geoidais no campus da Unisinos/RS. In: CONGRESSO BRASILEIRO DE CARTOGRAFIA, 20., 2001, Porto Alegre. Anais. Porto Alegre: SBC. 1 CD-ROM.

VUOLO, J.H. (1992). Fundamentos da teoria de erros. 1ed. São Paulo: Edgard Blücher. 225p.

WILLIAMS, D.C.; KAHMEN, H. (1984). Two wavelength angular refraction measurement. In BRUNNER, F.K. et al. Geodetic refraction: Effects of electromagnetic wave propagation through the atmosphere. Berlin: Spring-Verlag. Cap. 2, p.7-28. 


\section{Apêndice A}

Apresentam-se neste apêndice os gráficos com as diferenças entre as cotas obtidas por nivelamento trigonométrico e as cotas de referências em diferentes distâncias para as condições C4 e C15.
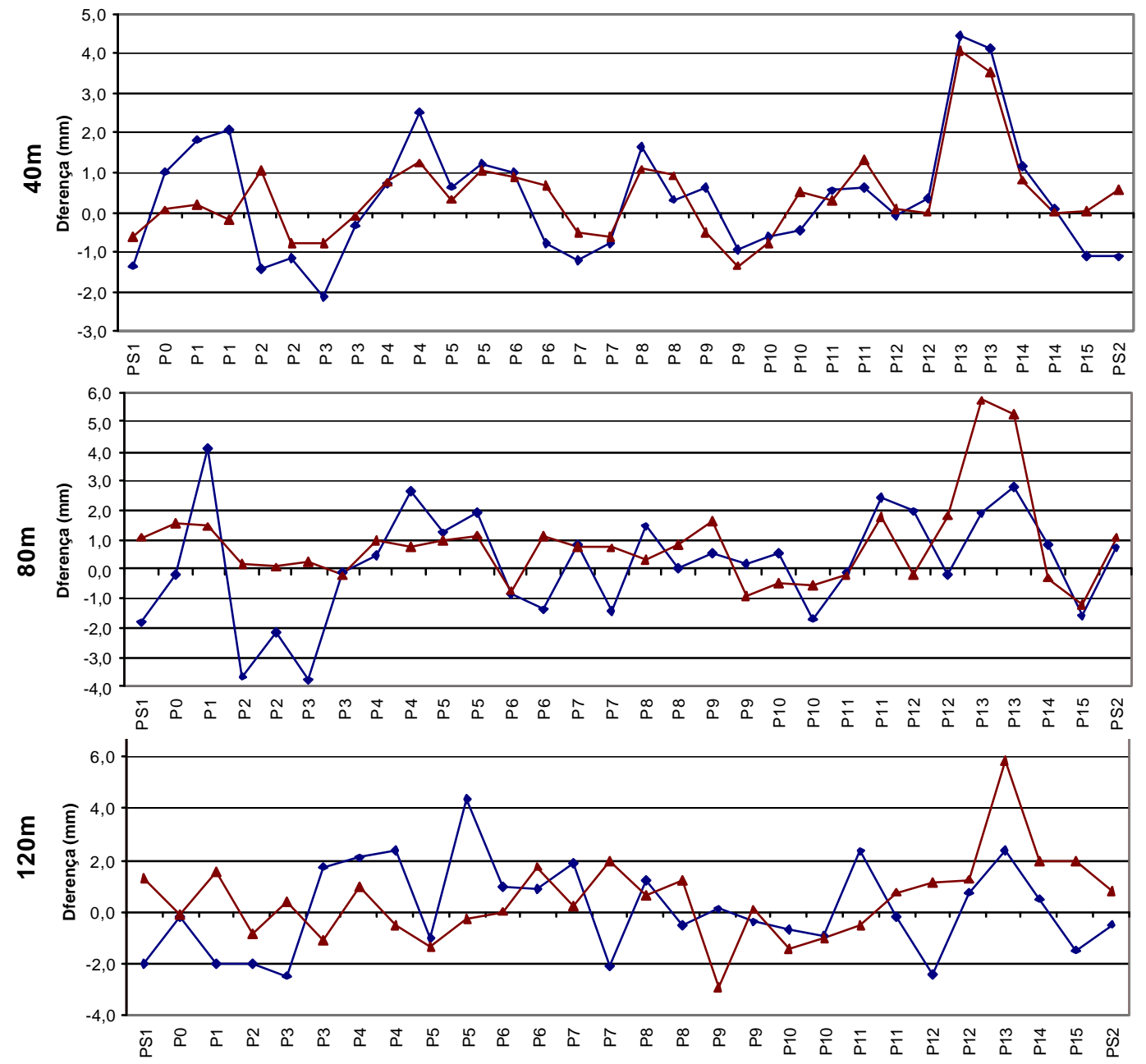

$\multimap-\mathrm{TC} 400 \multimap$-TC307

Gráfico 9.1 - Diferenças do nivelamento trigonométrico na condição C15 

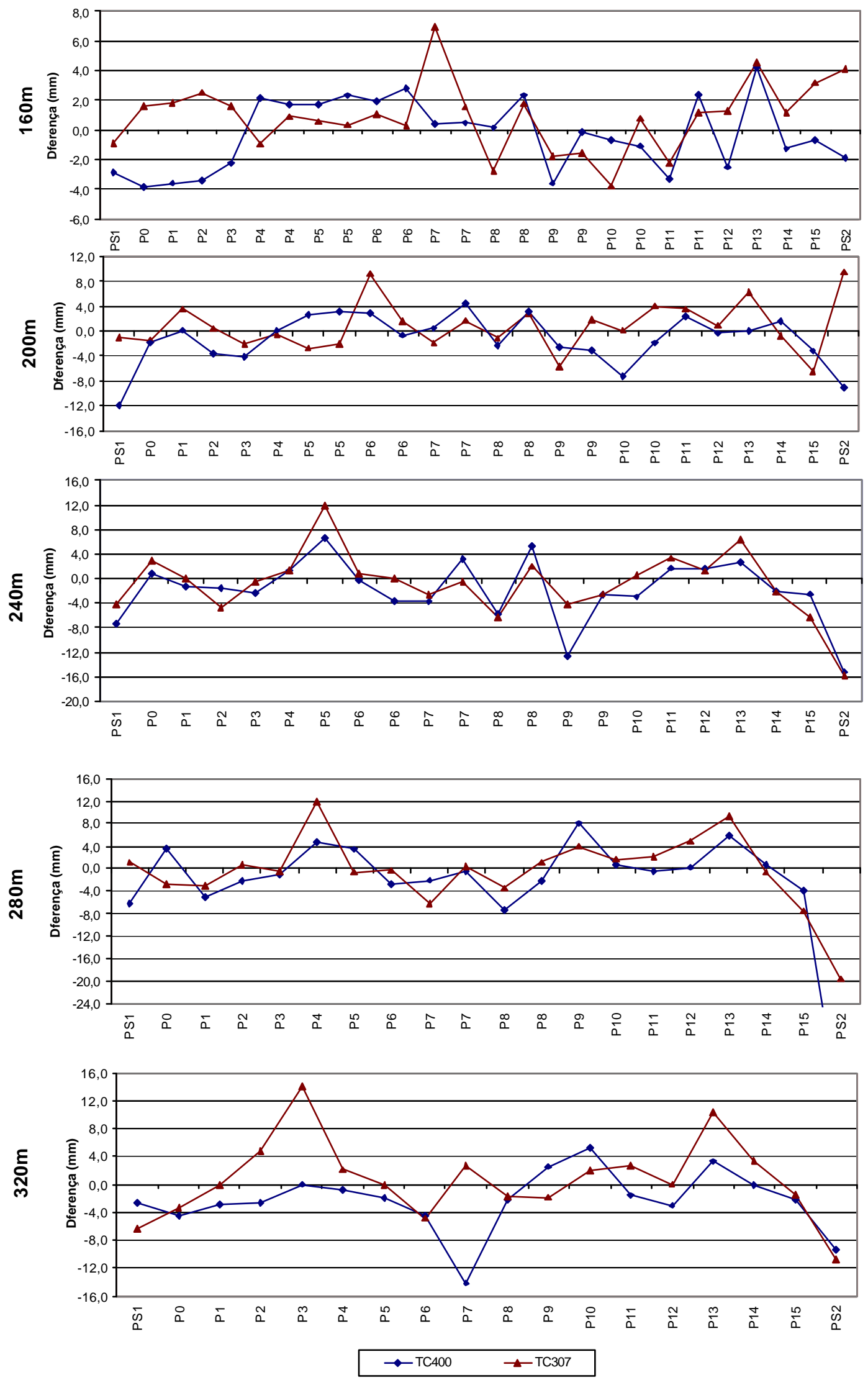

Gráfico 9.1b - Diferenças do nivelamento trigonométrico na condição C15 

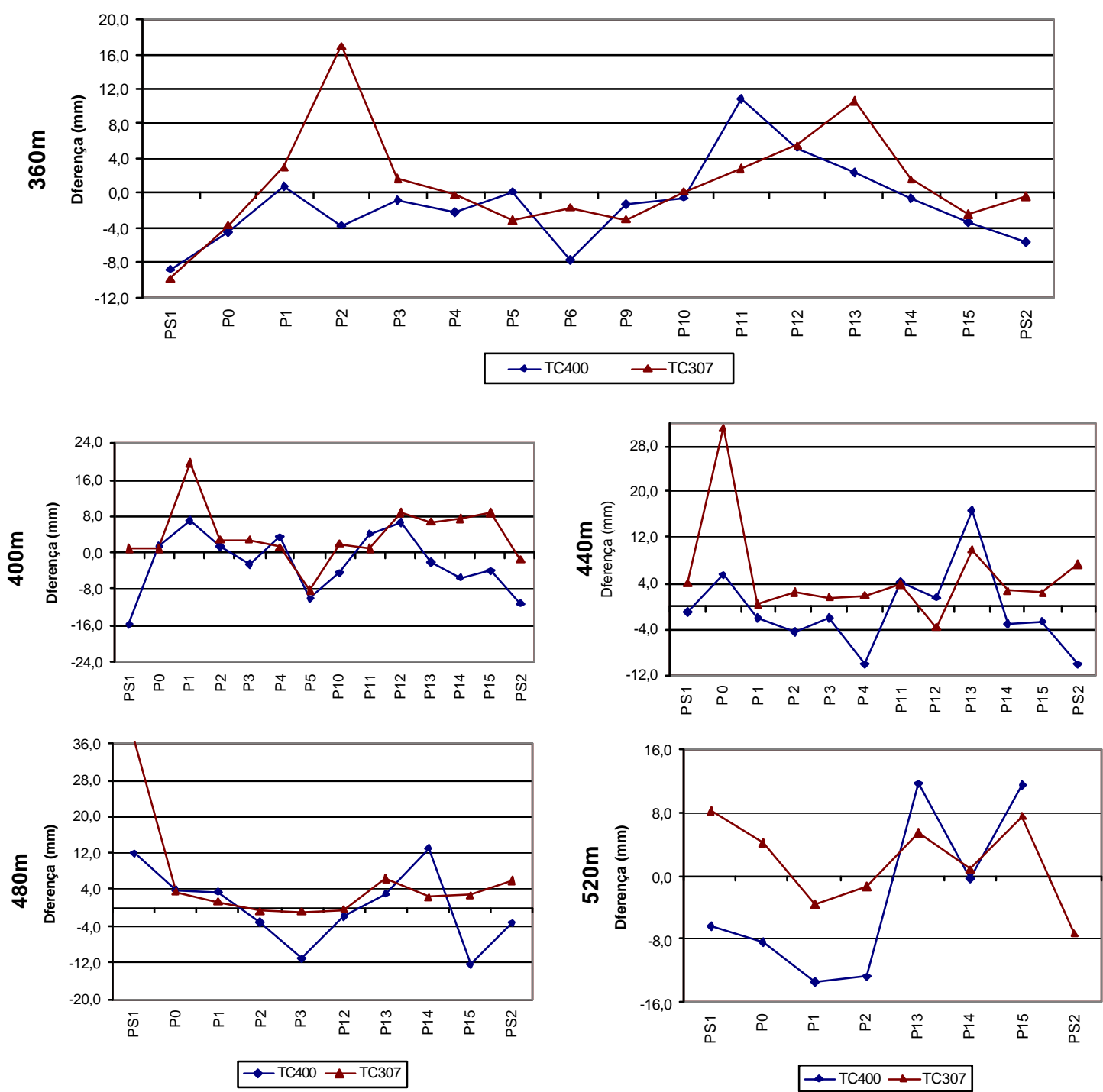

Gráfico 9.1c - Diferenças do nivelamento trigonométrico na condição C15 

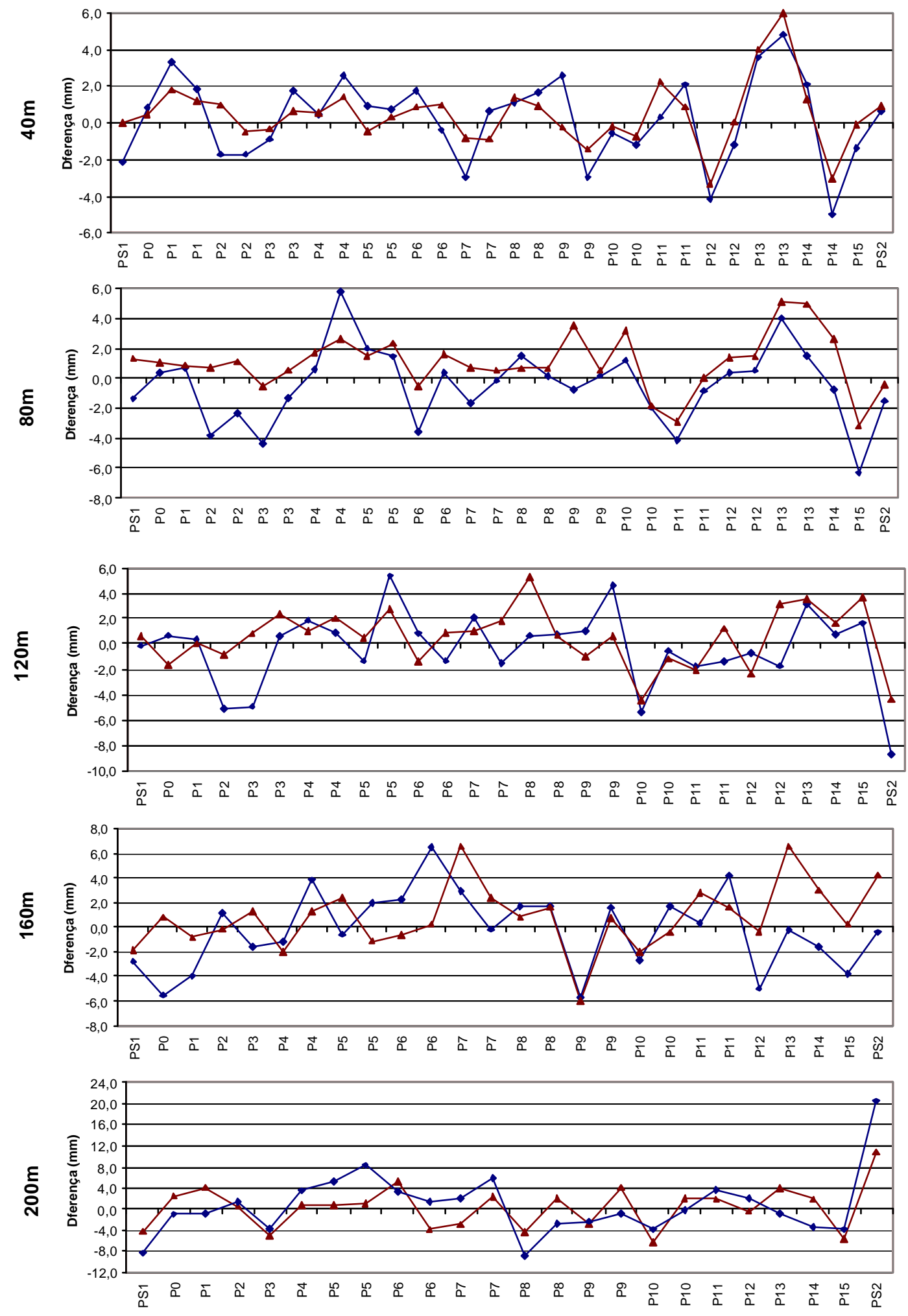

$\rightarrow$ TC307 $\rightarrow$-TC400

Gráfico 9.2 - Diferenças do nivelamento trigonométrico na condição C4 

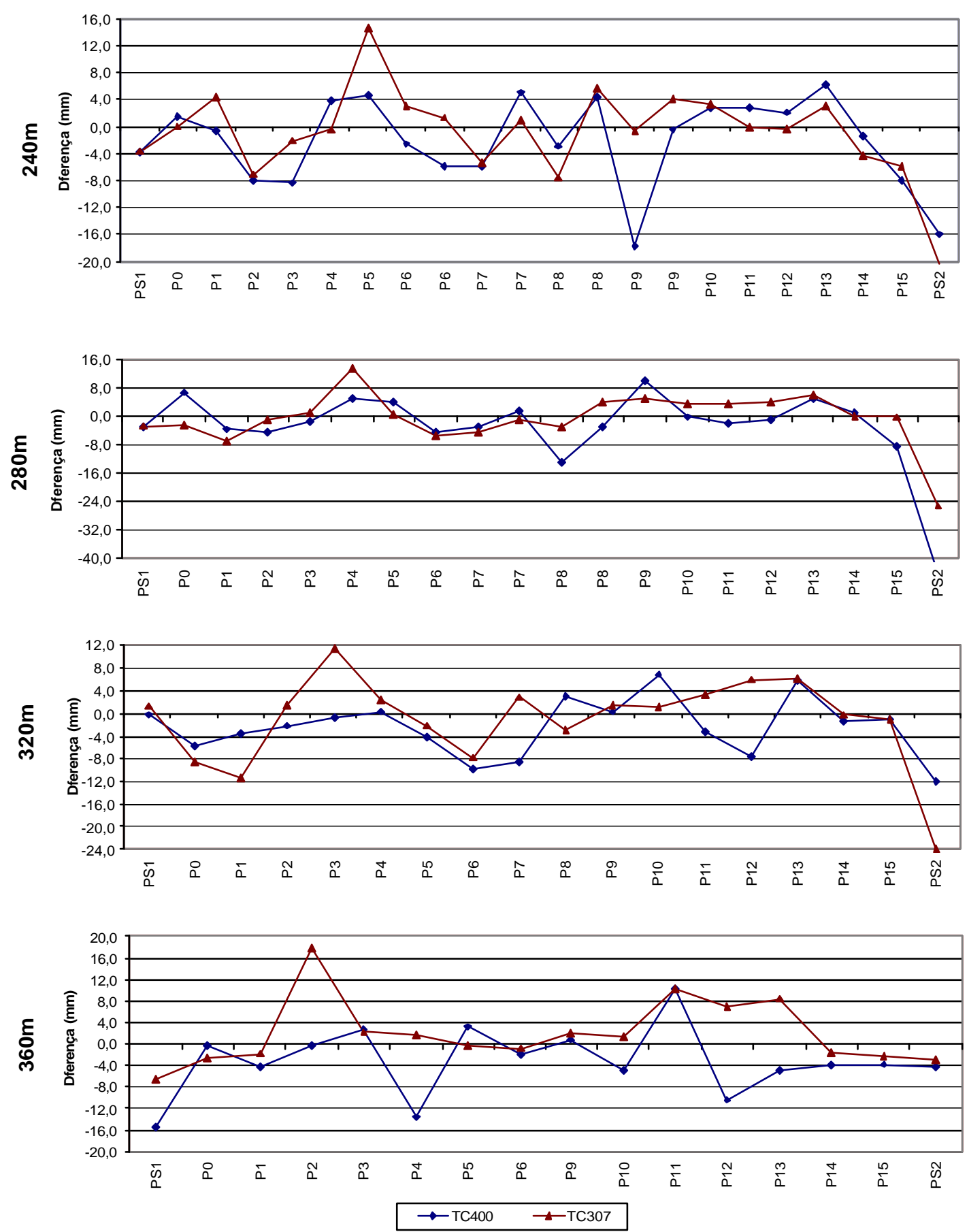

Gráfico 9.2b - Diferenças do nivelamento trigonométrico na condição C4 

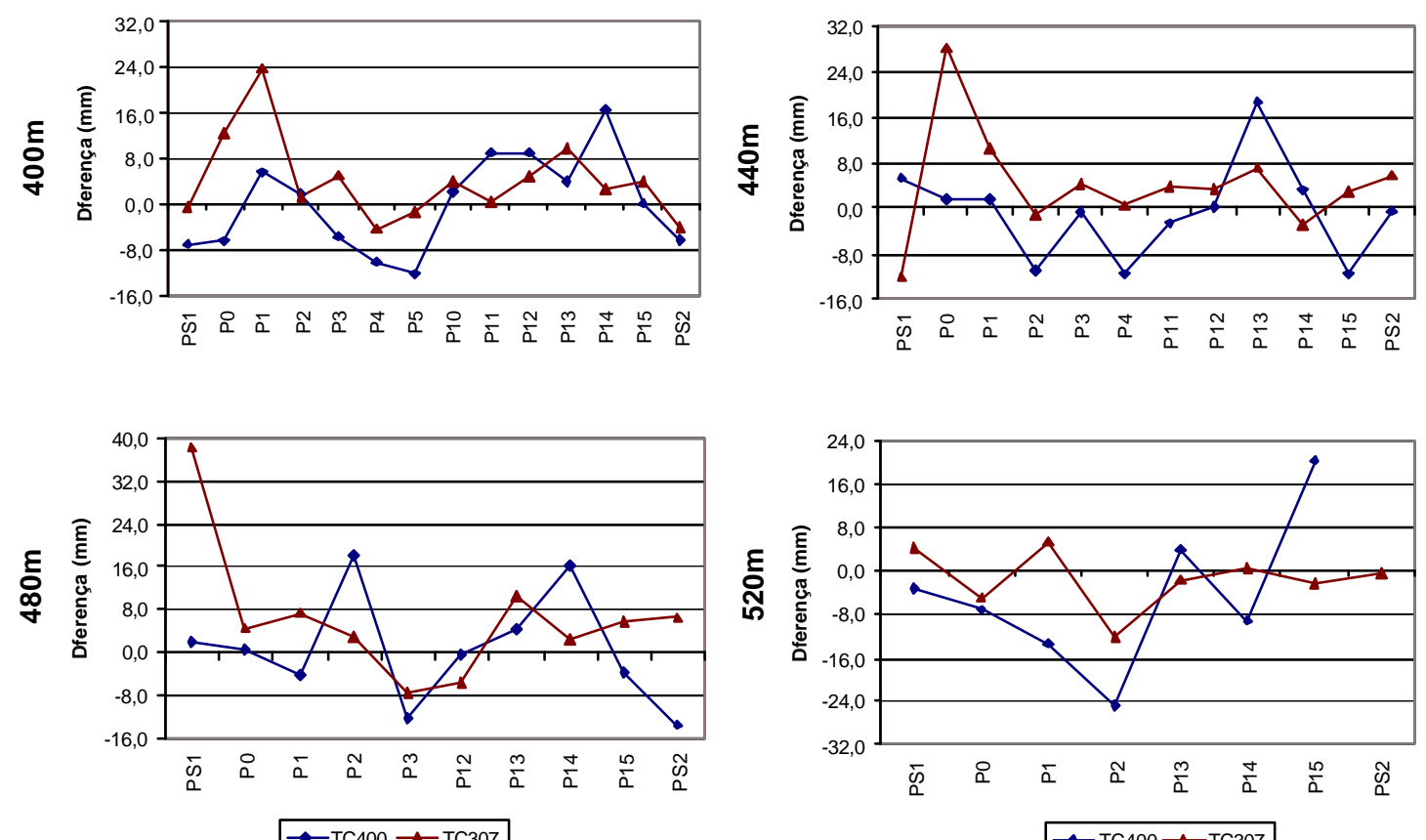

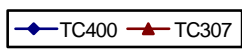

-๑TC400 —-TC307

Gráfico 9.2c - Diferenças do nivelamento trigonométrico na condição C4 


\section{Apêndice B}

Apresentam-se neste apêndice as condições atmosféricas quando da realização das observações de campo, relatório do programa Mapgeo v 2.0, o modelo de planilha usado nos cálculos das cotas e funções para o Microsoft@ Excel 2002 programadas em Visual Basic.

Tabela 9.1 - Condição do tempo durante o levantamento de campo - TC400

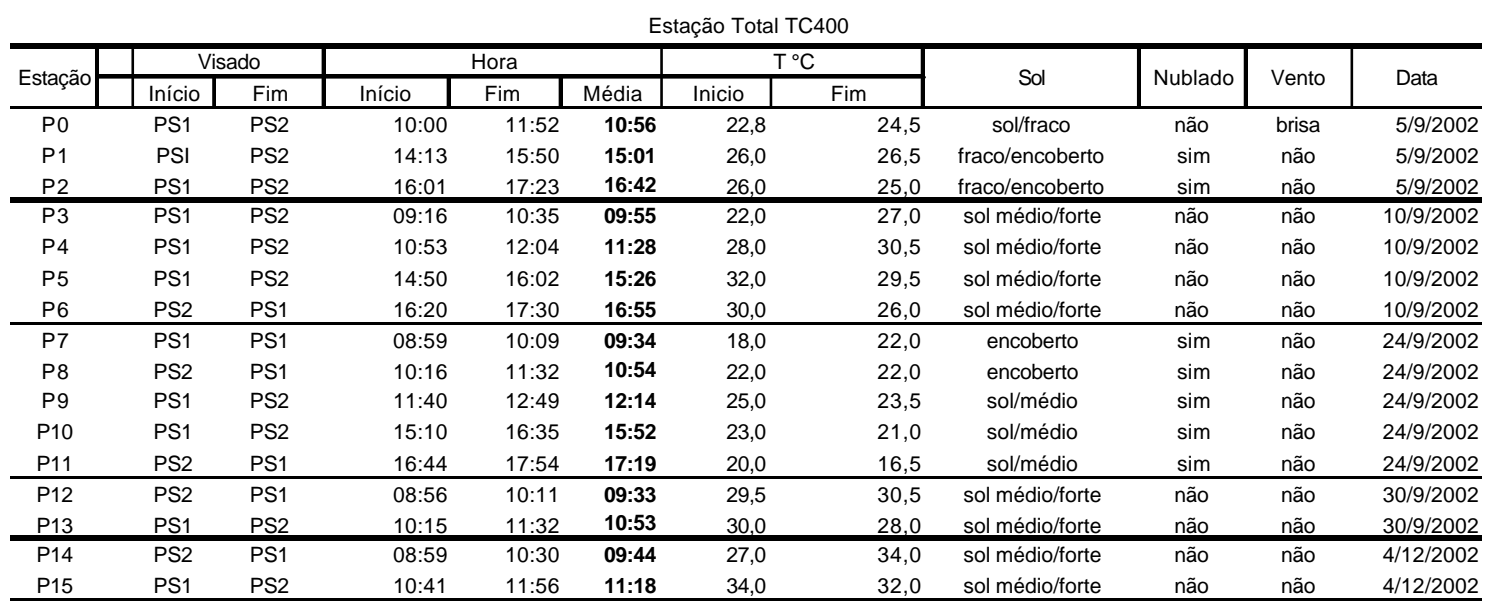

Tabela 9.2 - Condição do tempo durante o levantamento de campo - TC307

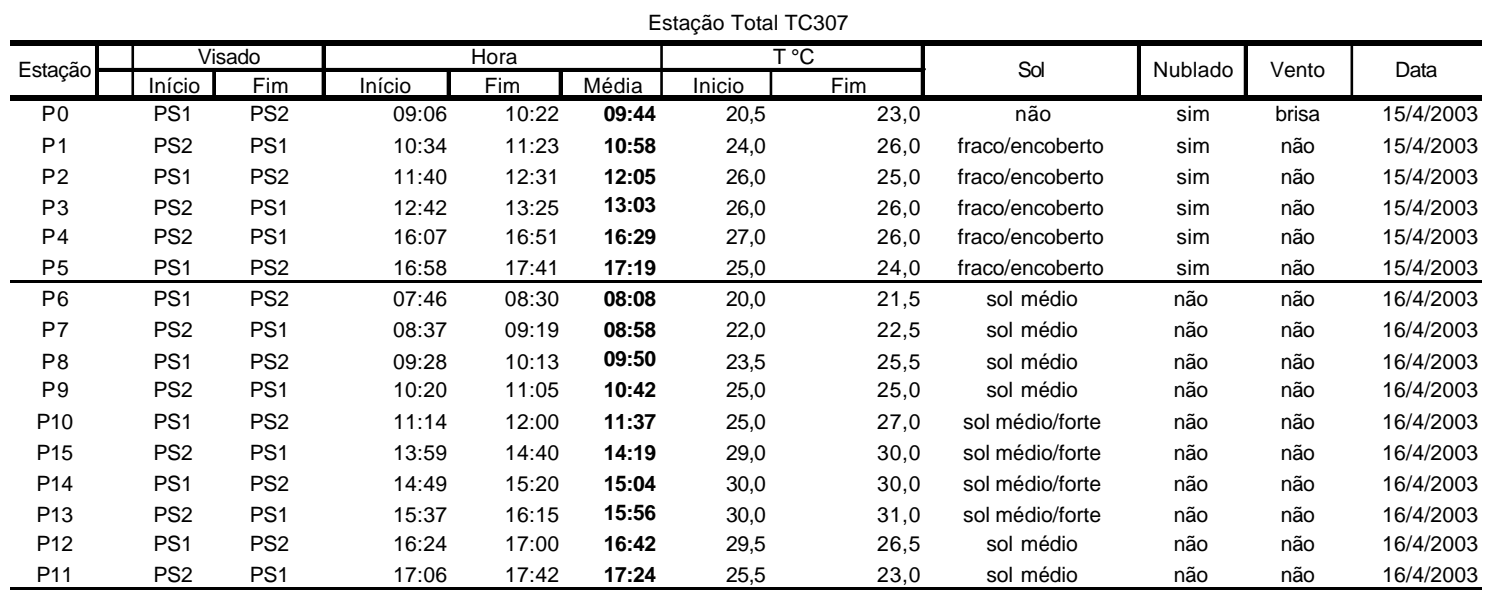


Tabela 9.3 - Umidade Relativa do AR. Fonte EMBRAPA (2003)

\begin{tabular}{cccccc}
\hline \multirow{2}{*}{ Mês/ano } & \multirow{2}{*}{ Dia } & \multicolumn{4}{c}{ Umidade Relativa do Ar (\%) } \\
\cline { 3 - 6 } & & $\mathbf{9 h}$ & $\mathbf{1 5 h}$ & $\mathbf{2 1 h}$ & Média \\
\hline set/02 & 5 & 98 & 67 & 100 & 91 \\
set/02 & 10 & 71 & 57 & 90 & 77 \\
set/02 & 24 & 98 & 80 & 85 & 87 \\
set/02 & 30 & 43 & 24 & 70 & 52 \\
dez/02 & 4 & 75 & 41 & 97 & 78 \\
abr/03 & 15 & 90 & 58 & 95 & 85 \\
abr/03 & 16 & 98 & 58 & 83 & 81 \\
\hline
\end{tabular}

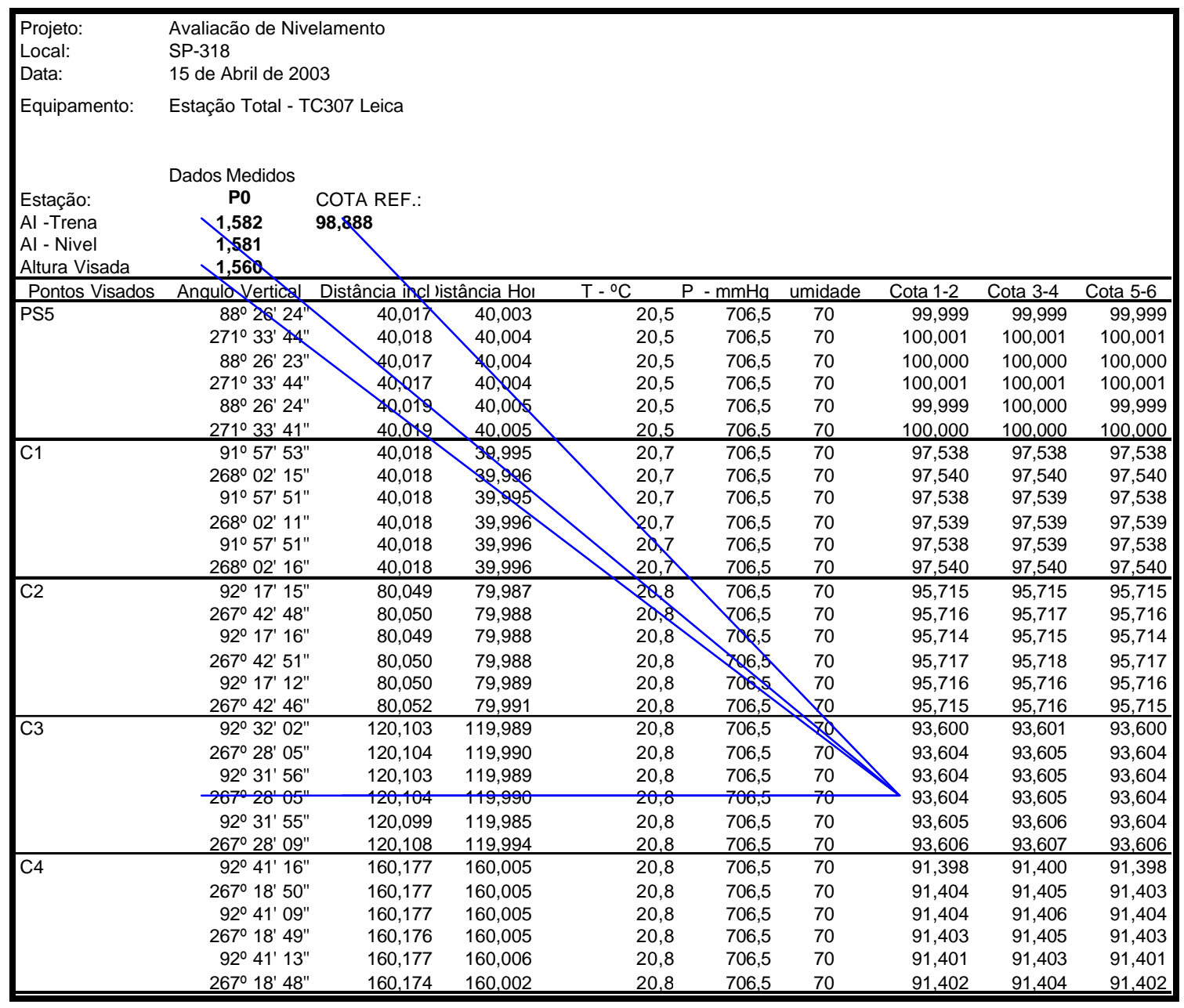

Figura 9.1 - Modelo de planilha usada nos cálculos das cotas 


\title{
RELATÓRIO DO PROGRAMA MAPGEO 2.0
}

\author{
PROGRAMA MAPGEO - v 2.0 \\ Interpolação de ondulações geoidais do mapa geoidal (versão 1992) \\ obtido a partir de alturas geoidais por satélite e do modelo \\ geopotencial (GEMT2). Sistema de referencia SAD-69 \\ Elaborado no âmbito do convênio IBGE - EPUSP/PTR
}

\begin{tabular}{|c|c|c|}
\hline \multicolumn{2}{|c|}{$\begin{array}{ll}\text { Absoluta : } & 3,0 \mathrm{~m} \\
\text { Relativa : } & 1,0 \mathrm{c}\end{array}$} & $\begin{array}{l}\text { dulação: } \\
\text { letros } \\
\mathrm{m} / \mathrm{Km}\end{array}$ \\
\hline $\begin{array}{l}\text { LATITUDE } \\
\text { (GG MM SS) }\end{array}$ & $\begin{array}{l}\text { LONGITUDE } \\
\text { (GG MM SS) }\end{array}$ & $\begin{array}{l}\text { ONDULACAO } \\
\text { (METROS) }\end{array}$ \\
\hline $\begin{array}{l}-214831 \\
-214809\end{array}$ & $\begin{array}{l}-475419 \\
-475415\end{array}$ & $\begin{array}{l}-3.36 \\
-3.33\end{array}$ \\
\hline
\end{tabular}

Em caso de duvidas e sugestões, favor entrar em contato com:

IBGE - Fundação Instituto Brasileiro de Geografia e Estatística D G C - Diretoria de Geociências

DEGED - Departamento de Geodésia

Avenida Brasil, 15671

Parada de Lucas

CEP: 21.241-051

Rio de Janeiro, RJ
Tel. (021) 391-8217

(021) $351-9355$

Fax: (021) $391-7070$

Telex: 2131929 


\section{FUNÇÕES PROGRAMADAS NO MICROSOFT® EXCEL 2002}

\section{Transforma grau sexagesimal em grau decimal}

Exemplo do formato de entrada SEXAGESIMAL: 17505'32,2" = 1750532,2 (NAO SEPARAR O GRAU POR PONTO)

Function GrauDecimal(GSexagesimal)

$\mathrm{a}=\operatorname{Sgn}($ GSexagesimal)

If $a<0$ Then

AbsGSexagesimal $=$ Abs $($ GSexagesimal $) / 10000$

Else

AbsGSexagesimal $=$ GSexagesimal $/ 10000$

End If

grau $=\operatorname{Int}($ AbsGSexagesimal $)$

minuto $=($ AbsGSexagesimal - grau $) * 100+0.00000000001$

Min $=\operatorname{Int}($ minuto $)$

seg $=($ minuto - Min $) * 100$

GrauDecimal $=($ grau + Min $/ 60+\operatorname{seg} / 3600) * a$

End Function

Transforma grau decimal em grau sexagesimal (grau, minuto e segundo)

Exemplo do formato de entrada DECIMAL: 175.09228

Function GrauSexagesimal(GrauDecimal)

If GrauDecimal $<0$ Then

$a=-1$

absGrauDecimal $=$ Abs $($ GrauDecimal $)$

Else

absGrauDecimal $=$ GrauDecimal

$\mathrm{a}=1$

End If

grau $=\operatorname{Int}($ absGrauDecimal $)$

minuto $=($ absGrauDecimal - grau $) * 60$

$\operatorname{Min}=\operatorname{Int}($ minuto $)$

seg $=($ minuto - Min $) * 60$

GrauSexagesimal $=($ grau + Min $/ 100+\operatorname{seg} / 10000) * a * 10000$

End Function

\section{Transforma grau sexagesimal em radiano}

Public Function GrauRadiano(AnguloSexagesimal)

$\mathrm{PI}=3.14159265359$

GrauRadiano $=$ PI $*($ GrauDecimal $($ AnguloSexagesimal $)) / 180$

End Function

Retorna a cota de um ponto conhecendo a cota de referencia, a distância inclinada o angulo zenital a altura do instrumento, pressão, temperatura e umidade do ar.

Public Function Cota(CotaRef, DistanciaIncl, AnguloZenital, AlturaInstrumento, AlturaAlvo, Temperatura, Pressao, UMIDADE)

$\mathrm{PI}=3.14159265359$

Distancia $=$ DistanciaIncl + DistanciaIncl $*$ CorrecaoAtmosferica $($ Temperatura, Pressao, UMIDADE $) / 1000000$

Difnivel $=(\operatorname{Cos}($ GrauRadiano $($ AnguloZenital $)) *$ Distancia $)+$ AlturaInstrumento - AlturaAlvo

Correcao $=$ CorCurvatura $($ Distancia $)-$ CorRefracao $($ Distancia $)$

Cota $=$ CotaRef + Difnivel + Correcao

End Function

Retorna a correção em ppm da distância pela fórmula de Barrel e Sears

Public Function CorrecaoAtmosferica(Temperatura, Pressao, UMIDADE)

'Calculo do expoente $x$

$\mathrm{x}=($ Temperatura $*(7.5)) /(237.3+$ Temperatura $)+0.7857$

'Conversao de $\mathrm{mmHg}$ para mbar

Pressao $=1.33322 *$ Pressao

CorrecaoAtmosferica $=281.5-(0.29035 *$ Pressao $) /(1+0.00366 *$ Temperatura $)+(11.27 *$ UMIDADE $* 10 \wedge x) /$ $(100 *(273.16+$ Temperatura $))$

End Function 


\section{Retorna distância horizontal a partir da distância inclinada e angulo zenital}

Public Function DistanciaHoriz(AnguloZenital, DistanciaIncl)

DistanciaHoriz $=\operatorname{Abs}(\operatorname{Sin}($ GrauRadiano(AnguloZenital $))) *$ DistanciaIncl

End Function

Retorna a correção da refração no nivelamento trigonométrico

Public Function CorRefracao(DistanciaIncl)

'Raio da Terra em São Carlos $\emptyset=21^{\circ} 58^{\prime} 00^{\prime}$

$\mathrm{PI}=3.14159265359$

RaioTerra $=6362734.001$

CorRefracao $=0.065 *$ DistanciaIncl ${ }^{\wedge} 2$ / RaioTerra

End Function

\section{Retorna a correção da curvatura da terra no nivelamento trigonométrico}

Public Function CorCurvatura(DistanciaIncl)

'Raio da Terra em São Carlos $\varnothing=21^{\circ} 58^{\prime} 00$ "

$\mathrm{PI}=3.14159265359$

RaioTerra $=6362734.001$

CorCurvatura $=($ DistanciaIncl $\wedge 2) /(2 *$ RaioTerra $)$

End Function

Retorna a altura do instrumento conhecendo o desnível do ponto visado e ponto estacionado

Public Function AlturaInstrumento(DesnivelInstAlvo, AlturaAlvo, AnguloZenital, DistanciaIncl) AlturaInstrumento $=$ DesnivelInstAlvo + AlturaAlvo - DistanciaIncl $* \operatorname{Cos}($ GrauRadiano(AnguloZenital $))$

End Function

Retorna a cota SEM correção atm. da distancia e SEM correção da refração e curvatura: C1, C2, C9 e C10

Public Function Cota12(CotaRef, DistanciaIncl, AnguloZenital, AlturaInstrumento, AlturaAlvo)

Distancia $=$ DistanciaIncl

Difnivel $=(\operatorname{Cos}($ GrauRadiano $($ AnguloZenital $)) *$ Distancia $)+$ AlturaInstrumento - AlturaAlvo

'Correcao $=$ CorCurvatura $($ Distancia, AnguloZenital $)-$ CorRefracao $($ Distancia, AnguloZenital $)$

Cota12 $=$ CotaRef + Difnivel

End Function

Retorna a cota SEM correção atm. da distancia e COM correção da refração e curvatura : C3, C4, C11 e C12

Public Function Cota34(CotaRef, DistanciaIncl, AnguloZenital, AlturaInstrumento, AlturaAlvo)

Distancia $=$ DistanciaIncl

Difnivel $=(\operatorname{Cos}($ GrauRadiano $($ AnguloZenital $)) *$ Distancia $)+$ AlturaInstrumento - AlturaAlvo

Correcao $=$ CorCurvatura $($ Distancia $)-$ CorRefracao $($ Distancia $)$

Cota34 $=$ CotaRef + Difnivel + Correcao

End Function

Retorna a cota COM correção atm. da distancia e SEM correção da refração e curvatura terra: C5, C6, C13 e C14 Public Function Cota56(CotaRef, DistanciaIncl, AnguloZenital, AlturaInstrumento, AlturaAlvo, Temperatura, Pressao, UMIDADE)

Distancia $=($ CorrecaoAtmosferica $($ Temperatura, Pressao, UMIDADE $) / 1000000) *$ DistanciaIncl + DistanciaIncl

Difnivel $=(\operatorname{Cos}($ GrauRadiano $($ AnguloZenital $)) *$ Distancia $)+$ AlturaInstrumento - AlturaAlvo

'Correcao $=$ CorCurvatura $($ Distancia, AnguloZenital $)$ - CorRefracao(Distancia, AnguloZenital $)$

Cota56 $=$ CotaRef + Difnivel

End Function

Retorna a cota COM correção atm. da distancia e COM correção da refração e curvatura: C7, C8, C15 e C16

Public Function Cota78(CotaRef, DistanciaIncl, AnguloZenital, AlturaInstrumento, AlturaAlvo, Temperatura, Pressao, UMIDADE)

Distancia $=($ CorrecaoAtmosferica $($ Temperatura, Pressao, UMIDADE $) / 1000000) *$ DistanciaIncl + DistanciaIncl

Difnivel $=(\operatorname{Cos}($ GrauRadiano $($ AnguloZenital $)) *$ Distancia $)+$ AlturaInstrumento - AlturaAlvo

Correcao $=$ CorCurvatura $($ Distancia $)-$ CorRefracao $($ Distancia $)$

Cota78 $=$ CotaRef + Difnivel + Correcao

End Function 


\section{Anexo A}

A seguir são apresentados as ficha técnicas dos equipamentos utilizados nesta pesquisa.

\begin{tabular}{|c|c|}
\hline \multicolumn{2}{|c|}{ Estação Total TC400 - Leica } \\
\hline \multicolumn{2}{|l|}{ Luneta } \\
\hline Aumento & $28 x$ \\
\hline Imagem & direta \\
\hline Abertura livre da objetiva & $28 \mathrm{~mm}$ \\
\hline Distância mínima de focagem & $2 \mathrm{~m}$ \\
\hline Campo de vista & $1^{\circ} 30^{\prime}$ (1.7 grados) \\
\hline Campo de vista da luneta a $100 \mathrm{~m}$ & $2,7 \mathrm{~m}$ \\
\hline \multicolumn{2}{|l|}{ Ângulo } \\
\hline Precisão -Norma DIN 18723/ISSO 18527 & 10" \\
\hline ânqulo exibido (selecionável) & $1 " / 5 " / 10^{\prime \prime}$ \\
\hline \multicolumn{2}{|l|}{ Prumo ótico } \\
\hline Aumento & $2 x$ \\
\hline Precisão & $0,5 \mathrm{~mm}$ \\
\hline \multicolumn{2}{|l|}{ Sensibilidade do nível eletrônico } \\
\hline Nível circular & $4^{\prime} / 2 \mathrm{~mm}$ \\
\hline Nível eletrônico & $5^{\prime \prime}$ \\
\hline \multicolumn{2}{|l|}{ Compensador: } \\
\hline \multicolumn{2}{|l|}{ Compensador vertical automático } \\
\hline Intervalo de trabalho & $\pm 5^{\prime}$ \\
\hline Precisão & $\pm 2 "$ \\
\hline \multicolumn{2}{|l|}{ Distância } \\
\hline Tipo infra-vermelho & $5 \mathrm{~mm}+10 \mathrm{ppm}$ \\
\hline Tempo de medição & $3 s$ \\
\hline distância com um prisma & $700 \mathrm{~m}$ \\
\hline Peso & $4,2 \mathrm{~kg}$ \\
\hline
\end{tabular}




\section{Estação Total TC307 - Leica}

\begin{tabular}{|c|c|}
\hline Luneta & \\
\hline Aumento & $30 x$ \\
\hline Imagem & direta \\
\hline Abertura livre da objetiva & $40 \mathrm{~mm}$ \\
\hline Distância mínima de focagem & 1.7 m (5.6 pés) \\
\hline Foco & fino \\
\hline Campo de vista & $1^{\circ} 30^{\prime}$ (1.7 grados) \\
\hline Campo de vista da luneta a 100m & $2.6 \mathrm{~m}$ \\
\hline Ângulo & \\
\hline Precisão -Norma DIN 18723/ISSO 18527 & 7" \\
\hline Resolução & $1 "$ \\
\hline Prumo a laser & \\
\hline Desvio em relação a linha de prumo (2S ) & $1,5 \mathrm{~mm} / 1,5 \mathrm{~m}$ \\
\hline Diâmetro do ponto laser & $2,5 \mathrm{~mm} / 1,5 \mathrm{~m}$ \\
\hline Sensibilidade do nível eletrônico & \\
\hline Nível circular & $6^{\prime} / 2 \mathrm{~mm}$ \\
\hline Nível eletrônico & $20 " / 2 \mathrm{~mm}$ \\
\hline Compensador: & \\
\hline Compensador líquido nos dois eixos & \\
\hline Resolução & $\pm 4^{\prime}(0.07$ grados $)$ \\
\hline Precisão & $2 "$ \\
\hline Distância & \\
\hline Tipo infra-vermelho & $2 m m+2 p p m$ \\
\hline $\begin{array}{l}\text { Tipo Raio laser } \\
\text { distância com um prisma }\end{array}$ & $\begin{array}{c}3 m m+2 p p m \\
2500 m\end{array}$ \\
\hline Peso & $5,2 \mathrm{~kg}$ \\
\hline
\end{tabular}

\section{Nível Ótico - NI07 Carl Zeiss-JENA}

\begin{tabular}{|c|c|}
\hline $\begin{array}{l}\text { Objetiva } \\
\text { Aumento da Luneta } \\
\text { Diâmetro do campo visual } \\
\text { Campo visual a } 100 \mathrm{~m} \\
\end{array}$ & $\begin{array}{l}31,5 X \\
40 \mathrm{~mm} \\
2,3 \mathrm{~m}\end{array}$ \\
\hline $\begin{array}{l}\text { Distância } \\
\text { Distância de Focagem mínima } \\
\text { Constante de mutiplicação } \\
\text { Constante de adição } \\
\end{array}$ & $\begin{array}{c}2,2 \mathrm{~m} \\
100 \\
0\end{array}$ \\
\hline $\begin{array}{l}\text { Compensador } \\
\text { Margem de Trabalho } \\
\text { Precisão de nivelamento } \\
\text { Tempo de nivelamento } \\
\end{array}$ & $\begin{aligned} & \pm 10^{\prime} \\
= & \pm 0,15^{\prime \prime} \\
= & \pm 1^{\prime \prime}\end{aligned}$ \\
\hline $\begin{array}{l}\text { Nível esférico } \\
\quad \text { Valor ângulo em } 2 \mathrm{~mm} \text { de desvio da bolha }\end{array}$ & $8^{\prime}$ \\
\hline $\begin{array}{l}\text { Acurácia } \\
\text { Miras com divisão de } 1 \mathrm{~cm} \text { e sem o micrometro de placa plana } \\
\text { Miras com divisão de } 0,5 \mathrm{~cm} \text { e com o micrometro de placa plana }\end{array}$ & $\begin{array}{l} \pm 2 \mathrm{~mm} / 1 \mathrm{~km} \\
\pm 0,5 \mathrm{~mm} / 1 \mathrm{~km}\end{array}$ \\
\hline
\end{tabular}

